NASA/TM-2008-215186

\title{
Characterization of Lunar Polar Illumination From a Power System Perspective
}

James Fincannon

Glenn Research Center, Cleveland, Ohio 


\section{NASA STI Program . . . in Profile}

Since its founding, NASA has been dedicated to the advancement of aeronautics and space science. The NASA Scientific and Technical Information (STI) program plays a key part in helping NASA maintain this important role.

The NASA STI Program operates under the auspices of the Agency Chief Information Officer. It collects, organizes, provides for archiving, and disseminates NASA's STI. The NASA STI program provides access to the NASA Aeronautics and Space Database and its public interface, the NASA Technical Reports Server, thus providing one of the largest collections of aeronautical and space science STI in the world. Results are published in both non-NASA channels and by NASA in the NASA STI Report Series, which includes the following report types:

- TECHNICAL PUBLICATION. Reports of completed research or a major significant phase of research that present the results of NASA programs and include extensive data or theoretical analysis. Includes compilations of significant scientific and technical data and information deemed to be of continuing reference value. NASA counterpart of peer-reviewed formal professional papers but has less stringent limitations on manuscript length and extent of graphic presentations.

- TECHNICAL MEMORANDUM. Scientific and technical findings that are preliminary or of specialized interest, e.g., quick release reports, working papers, and bibliographies that contain minimal annotation. Does not contain extensive analysis.

- CONTRACTOR REPORT. Scientific and technical findings by NASA-sponsored contractors and grantees.

- CONFERENCE PUBLICATION. Collected papers from scientific and technical conferences, symposia, seminars, or other meetings sponsored or cosponsored by NASA.

- SPECIAL PUBLICATION. Scientific, technical, or historical information from NASA programs, projects, and missions, often concerned with subjects having substantial public interest.

- TECHNICAL TRANSLATION. Englishlanguage translations of foreign scientific and technical material pertinent to NASA's mission.

Specialized services also include creating custom thesauri, building customized databases, organizing and publishing research results.

For more information about the NASA STI program, see the following:

- Access the NASA STI program home page at http://www.sti.nasa.gov

- E-mail your question via the Internet to help@ sti.nasa.gov

- Fax your question to the NASA STI Help Desk at 301-621-0134

- Telephone the NASA STI Help Desk at 301-621-0390

- Write to: NASA Center for AeroSpace Information (CASI) 7115 Standard Drive Hanover, MD 21076-1320 
NASA/TM-2008-215186

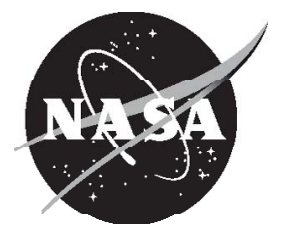

\section{Characterization of Lunar Polar Illumination From a Power System Perspective}

James Fincannon

Glenn Research Center, Cleveland, Ohio

Prepared for the

46th AIAA Aerospace Sciences Meeting and Exhibit

sponsored by the American Institute of Aeronautics and Astronautics

Reno, Nevada, January 7-10, 2008

National Aeronautics and

Space Administration

Glenn Research Center

Cleveland, Ohio 44135 
Level of Review: This material has been technically reviewed by technical management.

Available from

NASA Center for Aerospace Information 7115 Standard Drive

Hanover, MD 21076-1320
National Technical Information Service 5285 Port Royal Road Springfield, VA 22161

Available electronically at http://gltrs.grc.nasa.gov 


\title{
Characterization of Lunar Polar Illumination From a Power System Perspective
}

\author{
James Fincannon \\ National Aeronautics and Space Administration \\ Glenn Research Center \\ Cleveland, Ohio 44135
}

\begin{abstract}
This paper presents the results of illumination analyses for the lunar south and north pole regions obtained using an independently developed analytical tool and two types of digital elevation models (DEM). The first DEM was based on radar height data from Earth observations of the lunar surface and the other DEM was a combination of the radar data with a separate dataset generated using Clementine spacecraft stereo imagery. The analysis tool enables the assessment of illumination at most locations in the lunar polar regions for any time and any year. Maps are presented for the north and south lunar poles for the worst case winter period (the critical power system design and planning bottleneck) and for the more favorable best case summer period. Average illumination maps are presented to help understand general topographic trends over the regions. Energy storage duration maps are presented to assist in power system design. Average illumination fraction, energy storage duration, solar/horizon terrain elevation profiles and illumination fraction profiles are presented for favorable lunar north and south pole sites which have the potential for manned or unmanned spacecraft operations. The format of the data is oriented for use by power system designers to develop mass optimized solar and energy storage systems. More work is needed to improve the quality of the combined and filtered DEMs, but a filtered version of the radar DEM for the worst case lunar day at the best south pole site on the Crater Shackleton rim has 73 percent average illumination fraction and 71 to $113 \mathrm{hr}$ required for energy storage. The worst case lunar day at the best north pole site (on the rim of a small crater near the north pole) has a 52 percent average illumination fraction and 154 to 278 required energy storage hours. The illumination at these sites vary dramatically for each lunar day during a year, with as many as three lunar days with full illumination. This paper shows that by increasing the best identified north pole site height to $100 \mathrm{~m}$ using a tower reduces the energy storage duration by 4 percent with $0.2 \mathrm{hr}$ of energy storage duration savings per meter of tower height for heights up to $300 \mathrm{~m}$. Elimination of north pole energy storage occurs with tower heights near $1500 \mathrm{~m}$, quite different than has been seen with the south pole sites $(>3 \mathrm{~km})$. Combining two north pole sites that are separated by $3 \mathrm{~km}$ reduces the energy storage duration by 5 percent.
\end{abstract}

\section{Introduction}

The lunar poles have complex illumination environments in which some sites have potentially continuous darkness (offering the chance for resident ice or other volatiles) and other sites have potentially long duration illumination (quite different than regions closer to the lunar equator). Such illumination characteristics have made the polar regions key for permanently-manned base planning.

Most unobstructed locations on the Moon's surface have about 15 days of illumination followed by 15 days of darkness. Near the poles, due to site terrain heights, low Sun elevation angles, and high, shadow-casting terrain at various distances, it is possible to have greater than 15 days of illumination with somewhat random appearing illumination-darkness periods. These periods vary dramatically through the year, with illumination potentially nearly continuous during a number of months and highly variable for the remaining months. This is quite different from the $92 \mathrm{~min}$ orbit period of the International Space Station or Space Shuttle which have a gradually changing darkness period from zero to $36 \mathrm{~min}$. Most spacecraft deployed to lunar sites, including landers, rovers, and bases, require power provided by solar 
power generation and energy storage (e.g., batteries or fuel cells). Although an illumination environment with a high number of illumination days is beneficial because of higher likelihood of receiving sunlight, a high number of illumination-darkness periods translates to a reduced energy storage system requirement and, thus, lower deployed power system mass and volume. Comprehensive characterization of the lunar polar illumination environment is essential in optimum power system design.

Lunar illumination assessments by prior researchers have focused on estimating the average illumination for sites and regions. While this data helps locate potentially favorable locations from an illumination and power perspective, other illumination characteristics are equally (and perhaps more) important for adequate (and particularly optimum) sizing of the power system. These include the worst case energy storage duration (i.e., maximum darkness or eclipse time) and the worst case time-phased illumination profile. The worst case period is always critical in the proper sizing of power systems and, for the lunar poles, this time period is an entire lunar day. Analyses require that this time period be identified and analyzed for sites being considered.

A prior paper (ref. 1) by the author reviewed past data and analysis relevant to the topic of lunar illumination. That paper documented illumination analyses for key lunar south polar sites using unadjusted radar-derived lunar digital elevation models (DEM) and computer analysis software developed at NASA Glenn Research Center. In the present paper, the author reviews past illumination analyses and research for the lunar poles with emphasis on illumination maps and north pole illumination analyses. Using updated DEMs, this paper presents illumination maps, energy storage duration maps, tabular data, and illumination profiles for both the south and north poles in formats useful for planners and designers. Detailed site profiles are provided for either highly illuminated or low energy storage duration sites. Besides power system designers, illumination analyses may be used by thermal designers, operational planners and human factor engineers to design hardware for the lunar polar regions.

\section{Past Work}

Imagery analysis (i.e., overlaying images taken by a spacecraft of a region over a time period) by Spudis, Bussey, et al. (refs. 2 to 5) of images from the second Clementine spacecraft lunar day (3/27/94 to $4 / 25 / 94$ ) (the second lunar day past the worst case illumination period for the south pole) was used to produce average illumination maps for the north pole's highly illuminated summer season and the south pole's low illumination winter season. Because it was near the maximum illumination period, the north pole illumination map is of little use for spacecraft power system design (since illumination bottlenecks are used in sizing power systems, not times of abundant sunlight) although the south pole maps were useful to identify candidate sites. Kruijff et al. (refs. 6 and 7) performed a similar imagery analysis (but did not consider the north pole) for both the first and second Clementine spacecraft lunar days (one and two lunar days past the worst case time period). All these analyses have many caveats described in reference 1 which should be understood prior to using the data. Specifically, any spacecraft imagery analysis has, besides the standard spatial and temporal resolution limits, the inability of showing an illuminated site when the sun angle is at or below the zero elevation angle (i.e., the site surface is horizontal to the Sun's rays). This implies that other methods must be considered in analyzing illumination.

Reference 1 described the baseline lunar north and south pole region DEMs developed by scientists (refs. 8 and 9) and the potential inaccuracy/error and missing data (due to blockage of the radar beam by lunar terrain and areas outside the beam coverage) in those models. The missing data problem was addressed in the present paper by merging the radar DEMs with DEMs generated using Clementine stereo imagery (refs. 10 to 12). Interestingly, Bussey et al. (ref. 13) document the favorable comparison of south pole images generated using these two baseline sources of DEMs with both Lunar Orbiter and Clementine spacecraft images. This kind of assessment lends credence to and encouragement for the DEM analysis method as a viable approach for illumination quantification.

An analytical tool/simulation model was utilized (ref. 14) with the north and south polar radar DEMs to generate average illumination maps for both the worst and best case lunar days. This was the only 
published reference which quantified of the north pole illumination environment during its worst case "winter" period (this excludes the application of mapping the permanently shadowed locations at either pole, as illustrated in ref. 9). They found that: (1) there are relatively fewer north pole highly illuminated locations as compared with the south pole, (2) for winter, two areas were calculated to have over 75 percent illumination (the west rim of Crater Hermite and the south rim of Crater Peary), (3) the eastern rim of Hermite was calculated to have sites between 50 to 75 percent average illumination, and (4) during summer, the north pole region was highly illuminated ( $>95$ percent average) over large areas. Unfortunately, several issues exist regarding their assumptions and analysis procedure. Specifically, because of a perceived height noise (not based on comparison with actual lunar polar imagery), those authors applied a general smoothing filter on the entire (already smoothed) original DEM dataset, effectively reducing its fidelity/resolution. Also, their analysis approach did not represent the radar DEM data as areal elements, but rather as discrete analysis points between which they surface fit (i.e., interpolated) to obtain heights. This approach ignored the radar DEM data element's fundamental nature, namely that of being an average height over an entire spatial area. Interpolations created an artificial smoothness, assuming a shape or contour in the terrain blockage profile which may not exist. In addition, they modeled the Sun as a point source, rather than consider the actual finite solar disc width. Solar power systems are sensitive to the actual amount of illumination and in this kind of analysis it cannot be accounted for accurately without considering the Sun's subtended angle. For the worst case lunar day and other winter period at the poles, the Sun elevation angle is near or below zero elevation for long periods, which increases the number of passages of the Sun behind the terrain. This increases the percentage of time of possible partial illumination (partial Sun blockage by terrain). Another issue with their analysis was that they did not include the radar DEM height error of $\pm 50 \mathrm{~m}$ in their analysis, which also makes their estimates overly optimistic. To understand the cumulative impact of their assumptions and analysis approach, at the best lunar south pole site (on the Crater Shackleton rim), the average illumination from reference 14 was $\sim 20$ percent higher than that calculated in reference 1. Examination of their north pole illumination map shows that some of their identified high illumination sites were near the edge of the DEM and thus somewhat suspect in accuracy. Because the radar DEM does not cover the entire lunar surface, especially the far side of the Moon, key shadow casting terrain is not available. Usually, the most accurate analysis results will be for sites near the center of the radar DEM. The only way to improve this coverage is to increase the DEM area.

\section{Analysis Methods}

Reference 1 discussed the use of imagery overlays and 3-D computer models to assess illumination for the lunar south pole. Although Clementine imagery was available of the north pole, since the time period was near maximal illumination, imagery overlay analysis was not considered useful for identifying high illumination locations (i.e., a relatively large number of sites have very high illumination during this period). However, comparisons of Clementine imagery with images generated using the north and south pole DEMs were made to validate the basic analysis method used in this paper. Comparing the details of each image to enhance the DEMs (by hand editing DEM areal height elements) was not performed due to the time consuming nature of this process. Comparing 3-D computer model renderings with lunar north pole images was not performed for this paper due to computer memory limitations although the above imagery comparison method sufficiently duplicated this approach.

The method used in this paper, described in reference 1, was to use an analytical tool to calculate the blockage of the Sun by terrain defined using a DEM. Every non-blank point in the DEM was analyzed. Lunar illumination maps and energy storage duration maps for various energy storage recharge ratios were generated for the worst and best case lunar days for a selected representative year. This was done for both the north and south lunar poles. In addition to using the standard radar DEM, which had numerous blank areas caused by the limitations inherent in Earth-based radar beams, new DEMs were created which combined the Earth-based radar DEMs and the Clementine stereo imagery-derived DEMs. The blank areas in the baseline radar DEMs cause the omission of shadow casting terrain and result in 
overestimating illumination at particular sites. This is especially true for terrain near the DEM edges. Generally, the radar DEMs could be counted on to at least capture most of the high terrain for the regions. Using the radar DEM, the analysis process assumes the lowest DEM height is applied to all undefined terrain up to the horizon rather than using the mean lunar altitude, since, in many cases, the mean altitude would essentially place large amounts the polar regions in a "hole." Since the stereo imagery-derived DEMs were derived from Clementine spacecraft imagery, larger swaths of terrain were covered and many holes that were apparent in the radar DEM appeared filled with height data. Use of this DEM permitted the determination of potential shadow casting terrain up to the horizon for regions near the poles. However, the one drawback of using the stereo imagery-derived DEM in this way was that there was a substantial difference in heights from those of the radar DEMs. No published work documents any efforts to merge the two DEMs. However, an examination of both DEMs show substantially similar trends in relative heights. Therefore, a primary effort, documented here, was to determine a method to merge the DEMs.

Reference 1 identified some erroneous height areal elements in the radar DEM. To reduce the effect of these erroneous points, filters were developed to eliminate all areal elements which (1) existed without adjacent height points (rationale: the validity of the specific data element needed to be substantiated by contiguous terrain) and (2) had heights greater than $1.3 \mathrm{~km}$ from the highest adjacent terrain (rationale: examination of terrain imagery showed few terrain elements with higher height differences than $1.3 \mathrm{~km}$ over $600 \mathrm{~m}$ areal element distances). For the stereo imagery-derived DEM, the same type of filter was used to eliminated areal elements which (1) had less than three adjacent height elements (rationale: reduce unsubstantiated heights due to obvious erroneous heights within the craters) and (2) had heights greater than $1.3 \mathrm{~km}$ from the highest adjacent terrain. These DEM were then combined by assuming the radar DEM was the correct geo-referenced dataset. Any radar DEM areal element (which remained after filtering) was assumed to be the baseline reference areal element which the stereo imagery-derived DEM data was compared against. It was assumed that fitted stereo imagery-derived DEM areal elements were only used to fill the missing data regions in the radar DEM, whether the missing data was one areal element or an entire area beyond the radar DEM coverage. The fitting method was to minimize the error between the non-blank reference radar DEM and the stereo imagery-derived DEM areal elements by parametrically adjusting the two-dimensionally projected stereo imagery-derived DEM data along its X and $\mathrm{Y}$ axis to match the two sets zero (or pole) reference, adjust the scale of the stereo imagery-derived DEM map (both axes assumed to be the same scale needed to convert/match the latitudes), and adjust the heights of the stereo imagery-derived DEM areal elements (linearly referenced from the pole). Height corrections were needed because the heights of each DEM did not match, due possibly to geo-referencing differences which were based on using Clementine LIDAR terrain height data which only exist for lower latitudes. Regionally applicable correction formulae were preferred over complex locally-varied adjustments. The formula developed was not necessarily the best one possible, but the best found so far. Application of corrections based on distance of the point on the lunar surface to Earth did not provide as good of a correction as a simple linear height adjustment. For the south pole, the result of the fitting process provided an absolute average height difference (the average of the absolute difference in heights between each DEM areal element) of $0.6 \mathrm{~km}$ between the two DEMs. The height linear fit required to achieve this (that had to be added to the stereo imagery-derived DEM height data) was $5.1 \mathrm{~km}$ at $90^{\circ}$ South and $-0.9 \mathrm{~km}$ at $80^{\circ}$ South. For the north pole, the absolute height difference was $0.5 \mathrm{~km}$. The height linear fit required to achieve this was $0.8 \mathrm{~km}$ at $90^{\circ}$ North and $-2.2 \mathrm{~km}$ at $80^{\circ}$ North. After they were combined, the height difference filter was applied again.

To obtain a statistical understanding of the magnitude of these filter adjustments, the next few paragraphs summarize the number of areal elements that were eliminated.

The number of non-blank south pole radar DEM areal elements was 179296 . There were 21 areal elements without adjacent terrain. There were 27 areal elements with greater than $1.3 \mathrm{~km}$ in height difference, of which, six were for terrain higher than $2.5 \mathrm{~km}$. This is important is because higher terrain is likely to affect overall shadowing results more than lower lying terrain. Therefore, the six elements that were eliminated would likely affect the illumination results over a relatively large area. This specific filter 
eliminated the erroneous areal elements discovered in reference 1. An additional confirmation of the filter was an examination of Clementine imagery for the other areal elements which did not substantiate their existence. The number of non-blank north pole radar DEM areal elements was 175598. There were two areal elements without adjacent terrain and no areal elements with greater than $1.3 \mathrm{~km}$ in height difference. The height range for the north pole was much less than for the south pole, so it was unlikely to have substantial height differences.

The number of non-blank south pole stereo imagery-derived DEM areal elements was 1942411 (larger because the DEM covers a larger latitude range than the radar DEM). There were 21749 areal elements without adjacent terrain. This number of orphan or unsubstantiated elements appeared to be the result of the stereo imagery analysis method. There were 258 areal elements greater than $1.3 \mathrm{~km}$ in height difference, of which 26 were for terrain higher than $2.5 \mathrm{~km}$. The stereo imagery-derived DEM appeared to have more height scatter/noise. The number of non-blank north pole stereo imagery-derived DEM areal elements was 2245491. The difference in total areal element quantities appears to be due to the increased illumination of the north pole as compared to the south pole due to the lower extremes of height at the north pole and more favorable time of year (summer) for that pole. There were 10461 areal elements without adjacent terrain. There were 301 areal elements with greater than $1.3 \mathrm{~km}$ in height difference, of which, 33 were for terrain higher than $2.5 \mathrm{~km}$.

The number of non-blank combined south pole stereo imagery-derived/radar DEM areal elements was 1209740. The reason the total quantities of areal elements is so much less than the prior DEMs is because a smaller latitude range of data was selected to be fitted. There were 34 areal elements with greater than $1.3 \mathrm{~km}$ in height difference, of which, seven were for terrain higher than $2.5 \mathrm{~km}$. The number of non-blank combined north pole stereo imagery-derived/radar DEM areal elements was 1401906 . There was one areal element with greater than $1.3 \mathrm{~km}$ in height difference, of which none were for terrain higher than $2.5 \mathrm{~km}$.

Comparing the above results shows that using the combined DEM instead of the radar DEM alone improves the terrain coverage (non-blank data) for the same latitude range ( 80 to $90^{\circ}$ ) from 12 to 97 percent for the north pole and from 12 to 84 percent for the south pole.

The combined radar/stereo imagery-derived DEMs for the south and north pole are shown in figure 1 and 2. Only a part of the DEMs used in the analyses of this paper are shown in the figure. For the south pole (fig. 1), the hash marks on the sides of the DEM figure represent $0^{\circ}$ (top: Earthward), $90^{\circ}$ (right), $180^{\circ}$ (bottom), and $270^{\circ}$ (left) longitude. The latitude at the hash marks is $80.6^{\circ}$ South, with latitude a linear function based on the radial distance from the center of the image (i.e., the south pole). The heights are gray scale and are linearly represented as $-11.92 \mathrm{~km}(1)$ to $7.97 \mathrm{~km}(255)$ with zero meaning no data. For the north pole (fig. 2), the hash marks represent $0^{\circ}$ (top: Earthward), $90^{\circ}$ (left), $180^{\circ}$ (bottom), and $270^{\circ}$ (right) longitude. The latitude at the hash marks is $80.6^{\circ}$ North, with latitude a linear function based on the radial distance from the center of the image (the north pole). The heights are gray scale from $8.48 \mathrm{~km}$ (1) go to $4.44 \mathrm{~km}$ (255) with zero meaning no data. The line showing the demarcation of the original radar DEM data can be seen which illustrates the extra range of coverage beyond that data set. This extra range is valuable for enhancing the likelihood of including all long range shadow casting terrain. In order to fit in this paper, these DEMs were re-scaled to be 80 percent of their full size. The full resolution DEMs are available from the author and will become available on the NASA Glenn Research Center web site (http://spaceflightsystems.grc.nasa.gov/articles/Lunar-Topographic.php).

Figure 3 shows a comparison image generated using the combined south pole DEM and images taken using the Clementine spacecraft. The illumination analysis computer program was used to generate the illumination map for the days and regions of interest with no error applied to the DEM heights. The overlaid Clementine images were from revolution 298 during 4-23-1994 during a period with solar sublongitude of $33^{\circ}$. The image derived from computer analysis has a number of streak shadows which are likely erroneous height areal elements which need additional filtering in the combined DEM to correct. Figure 4 shows a comparison image generated using the combined north pole DEM and images taken using the Clementine spacecraft. The Clementine images were from revolution 26 during 2-251994 during a period of solar sublongitude of $1^{\circ}$. These comparison images seem substantially equivalent, 
at least from the perspective of analysis software operation. Perfect comparisons and replications of orbital spacecraft imagery are unlikely due to the resolution of the DEMs, the height "noise" in the DEMs, and the flatness of the areal elements (versus the reality of complex slopes of the terrain).

\section{Analysis Results}

Illumination cycles for a site are fairly repetitive each year. The primary variation is the time phasing of the cycle which affects which lunar day during a year has the worst and best case illumination. The worst case lunar day is defined to be the lunar day in which the average solar elevation is a minimum for the lunar year. The worst case lunar day could possibly be different if one chooses to base it on some other metric (since the exact placement of the lowest sun elevation can be improved or worsened based on the horizon terrain profile). Since it is arbitrary which year is analyzed, analyses are presented for the worst case and best case lunar days of 1994. The worst case lunar south pole day (the best case day for the lunar north pole) is from 1/30/94 to 3/2/94. The best case lunar south pole day (the worst case day for the lunar north pole) is from $7 / 29 / 1994$ to $8 / 28 / 1994$. For 2020, the worst case lunar day for the south pole occurs in September of that year; for the north pole it occurs in March of that year. Note that the sun angle (either solar sublongitude or site azimuth) repeats every $710 \mathrm{hr}$. In this paper, the maps were generated using the $728 \mathrm{hr}$ and the profiles were based on $710 \mathrm{hr}$.

The DEMs have error in terms of height and spatial placement. In this paper, no error is assumed for spatial data (i.e., X-Y placement on the surface). For the radar DEM areal element height, a conservative error of $-50 \mathrm{~m}$ is subtracted to the site height and $50 \mathrm{~m}$ is added to the terrain height. This kind of conservative error essentially places the site in a "hole" with respect to its surroundings, emphasizing the benefits of high areal elements during worst case lunar days. Conservative height error is the most appropriate approach for power system design. The other component of the combined DEM, the stereo imagery-derived DEMs, have $\pm 75 \mathrm{~m}$ height error. In this paper, the combined DEMs were assumed to have an error to be the same as the radar DEM. The rationale was that the baseline radar DEM areal elements should not have degraded height error simply because of the merging of other data of lesser height accuracy, primarily because the radar DEM areal elements take precedence. However, because the overall absolute average height difference was on the order of half a kilometer, some other error level seems appropriate but it is not clear what it should be. Using $\pm 0.5 \mathrm{~km}$ would render the DEM useless for shadowing analysis.

In subsequent figures, terms such as average illumination and energy storage duration are used. Average illumination is the sum of the illumination (partial or full illumination for each hour) for each hour of an entire lunar day divided by the number of hours in the lunar day. Energy storage duration is the net number of hours of energy required to attain an energy balance over a lunar day given an assumed recharge ratio. This ratio characterizes the energy generation-energy storage design and is used to remove the precise power system design from consideration. A fast recharge ratio of 0.25 means that it takes $1 / 4$ recharge hour to charge one discharged hour of energy storage. A slow recharge ratio of 4 means that it takes 4 recharge hours to charge one discharged hour of energy storage. The continuum of recharge ratios and how they relate to power systems is approximate. Low Earth orbiting spacecraft are approximately a 1.5 ratio. When the ratio is applied to the illumination fraction profile (a function of time), then the cumulative total of energy storage hours charged/discharged can be tallied without having to consider system efficiencies, operating power levels, system limitations/characteristics. For every time step (i.e., one Earth hour intervals) during the profile when there is full illumination, the illumination is divided by the recharge ratio and this amount is added to the cumulative total. For partial illumination or no illumination, the power system is assumed to discharge to maintain the nominal operating power level which would normally occur when there is full illumination. In this case, the difference in illumination from 1.0 is subtracted from the recharge hour cumulative total. This process is repeated for the entire lunar day. When starting with a zero value in the cumulative total, the deficit over the lunar day would indicate the energy storage hours required for that case. 


\section{Analysis Results: Maps}

Figures 5 to 28 show various kinds of illumination maps for the various DEMs and polar regions. Maps are shown for the north and south pole, radar DEMs and combined DEMs, and worst and best case lunar days. Both DEMs are shown in order to permit the reader to select either the radar DEM (which has less coverage but seems to have less height "noise") or the combined DEM (which, although has more terrain coverage, may have more height anomalies). The approximate distance scale is also shown in each figure. South pole maps were scaled 90 percent to fit in this paper. For the south pole figures, the upper hash mark is at $80.55^{\circ}$ latitude, the right hash mark is at $82.39^{\circ}$ latitude, the lower hash mark is at $85.72^{\circ}$ latitude, and the left hash mark is at $81.92^{\circ}$ latitude. North pole maps were scaled 85 percent to fit in this paper. For the north pole figures, the upper hash mark is at $80.68^{\circ}$ latitude, the right hash mark is at $81.94^{\circ}$ latitude, the lower hash mark is at $87.2^{\circ}$ latitude, and the left hash mark is at $81.08^{\circ}$ latitude. The intent in providing the data in this format is to allow the analyst to select various locations based on their spacecraft, mission, or other operational requirements and to quantify the illumination environment based on reading the gray scale values of the particular pixel. This can be done by copying the image of interest to image processing software and reading pixel values. Depending on the user, more complex reading of the images and converting pixel locations to latitude and longitude can be also performed.

The maps for average illumination (figs. 5 to 8 and 17 to 20) show a linear gray scale with 0 percent average illumination (0) and 100 percent average illumination (255). These maps may be compared to those of Bussey et al. (i.e., the south pole "near" the worst lunar day (refs. 2, 3, and 5), the north pole "near" the best lunar day (ref. 3)), Kruijff (i.e., the south pole "near" the worst case lunar day (refs. 6 and 7)), and Zuber (i.e., both poles at both best and worst lunar days (ref. 14)). Although the formats are different and the analysis time periods not the same, it is clear that (1) the imagery analysis methods offer much less analyzed lunar surface area as compared with computer analysis (limited by spacecraft imaging coverage), (2) the general trends of average illumination between the methods seem similar for the south pole, and (3) for the north pole, the results in reference 14 appear to overestimate the average illumination for reasons previously discussed.

The maps for energy storage duration (figs. 9 to 16 and 21 to 28) show a linear gray scale with $728 \mathrm{hr}$ (0) and $0 \mathrm{hr}$ (255). No prior authors have depicted a map of these hours since such data are mainly of interest to power system designers. Maps are included for two energy storage recharge ratio options (fast and slow). The fast recharge cases approximate the maximum contiguous shadowed time period (i.e., the largest amount of shadowing terrain). The slow recharge cases tend to merge adjacent shadowed time periods with short illumination periods between them.

\section{Analysis Results: Tabulated Summary}

The process of generating the maps in the prior section involved performing the detailed illumination analysis for each non-blank DEM areal element. This resulted in tables of data that were sorted to be able to identify locations with high average illumination and low energy storage durations. In considering this data, note that the average illumination value of 50 percent and an energy storage duration of $364 \mathrm{hr}$ are the nominal values for most latitudes beyond the poles, thus it is highly desirable to obtain more favorable values. Since 50 percent average illumination can be either one contiguous shadowed period or many smaller shadowed periods, there is not necessarily a one-to-one correlation between the two metrics.

For the worst case lunar day, out of the possible 179275 sites in the south pole radar DEM, there were 375 sites ( $\sim 0.2$ percent of the entire region's data or, in other words, only $\left.135 \mathrm{~km}^{2}\right)$ with over 50 percent average illumination, 39 sites over 60 percent, 5 sites over 70 percent, and 0 sites over 80 percent. For the best case lunar day, there were 4758 sites ( $\sim 2.6$ percent of the entire region's data) with over 50 percent average illumination, 1540 sites over 60 percent, 661 sites over 70 percent, 300 sites over 80 percent, and 102 sites over 90 percent. For the fast recharge energy storage duration on the worst case lunar day, there were 5683 sites ( $\sim 3.2$ percent of the entire region's data) under $364 \mathrm{hr}, 45$ sites under $182 \mathrm{hr}$, and 4 sites under $91 \mathrm{hr}$. For the slow recharge energy storage duration on the worst case lunar day, there were 1109 
sites under $364 \mathrm{hr}, 6$ sites under $182 \mathrm{hr}$, and 0 sites under $91 \mathrm{hr}$. For the fast recharge energy storage duration on the best case lunar day, there were 32085 sites ( $~ 18$ percent of the entire region's data) under $364 \mathrm{hr}, 2357$ sites under $182 \mathrm{hr}, 519$ sites under $91 \mathrm{hr}$, and 155 sites under $45 \mathrm{hr}$. For the slow recharge energy storage duration on the best case lunar day, there were 10712 sites under $364 \mathrm{hr}, 865$ sites under $182 \mathrm{hr}, 295$ sites under $91 \mathrm{hr}$, and 101 sites under $45 \mathrm{hr}$. This data shows that even with beneficial summer sun angles, the amount of terrain with over 50 percent average illumination is quite small. However, by considering the energy storage hours less than that required at the equator, the amount of terrain is greatly increased (from 0.2 to 3.2 percent of the region's data for the worst case lunar day). The reason is the increased number of sun and shadow periods during the lunar day, thus the benefit of determining this metric for power system design is shown.

For the worst case lunar day, out of the possible 456544 sites in the south pole combined DEM, there were 869 sites $\left(\sim 0.2\right.$ percent of the entire region's data, $\left.313 \mathrm{~km}^{2}\right)$ with over 50 percent average illumination for the worst case lunar day, 80 sites over 60 percent, 23 sites over 70 percent, 4 sites over 80 percent, and 4 sites over 90 percent. For the best case lunar day, there were 10943 sites $(\sim 2.4$ percent of the region's data) with over 50 percent average illumination for the worst case lunar day, 2007 sites over 60 percent, 809 sites over 70 percent, 318 sites over 80 percent, and 108 sites over 90 percent. For the fast recharge energy storage duration on the worst case lunar day, there were 35255 sites $(\sim 7.7$ percent of the region's data) under $364 \mathrm{hr}, 80$ sites under $182 \mathrm{hr}, 12$ sites under $91 \mathrm{hr}$, and 4 sites under $45 \mathrm{hr}$. For the slow recharge energy storage duration on the worst case lunar day, there were 2733 sites under $364 \mathrm{hr}$, 24 sites under $182 \mathrm{hr}, 4$ sites under $91 \mathrm{hr}$, and 3 sites under $45 \mathrm{hr}$. For the fast recharge energy storage duration on the best case lunar day, there were 104961 sites ( 23.0 percent of the region's data) under 364 hr, 2891 sites under $182 \mathrm{hr}, 578$ sites under $91 \mathrm{hr}$, and 163 sites under $45 \mathrm{hr}$. For the slow recharge energy storage duration on the best case lunar day, there were 31922 sites under $364 \mathrm{hr}, 1099$ sites under $182 \mathrm{hr}$, 313 sites under $91 \mathrm{hr}$, and 110 sites under $45 \mathrm{hr}$. Even though the amount of terrain in this DEM is larger than the radar DEM (by a factor of 2.5), the relative percentages of terrain for $>50$ percent average illumination and $<364 \mathrm{hr}$ energy storage duration are similar. Again, the merits of the energy storage duration metrics are shown by comparison with the amounts of terrain with over 50 percent average illumination (from 0.2 to 7.7 percent of the entire region's data for the worst lunar day).

Figure 29 illustrates the difference between the average illumination and fast/slow recharge energy storage duration metrics for the worst case lunar day using the south pole radar DEM. For the worst case lunar day, when sites with greater than 50 percent average illumination are sorted by fast recharge energy storage duration and plotted in ascending order, the increase in energy storage duration due to slow recharge is apparent at some sites, although a large number of the sites have similar durations regardless of rate, indicating the illumination profiles have far enough apart shadowed periods to be little affected by recharge rates. However, what is also apparent is the widely varying average illumination which seems highly correlated to the slow recharge energy storage duration. There seems little incentive to utilize slow recharge energy storage systems, therefore, table 1 lists the sites with under $182 \mathrm{hr}$ for fast recharge energy storage duration for the south pole radar DEM. Each site has a unique code identification and is grouped by area code for reference on the maps. Reference pixel locations are useful as a general guide to locating the sites. Reference latitudes and longitudes are approximate due to polar grid variations. Figure 30 illustrates the difference between the average illumination and fast/slow recharge energy storage duration metrics for the worst case lunar day using the south pole combined DEM. Table 2 lists the sites with under $182 \mathrm{hr}$ for fast recharge energy storage duration for the south pole combined DEM.

Comparing the sites of tables 1 and 2 shows the effects of the increased DEM coverage on the results. Because of the filling of nearby or adjacent blank radar DEM areal elements with stereo imagery-derived DEM areal elements that were higher than surrounding reference radar DEM terrain, the previous radar DEM high illumination sites were superseded (and shadowed) by the new adjacent terrain. This occurs near the rim of Shackleton crater and could be the result of spatial and/or height error in specific stereo imagery-derived DEM areal elements (highlighted orange). This implies a need to further refine the combined DEM with improved filtering/merging algorithms. In a few cases (highlighted light blue), however, the same points exist in both tables. In particular, site 2RS (the same as site 43CS), which was 
at the edge of the radar DEM, had one of the best fast recharge energy storage durations (66 hr using the radar DEM alone) but it increased to $154 \mathrm{hr}$ using the added topography of the combined DEM. Sites near this location also had similar increases of energy storage duration. The other blue highlighted sites were not affected by the added topography, mainly because most of the high shadow casting terrain within viewing range had been covered with the radar DEM. Figure 31 shows these sites grouped by area for the south pole radar DEM for the worst case lunar day. Figure 32 shows these sites grouped by area for the south pole combined DEM for the worst case lunar day. The hash mark in the images represents the pole. The orientations of the longitudes are the same as with the previous maps. Circles encompass collections of sites and are referred to as "Areas" in the tables.

For the worst case lunar day, out of the possible 175596 sites in the north pole radar DEM, there were 55 sites $\left(\sim 0.03\right.$ percent of the entire region's data, $\left.20 \mathrm{~km}^{2}\right)$ with over 50 percent average illumination and 0 sites over 60 percent. For the best case lunar day, there were 6287 sites (less than 3.6 percent of the entire region's data, $2263 \mathrm{~km}^{2}$ ) with over 50 percent average illumination for the worst case lunar day, 2093 sites over 60 percent, 792 sites over 70 percent, 316 sites over 80 percent, and 116 sites over 90 percent. For the fast recharge energy storage duration on the worst case lunar day, there were 10466 sites ( $\sim 6$ percent of the region's data) under $364 \mathrm{hr}$, and 2 sites under $182 \mathrm{hr}$. For the slow recharge energy storage duration on the worst case lunar day, there were 317 sites under $364 \mathrm{hr}$, and 0 sites under $182 \mathrm{hr}$. For the fast recharge energy storage duration on the best case lunar day, there were 33085 sites ( $\sim 19$ percent of the region's data) under $364 \mathrm{hr}, 2179$ sites under $182 \mathrm{hr}, 480$ sites under $91 \mathrm{hr}$, and 169 sites under $45 \mathrm{hr}$. For the slow recharge energy storage duration on the best case lunar day, there were 11285 sites under $364 \mathrm{hr}, 937$ sites under $182 \mathrm{hr}, 286$ sites under $91 \mathrm{hr}$, and 120 sites under $45 \mathrm{hr}$. It is disappointing to observe the meager number of sites with above average illumination and below average energy storage duration, however, it is not surprising considering the magnitude of the observed extremes in height (using the radar DEM): $5.7 \mathrm{~km}$ for the north pole and $14.5 \mathrm{~km}$ for the south pole. A higher magnitude difference increases the likelihood of high terrain with more illumination and low terrain that remains in darkness for long periods.

For the worst case lunar day, out of the possible 528763 sites in the north pole combined DEM, there were 179 sites (less than 0.03 percent of the entire region's data, $64 \mathrm{~km}^{2}$ ) with over 50 percent average illumination for the worst case lunar day and 0 sites over 60 percent. For the best case lunar day, there were 13292 sites (less than 2.5 percent of the entire region's data, $4785 \mathrm{~km}^{2}$ ) with over 50 percent average illumination for the worst case lunar day, 2588 sites over 60 percent, 852 sites over 70 percent, 361 sites over 80 percent, and 140 sites over 90 percent. For the fast recharge energy storage duration on the worst case lunar day, there were 58658 sites ( $\sim 11$ percent of the region's data) under $364 \mathrm{hr}$ for the fast recharge ratio and 8 sites under $182 \mathrm{hr}$. For the slow recharge energy storage duration on the worst case lunar day, there were 2436 sites under $364 \mathrm{hr}$ for the fast recharge ratio and 0 sites under $182 \mathrm{hr}$. For the fast recharge energy storage duration on the best case lunar day, there were 115992 sites $(\sim 22$ percent of the region's data) under 364 hr, 2733 sites under 182 hr, 532 sites under 91 hr, and 197 sites under 45 hr. For the slow recharge energy storage duration on the best case lunar day, there were 35709 sites under $364 \mathrm{hr}$, 1032 sites under $182 \mathrm{hr}, 323$ sites under $91 \mathrm{hr}$, and 146 sites under $45 \mathrm{hr}$.

Figure 33 illustrates the difference between the average illumination and fast/slow recharge energy storage duration metrics for the worst case lunar day using the north pole radar DEM. The fewer number of sites coupled with less mountainous terrain seems to cause more alignment between the fast and slow energy storage duration. Figure 34 illustrates the difference between the average illumination and fast/slow recharge energy storage duration metrics for the worst case lunar day using the north pole combined DEM. Again, there seems to be a closer alignment between the two energy storage duration types, likely due to the less mountainous terrain. Table 3 lists the sites with under $182 \mathrm{hr}$ for fast recharge energy storage duration for both the north pole radar and combined DEMs. Figure 35 shows these sites grouped by area for both the north pole radar and combined DEMs for the worst case lunar day. 


\section{Analysis Results: Illumination Profiles for North and South Pole Sites}

In this section, the term elevation refers to the angle of the terrain at the horizon or the Sun as measured from the tangent plane to the site under consideration (and not to 'elevation' such as kilometers or meters in terms of height). The figures present the Sun/horizon terrain elevation and illumination fraction as a function of time (power system designers can utilize this data easier this way). Conversions to site azimuth and solar sublongitude are provided for each site location. The illumination fraction profile has high values meaning fully illuminated, low values being fully shadowed, and a linear variation in between representing partial illumination. These profiles permit the reader to simulate a visual panning from the site and enable one to visualize the horizon as well as the sun position relative to the horizon. The illumination fraction assumes the viewer (or solar array) is facing directly at the Sun. No reflected energy or albedo is included in this fraction. No shadowing due to locally deployed hardware (e.g., other solar arrays) or eclipses due to the Earth at the site (1 to $1.7 \mathrm{hr}$ full, 1 to $3.9 \mathrm{hr}$ partial, up to 3 times per year) are included in these results. The illumination fraction is shown for the worst case lunar day and sun elevation profiles are shown for the worst and best case lunar day. These profiles enable one to compare and understand how illumination varies through each of the lunar day extremes. Profiles based on the original radar DEM for selected south pole sites were previously documented (ref. 1).

For the south pole, sites were selected for illumination profiles based on site feasibility. For instance, the high illumination sites at Areas F-SR/F-SC and C-SC appear to be in very rough terrain with poor accessibility, so are not presented. Sites in Area B-SC are suspect since they do not appear in the radar DEM results and are the result of filling in small blank regions in the radar DEM with terrain heights much higher than surrounding radar DEM terrain. This is not likely since the terrestrial radar would have been able to capture such terrain heights and thus there would have been no missing terrain . Based on such comparatively high adjacent terrain, additional filters will have to be developed for future analyses which exclude stereo imagery-derived DEM terrain heights which are beyond heights inferred from radar visibility/angles. Another option would be to exclude stereo imagery-derived data for local areas wellrepresented by the radar data. Areas A-SR/A-SC also show these kind of height differences from adjacent terrain.

For the Shackleton Crater rim area (Areas A-SR/A-SC), for comparison purposes, the illumination profiles for Sites 1CS and 4RS are presented in figure 36, which although separated by only one areal element seem to be essentially the same site. The drastically better energy storage duration (radar DEM: $71 \mathrm{hr}$ versus combined DEM: $26 \mathrm{hr}$ ) and average illumination (radar DEM: 73 percent versus combined DEM: 93 percent) is due to the much higher combined DEM areal element height. It is unlikely the Site $1 \mathrm{CS}$ data has the correct height based on imagery review, therefore added DEM filtering is required for future analyses. For the south pole site profiles, data is shown starting at $4966 \mathrm{hr}$ in 1994 (7-27-94) for the best case lunar day and $717 \mathrm{hr}$ for the worst case lunar day (1-30-94). For the south pole sites in general, solar sublongitude decreases by $0.51^{\circ} / \mathrm{hr}$, starting at $311.7^{\circ}$ for the best case lunar day and $318.6^{\circ}$ for the worst case lunar day. Azimuth (referenced with zero pointing to the north pole) starts at $102^{\circ}$ for both lunar days and decreases by $0.51 \% \mathrm{hr}$.

The illumination profiles for Sites 43CS and 2RS (in Area D-SR/D-SC) are presented in figure 37 to illustrate how is it possible the combined DEM's added terrain can increased the energy storage duration (radar DEM: $66 \mathrm{hr}$ versus combined DEM: $154 \mathrm{hr}$ ). However, since most of the shadowing is caused by Shackleton Crater terrain that may be erroneously high, the combined DEM results are somewhat suspect for certain times. For these sites, azimuth starts at $185.5^{\circ}$ for both lunar days and decreases by $0.51^{\circ} / \mathrm{hr}$.

The illumination profiles for Sites 49CS and 16RS (in Area E-SR/E-SC) presented in figure 38 show how even with more terrain coverage, it is still possible to get the same results based on energy storage duration and average illumination. It is apparent that the radar DEM had a large swath of missing terrain (as seen by the long flat line). However, even though the combined DEM fills in the data, it does not make much difference due to the nature of the sun elevation profile and the fact that most of the relevant terrain was already represented by the radar DEM. For these sites, azimuth (referenced with zero pointing to the north pole) starts at $176.4^{\circ}$ for both lunar days and decreases by $0.51 \% \mathrm{hr}$. 
For the north pole, the illumination profile of Site 1RN and 2CN (in Area A-N) are presented in figure 39. For the north pole site profiles, data is shown starting at $736 \mathrm{hr}$ in 1994 (1-31-94) for the best case lunar day and $4985 \mathrm{hr}$ for the worst case lunar day (7-27-94). For the north pole sites, solar sublongitude decreases by $0.51^{\circ} / \mathrm{hr}$, starting at $309.0^{\circ}$ for the best case lunar day and $302.0^{\circ}$ for the worst case lunar day. For these sites, azimuth starts at $353.9^{\circ}$ for both lunar days and increases by $0.51^{\circ} / \mathrm{hr}$.

Figure 40 shows Site $3 \mathrm{CN}$ (in Area B-N). Azimuth starts at $336.5^{\circ}$ for both lunar days and increases by $0.51 \%$ hr.

\section{Analysis Results: Ancillary Shadowing Information for North Pole Sites}

To understand what terrain is causing shadowing onto Site $1 \mathrm{RN}$, figure 41 shows a white line on a background radar backscatter image (ref. 9) which spatially depicts the highest terrain (i.e., the horizon terrain elevation) as viewed from the site using the radar DEM. Blue dots highlight the terrain which is shadowing the site during the worst case lunar day (a shadow is defined here as $>50$ percent illumination blockage each time step). Figure 42 shows the heights and distance of the shadowing terrain for Site 1RN, with blue dots highlighting the worst case shadowing terrain as in the previous figure. The start time for the worst case lunar day is referenced from $4985 \mathrm{hr}$ into 1994 (7-27-94).

Figure 43 shows the average illumination and energy storage duration throughout the year for Site $1 \mathrm{RN}$. The time period shown is 1994 and the lunar days start at 1-1-94. The recharge rate makes a substantial difference in energy storage duration for the higher shadowing periods during the year.

\section{Analysis Results: Effect of Tower Heights and Site Linkages}

Figure 44 shows the effect of using a power tower of various heights at the north pole Sites 1RN and $2 \mathrm{RN}$ as well as how the results are affected if the sites are electrically connected for the worst case lunar day. Reference 1 discusses using towers in more detail and how they affect the metrics for various south pole sites. Without the analysis of DEMs, the benefits of such tower heights cannot be assessed.

\section{Future Work}

There are several approaches to enhancing the quality of lunar polar illumination analysis. High resolution radar DEMs developed recently at JPL will have enhanced resolution. SMART-1 imagery of the lunar polar regions for the entire year and especially for the worst case lunar day have also been captured which could provide more data in making DEM improvements. On-going and future surface radar and image mapping lunar missions will also provide added temporal and spatial coverage and resolution. Notable results are currently being obtained by the Terrain Camera of the Japan Aerospace Exploration Agency's Kaguya spacecraft. Combined annual coverage of the Terrain Camera (which produces DEMs from stereo images) with Earth-based radar DEMs should provide definitive DEMs for polar illumination analyses.

Using the present sources for DEMs, given adequate orbital imagery, detailed assessments could be performed to correct specific high shadow causing area elements as well as make more general corrections which would enhance comparisons with available imagery. It became apparent during the course of this analysis that additional improvements are needed to correct or filter some of the stereo imagery-derived DEM height data which were erroneously high. This will involve determination of radar visibility and projected maximum heights and factoring this information into the process of combining DEMs. Similarly, the formulae for optimized merging of the DEMs, particularly in the area of height matching, needs further examination to reduce the average absolute DEM height error.

To address the proper geo-referencing of the DEM areal elements (which are currently tied to the Clementine LIDAR that only exist for lower absolute latitudes), comparisons with occultation data from Earth-based telescopic observations of the lunar limb could be used to validate and improve the data 
surface fitting. C.B.Watts (ref. 15) and D. Büttner (ref. 16) have developed occultation data which will be useful in this respect.

Finally, a more thorough investigation of connecting reasonably separated north pole sites should be performed to reduce the energy storage duration. Because of the time phasing of shadowing events, it is not a straightforward process to find which sites are best to connect to reduce this crucial metric. It is possible that two poor performing connected sites (via any metric) could outperform any two good performing connected sites. This may require a brute force search process which connects all possible sites (within a specific distance) in the DEM. Such a study would also ideally include a mass comparisons of power cable versus energy storage mass.

\section{Conclusion}

This paper has presented maps of average illumination and energy storage hours for the lunar north and south pole generated using an independently developed computer program and two types of DEMs. This data can be used in mission/route planning/operations, rover/lander design and power/thermal system design. This paper has elucidated and extended the findings of the other researchers in the field, particularly as lunar illumination pertains to spacecraft power system sizing and design. The radar DEMs were enhanced (blank data regions filled and areas beyond the radar coverage) using Clementine spacecraft stereo imagery-derived DEMs with the goal of extending the illumination analysis coverage/accuracy. Although significant progress was made in this combination of DEMs, more work in this area is required. The sun/shade times depicted by the illumination profiles and the estimates of energy storage duration provide useful engineering data enabling the detailed analysis and design of various lunar polar based systems. This paper has shown several north pole sites with moderately favorable illumination characteristics (based on energy storage duration). A significant contribution, inherent in using DEM analysis methods, was the definition, location, and quantification of the shadow-inducing terrain for the worst-case energy storage periods which was not previously available for the lunar north pole. Another key aspect of the illumination analysis method demonstrated in this paper was the assessment of varying the solar array heights using towers at north pole sites and the connection nearby north pole sites to improve the illumination characteristics from a power perspective.

\section{References}

1. Fincannon, H.J., "Lunar South Pole Illumination: Review, Reassessment and Power System Implications," 5th International Energy Conversion Engineering Conference, AIAA-2007-4700, Jun. 2007.

2. Bussey, D.B.J., Spudis, P.D., and Robinson, M.S., "Illumination Conditions at the Lunar South Pole," Geophysical Research Letters, Vol. 26, No. 9, May 1999, pp. 1187-1190.

3. Bussey, D.B.J., Robinson, M.S., Fristad, K., and Spudis, P.D., "Permanent Sunlight at the Lunar North Pole," 35th Lunar and Planetary Science Conference, Mar. 2004, Abstract 1387.

4. Bussey, D.B.J., and Spudis, P.D., "The Lunar Polar Illumination Environment: What We Know \& What We Don't," Proceedings of Space Resources Roundtable VI, Lunar and Planetary Institute, Nov. 2004, LPI Contribution 1224, pp.14.

5. Bussey, D.B.J. and Spudis, P.D., "Extreme Lighting Conditions at The Lunar Poles," AAS 03-717, Proceedings of the International Lunar Conference 2003, Exploration Working Group 5, Nov. 2003, pp. 125.

6. de Weerd, J.F., Kruijff, M., and Ockels, W.J., "Search for Eternally Sunlit Areas at the Lunar South Pole From Recent Data: New Indications Found," 49th International Astronomical Congress, IAF98-Q.4.07, Sept 1998.

7. Kruijff, M., "Peaks of Eternal Light on the Lunar South Pole: How They Were Found and What They Look Like," 4th International Conference on Exploration and Utilization of the Moon, ESTEC, ESA SP-462, July 2000, pp. 333. 
8. Margot, J.L., Campbell, D.B., and Slade, M.A., "Digital Elevation Models of the Moon From EarthBased Radar Interferometry," IEEE Transactions on Geoscience and Remote Sensing, Vol. 38, No. 2, Mar. 2000, pp. 1122-1133.

9. Margot, J.L., Campbell, D.B., Jurgens, R.F., and Slade, M.A., "Topography of the Lunar Poles From Radar Interferometry: A Survey of Cold Trap Locations," Science, Vol. 284, Issue 5420, Jun. 1999, pp. $1658-1660$.

10. Cook, A.C., Spudis, P.D., Robinson, M.S., Watters T.R., and Bussey, D.B.J., "The Topography of the Lunar Poles From Digital Stereo Analysis," 30th Annual Lunar and Planetary Science Conference, Mar. 15-29, 1999, Abstract 1154.

11. Cook, A.C., Oberst, J., Roatsch, T., Jaumann, R., and Acton, C., "Clementine Imagery: Selenographic Coverage for Cartographic and Scientific Use," Planetary and Space Science, Vol. 44, No. 10, 1996, pp. 1135-1148.

12. Spudis P.D., Cook, A.C., Robinson, M.S., Bussey, D.B.J., and Fessler, B., "Topography of the South Polar Region From Clementine Stereo Imaging," Workshop on New Views of the Moon, Lunar and Planetary Institute, 1998, pp.79-80.

13. Bussey, D.B.J., Robinson, M.S., Edwards, K., Cook, A.C., and Watters, T., "Simulation of Illumination Conditions at the Lunar South Pole," 32nd Annual Lunar and Planetary Science Conference, Mar. 2001, Abstract 1907.

14. Garrick-Bethell, I., Byrne, S., Hoffman, J.A., and Zuber, M.T., "Areas of Favorable Illumination at the Lunar Poles Calculated From Topography," 36th Annual Lunar and Planetary Science Conference, Mar. 14-18, 2005, Abstract 2006.

15. Morrison, L.V. and Martin, R.J., "A Digitized Version of C.B. Watts' Charts of the Marginal Zone of the Moon," The Moon, Vol. 2, Issue 4, pp. 463-467.

16. Büttner, D., "MOONLIMB - new lunar limb data from occultation observations," Occultation Newsletter, Vol. 7, No. 3, Nov. 1998, pp. 4-12. 


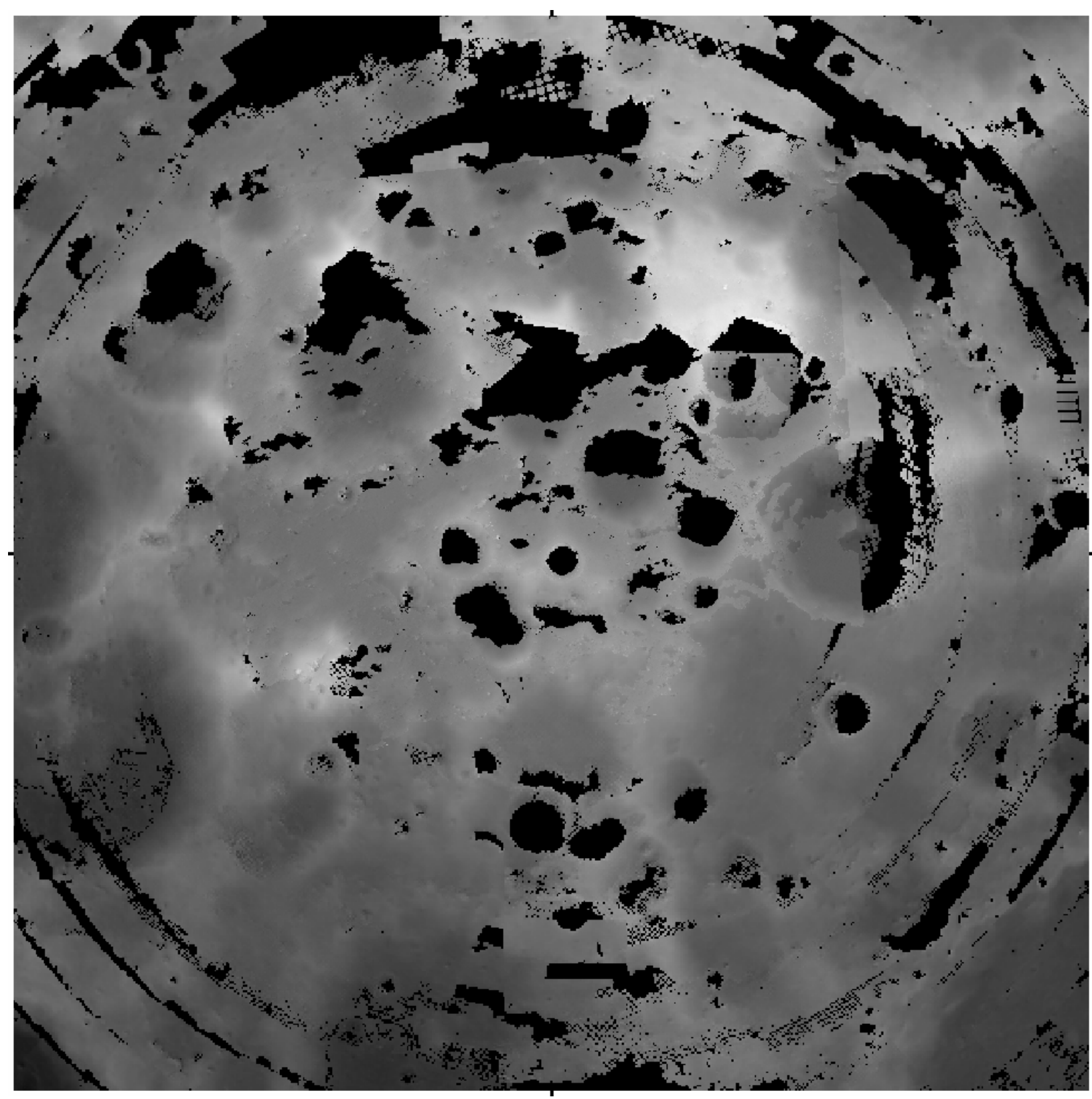

Figure 1.-Lunar south pole combined radar-stereo imagery derived DEM. 


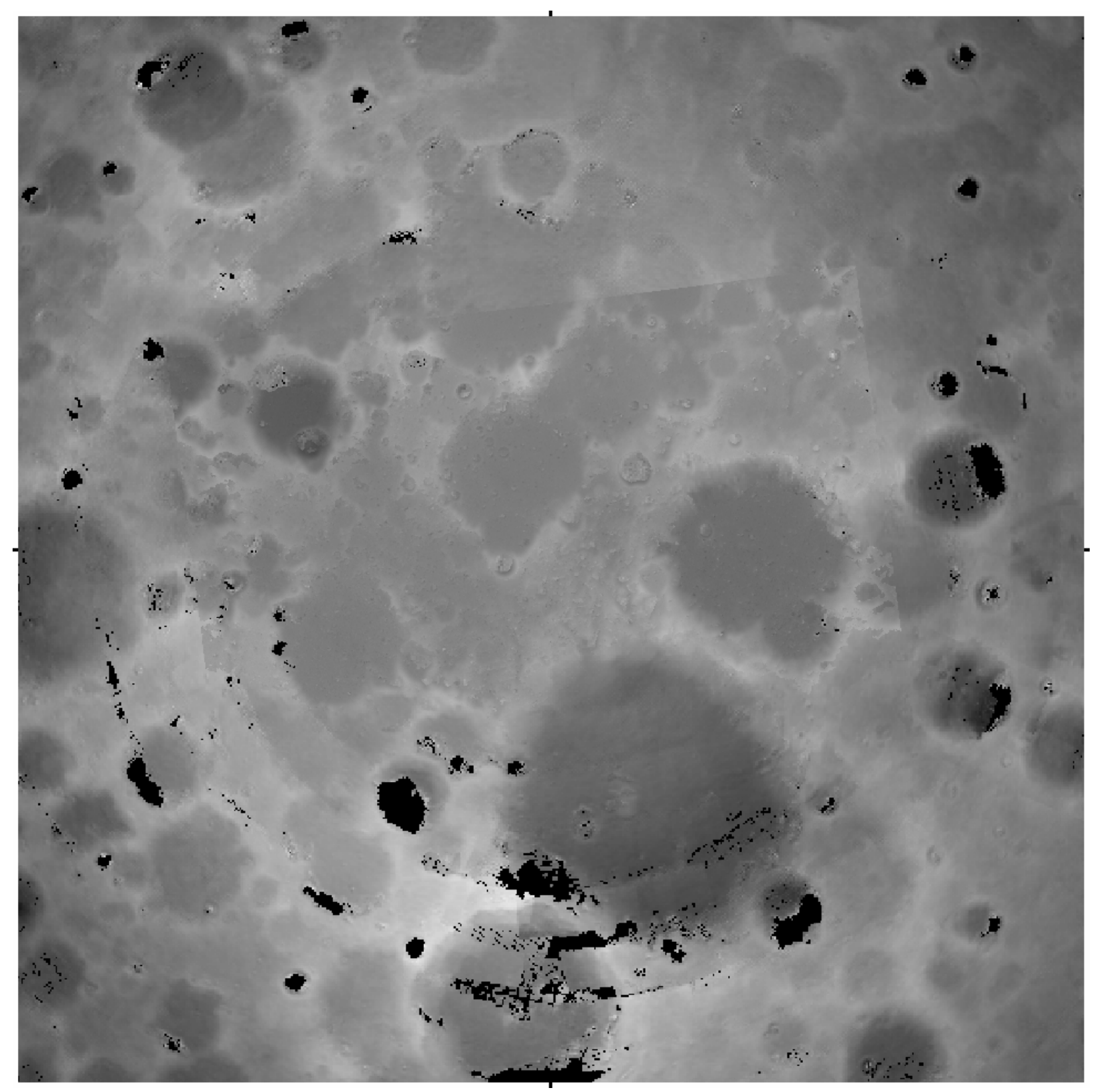

Figure 2.-Lunar north pole combined radar-stereo imagery derived DEM. 


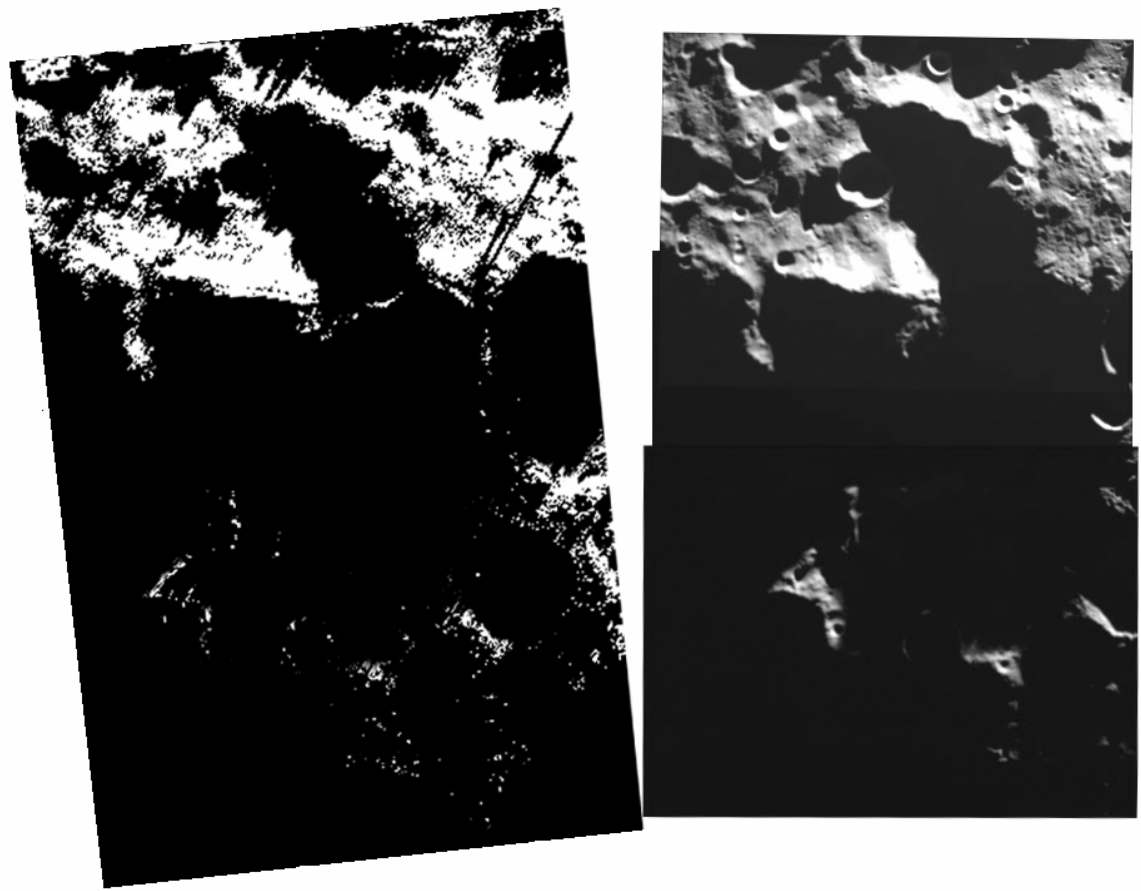

Figure 3.-Comparison of combined lunar south pole DEM generated image (left) with Clementine image (right).
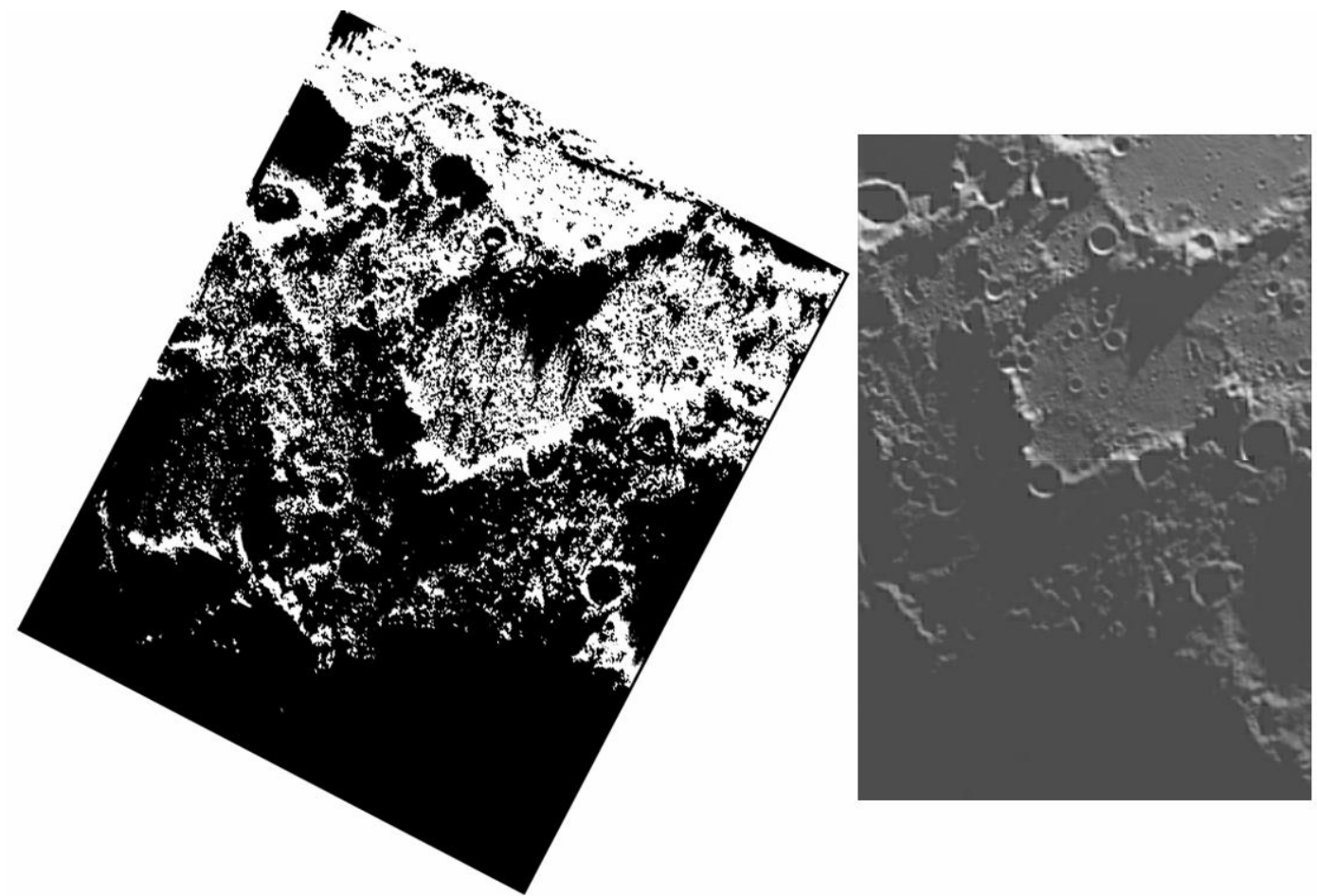

Figure 4.-Comparison of combined lunar north pole DEM generated image (left) with Clementine image (right). 


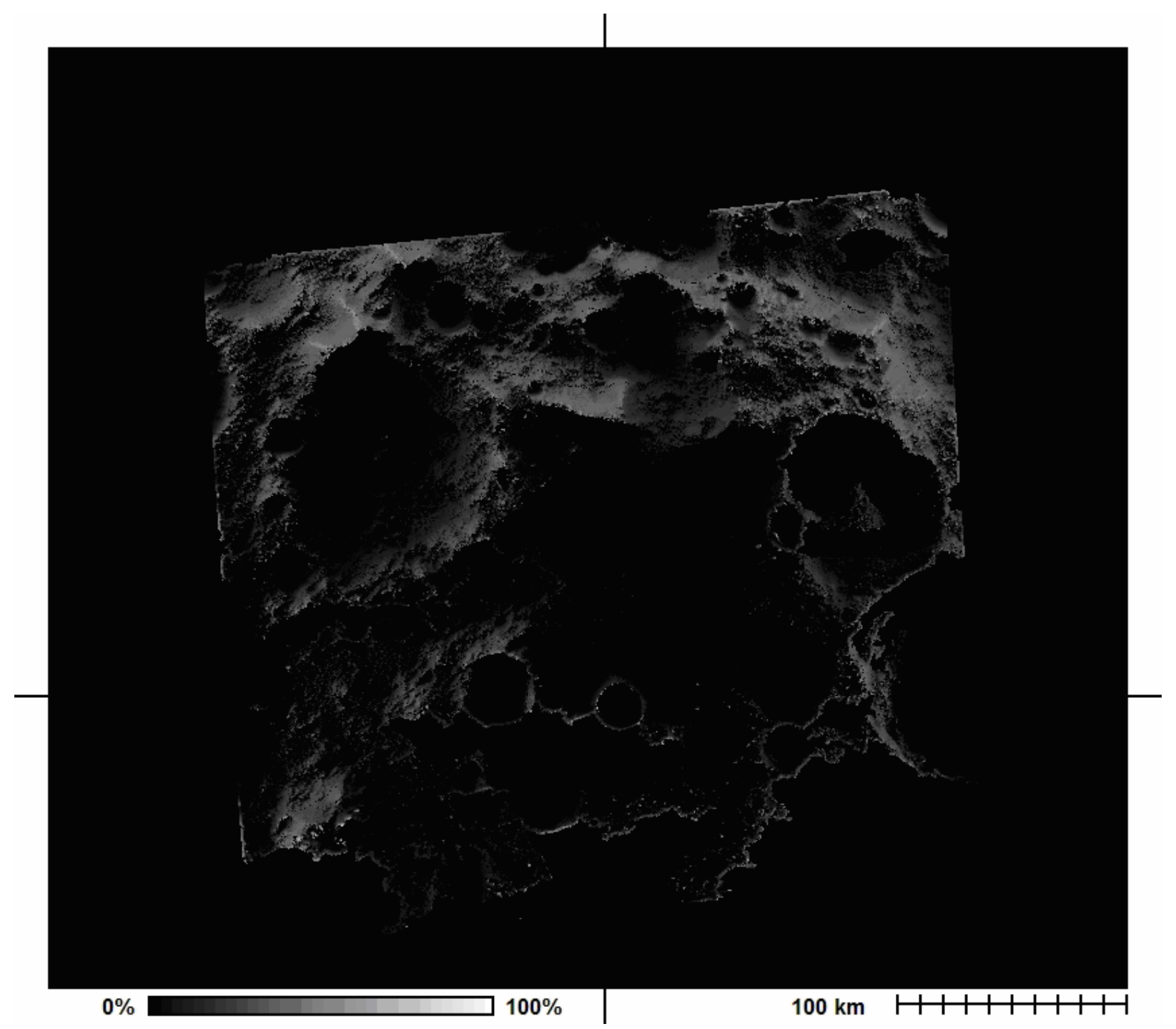

Figure 5.-Lunar south pole average illumination (worse case lunar day, radar DEM). 


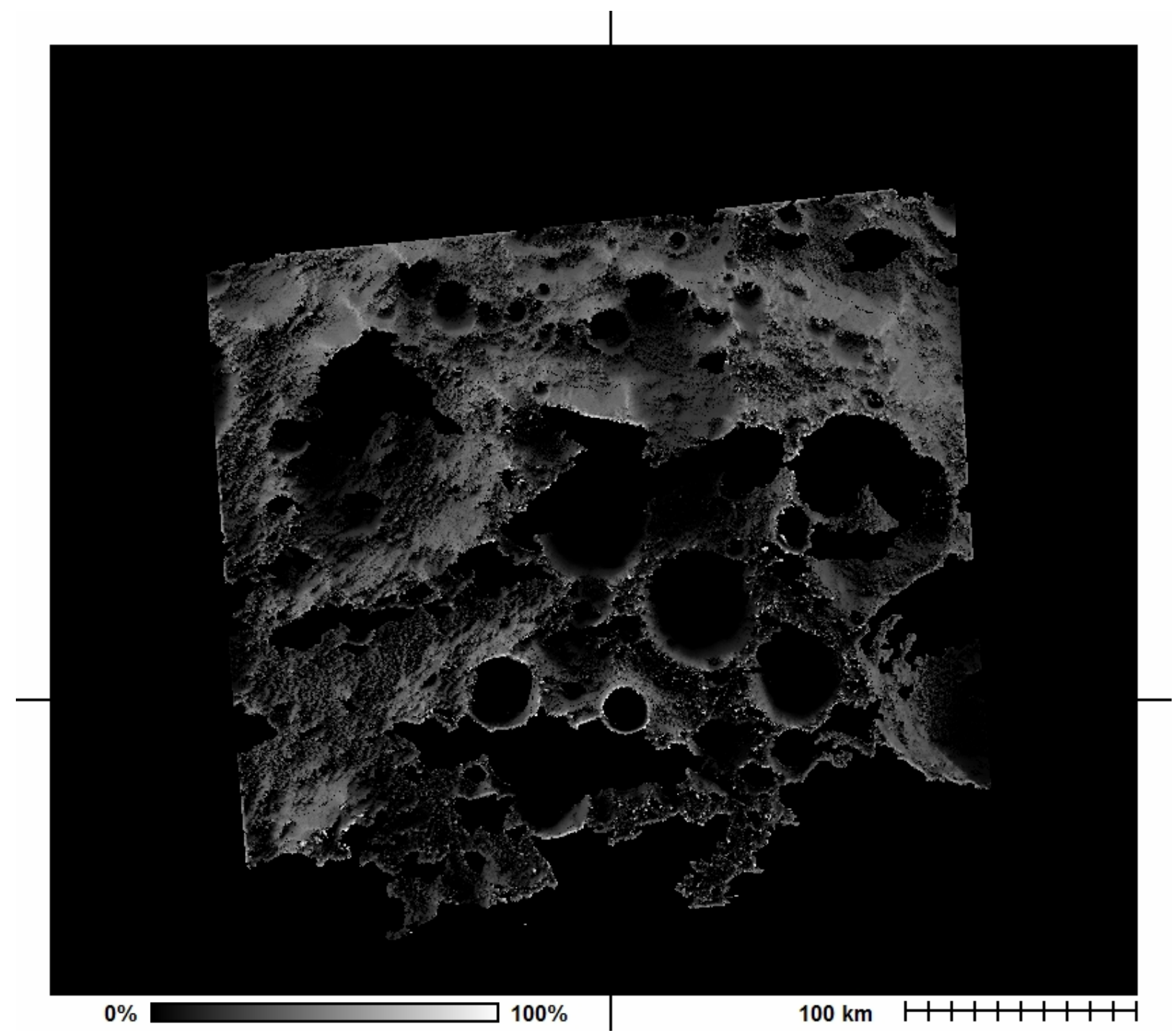

Figure 6. - Lunar south pole average illumination (best case lunar day, radar DEM). 


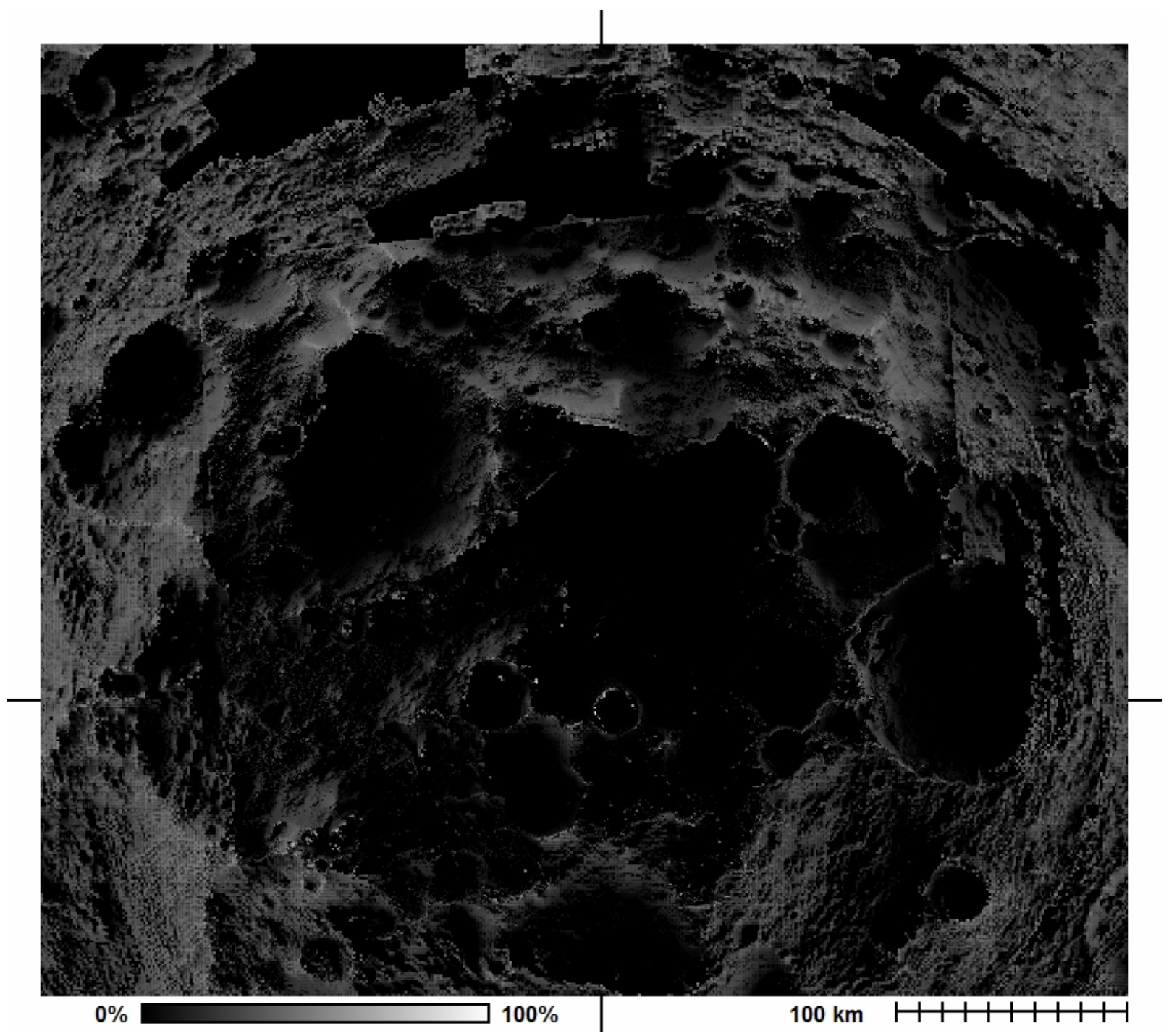

Figure 7.-Lunar south pole average illumination (worst case lunar day, combined DEM). 


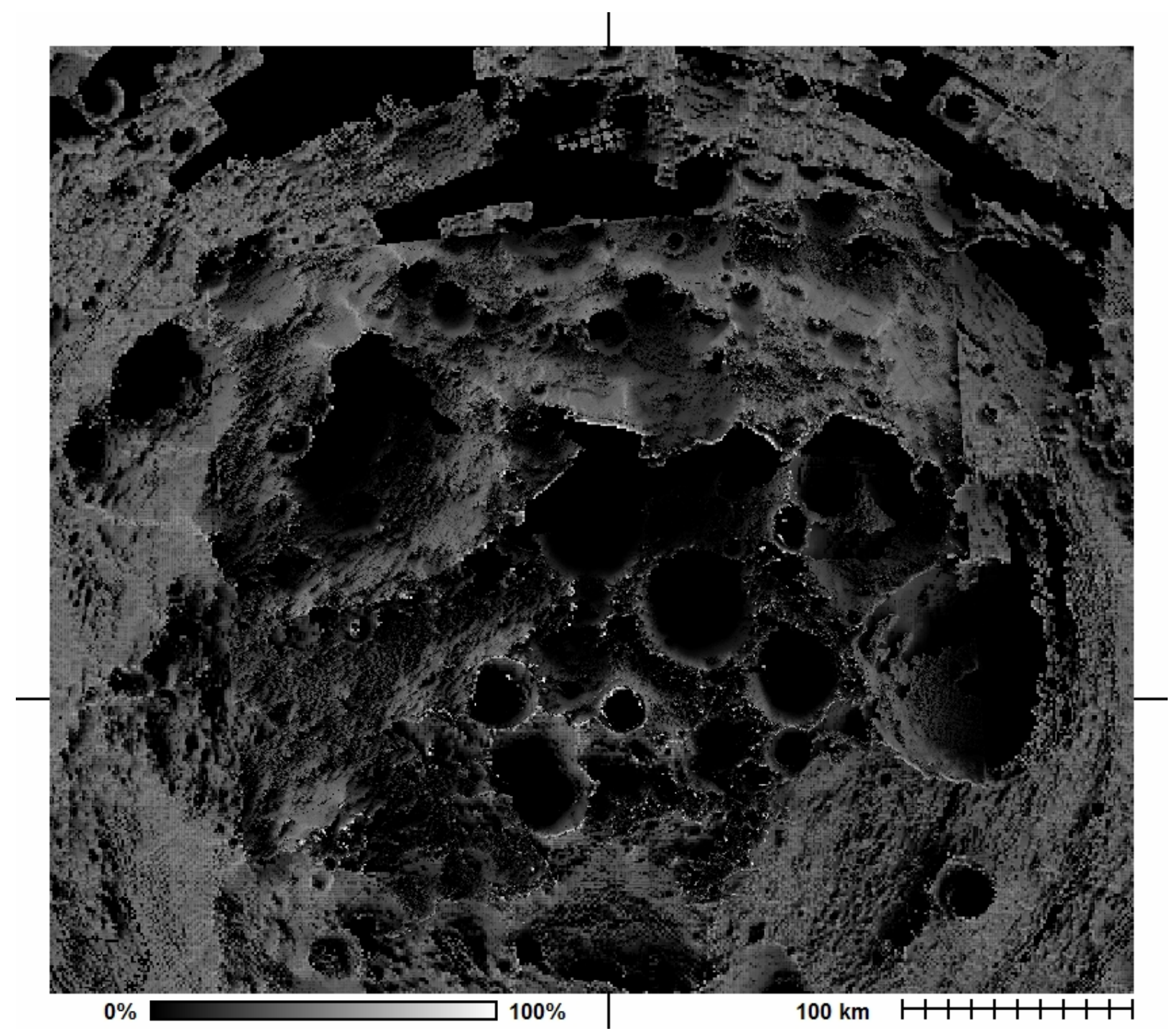

Figure 8.-Lunar south pole average illumination (best case lunar day, combined DEM). 


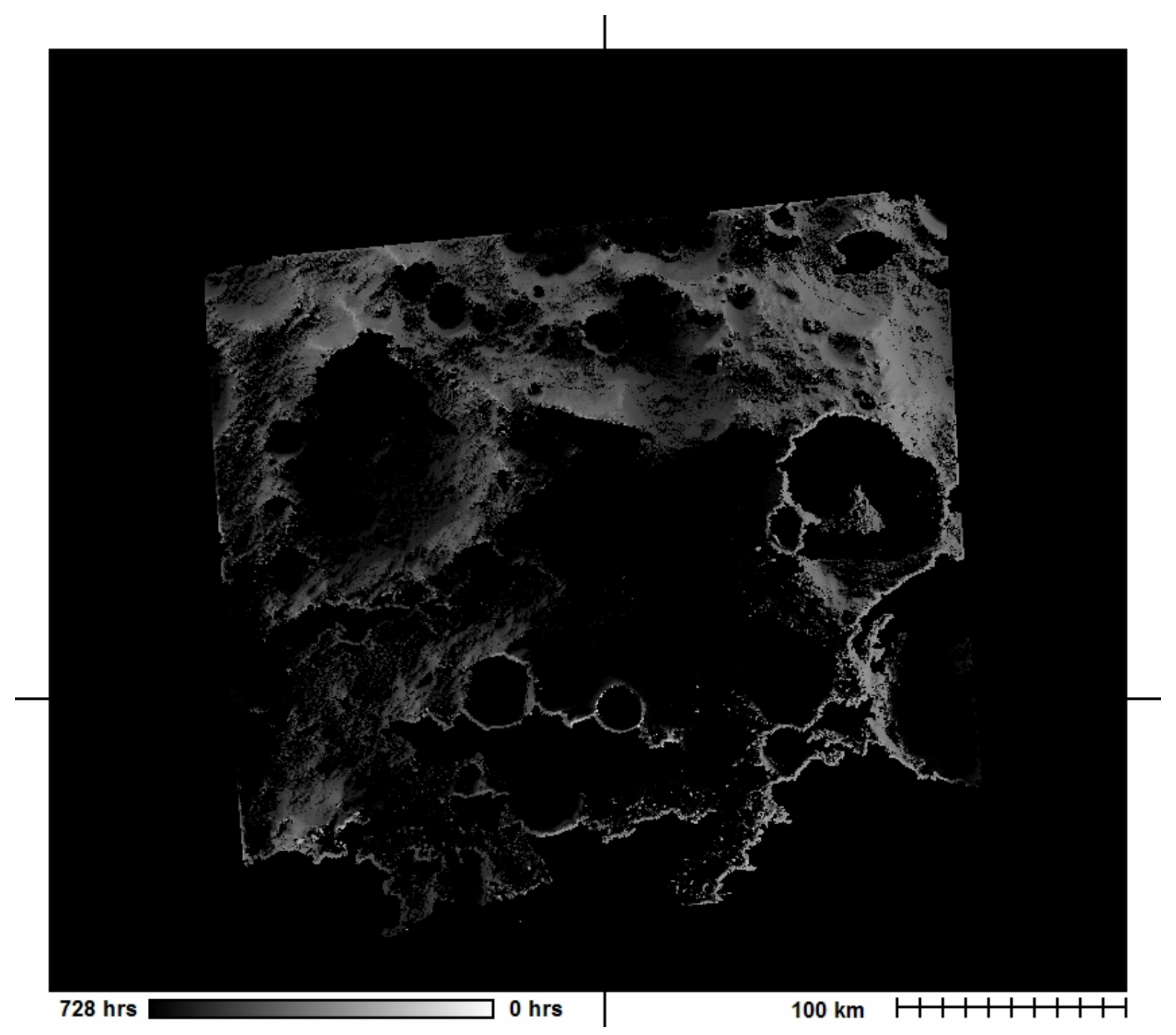

Figure 9.-Lunar south pole fast recharge energy storage duration (worst case lunar day, radar DEM). 


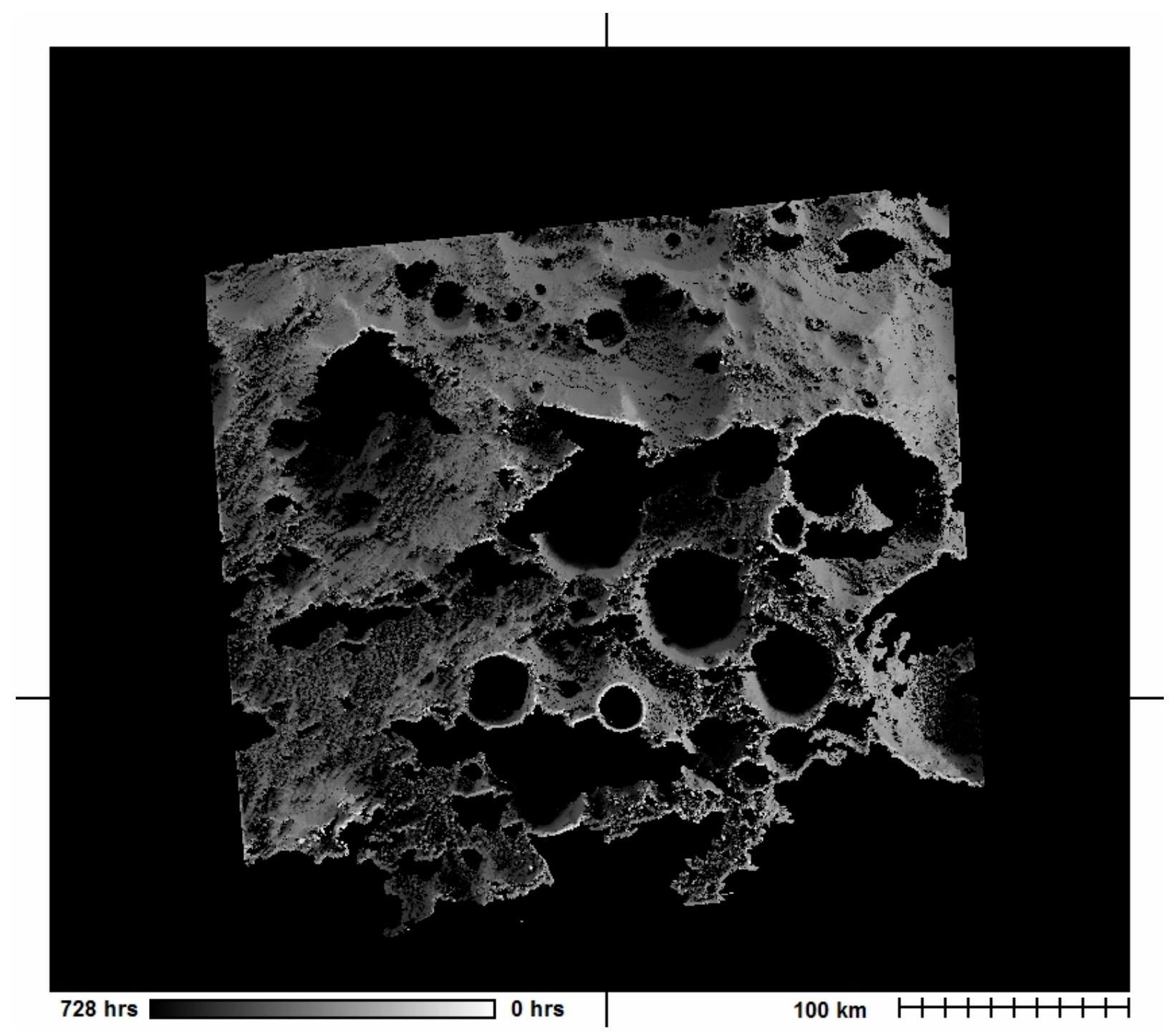

Figure 10.-Lunar south pole fast recharge energy storage duration (best case lunar day, radar DEM). 


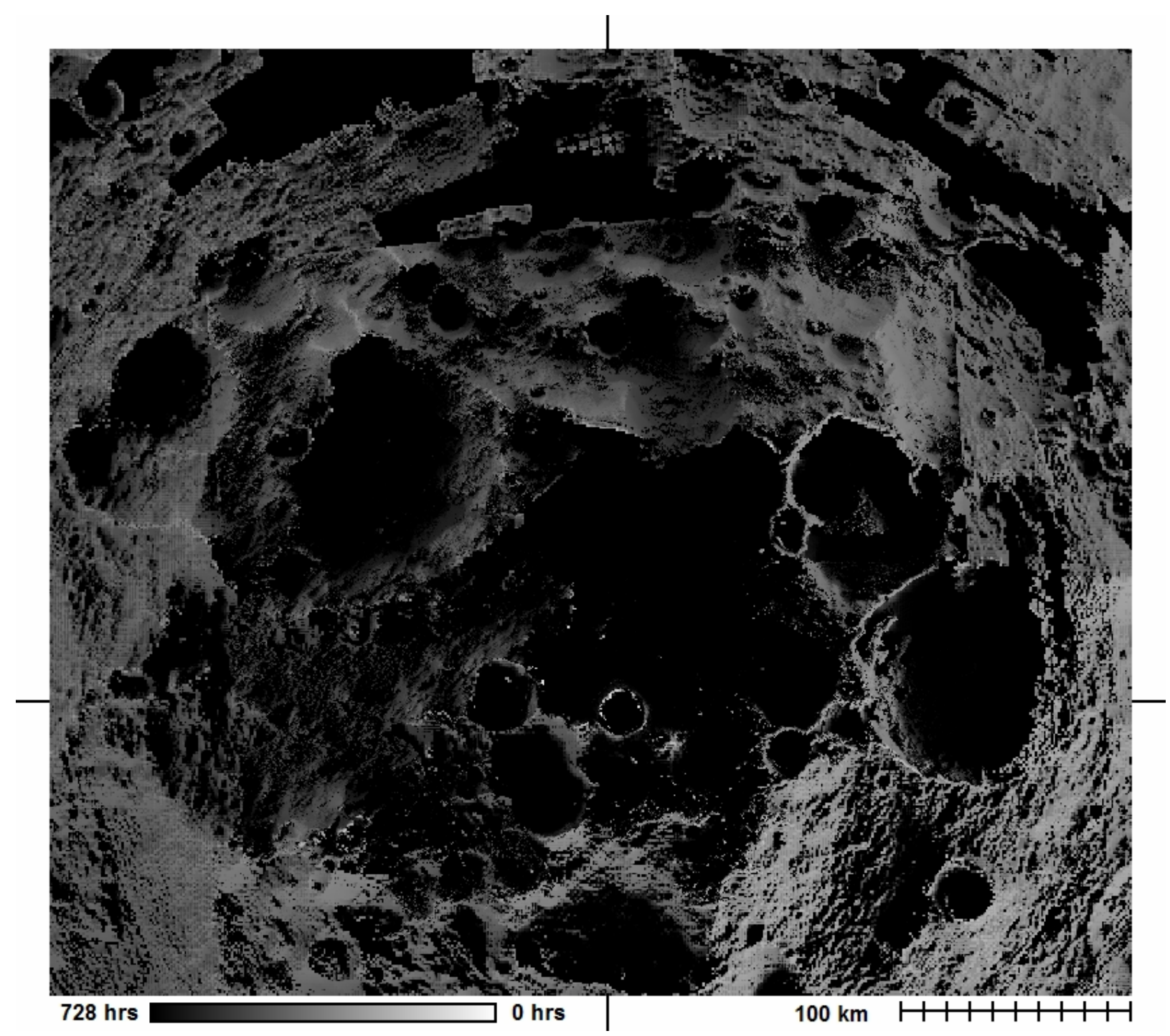

Figure 11. - Lunar south pole fast recharge energy storage duration (worst case lunar day, combined DEM). 


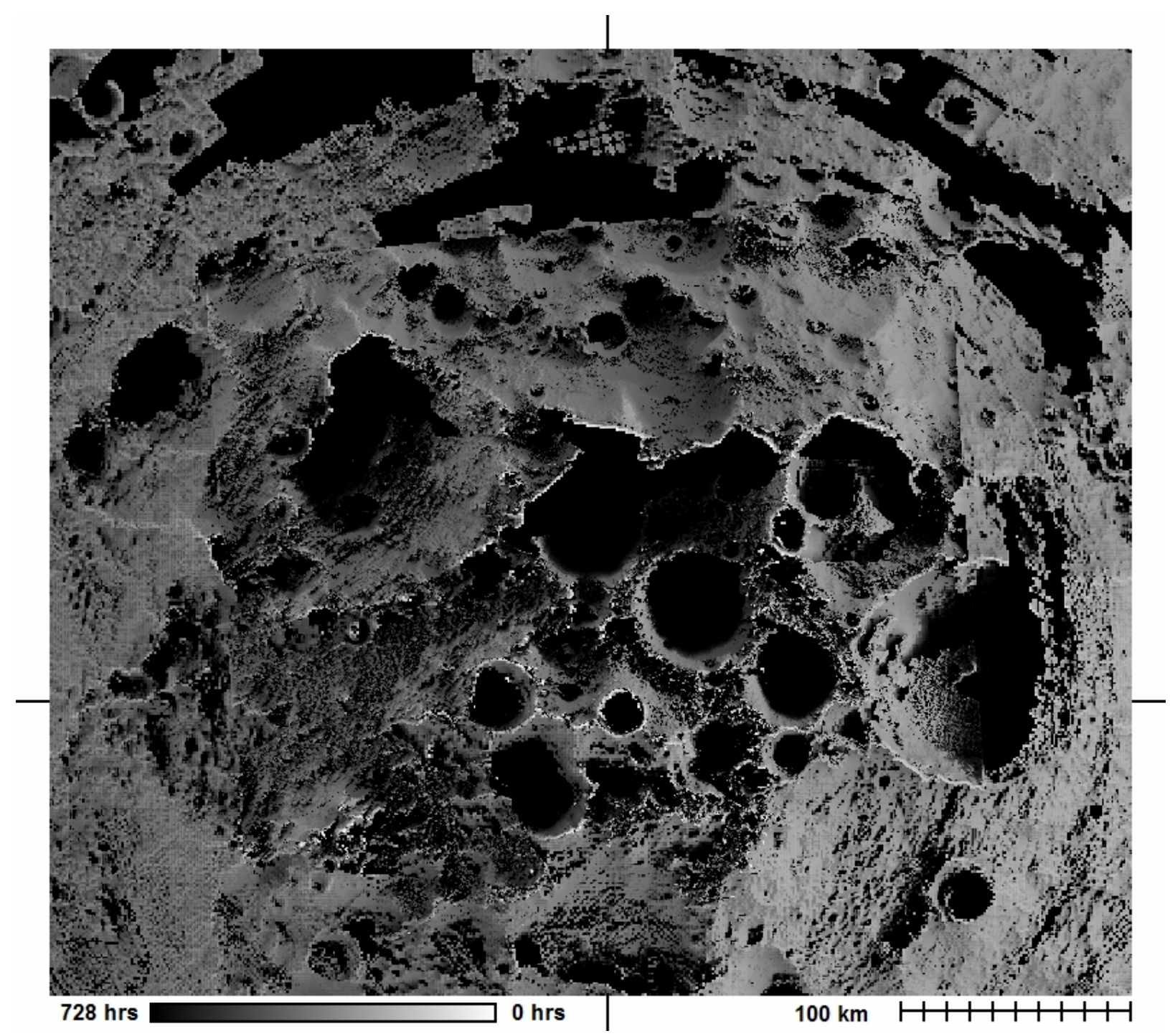

Figure 12.-Lunar south pole fast recharge energy storage duration (best case lunar day, combined DEM). 


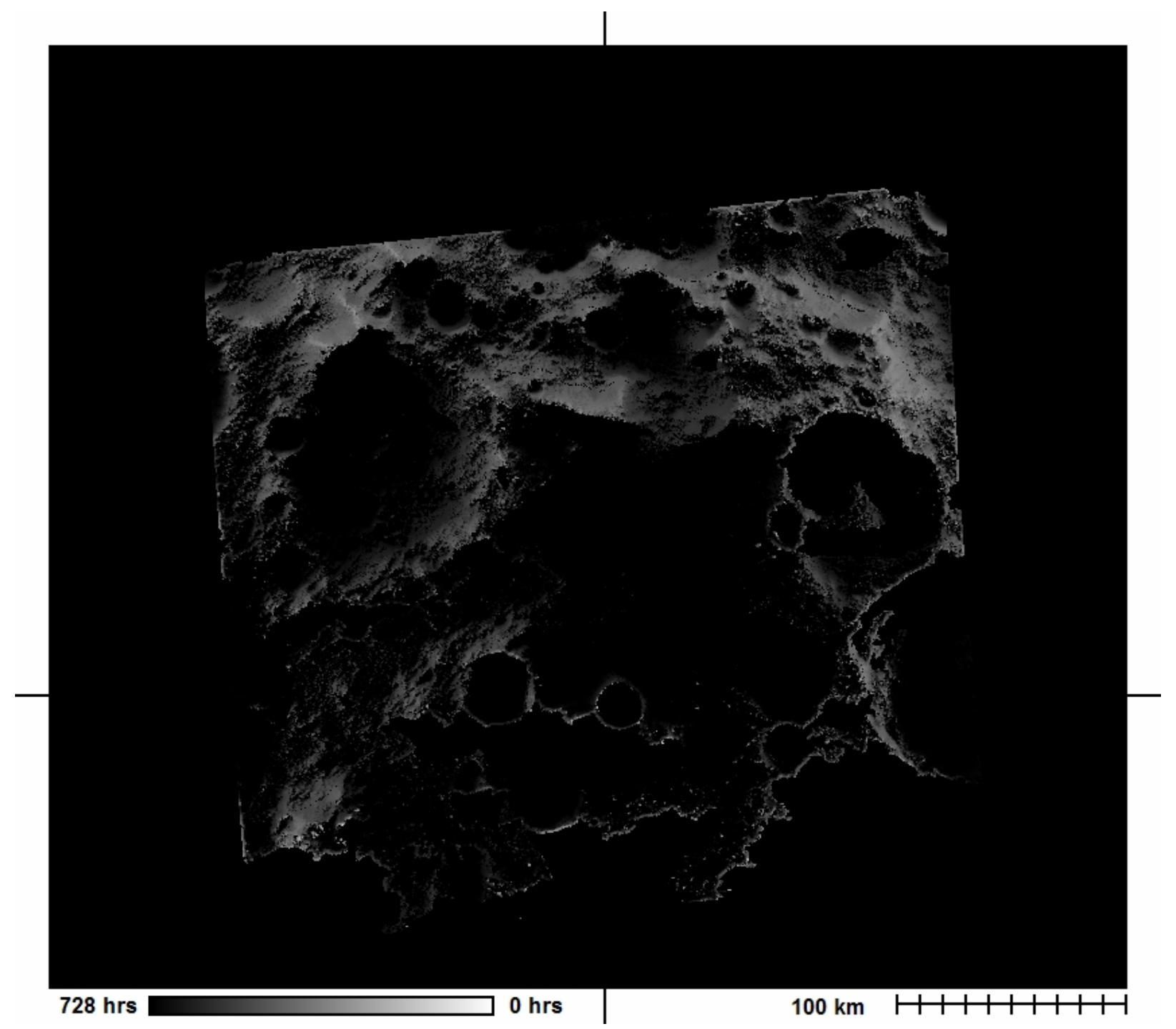

Figure 13.-Lunar south pole slow recharge energy storage duration (worst case lunar day, radar DEM). 


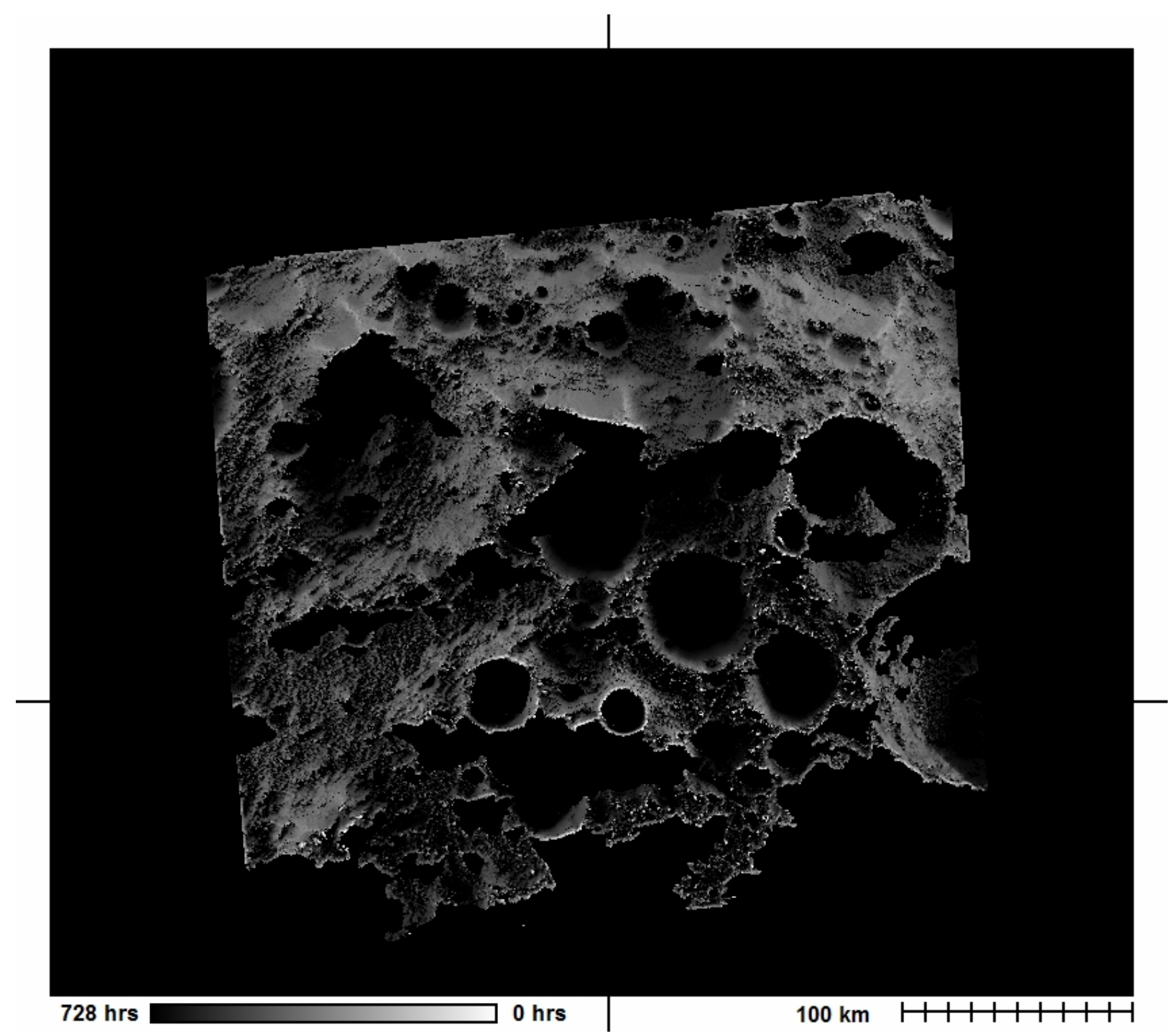

Figure 14.-Lunar south pole slow recharge energy storage duration (best case lunar day, radar DEM). 


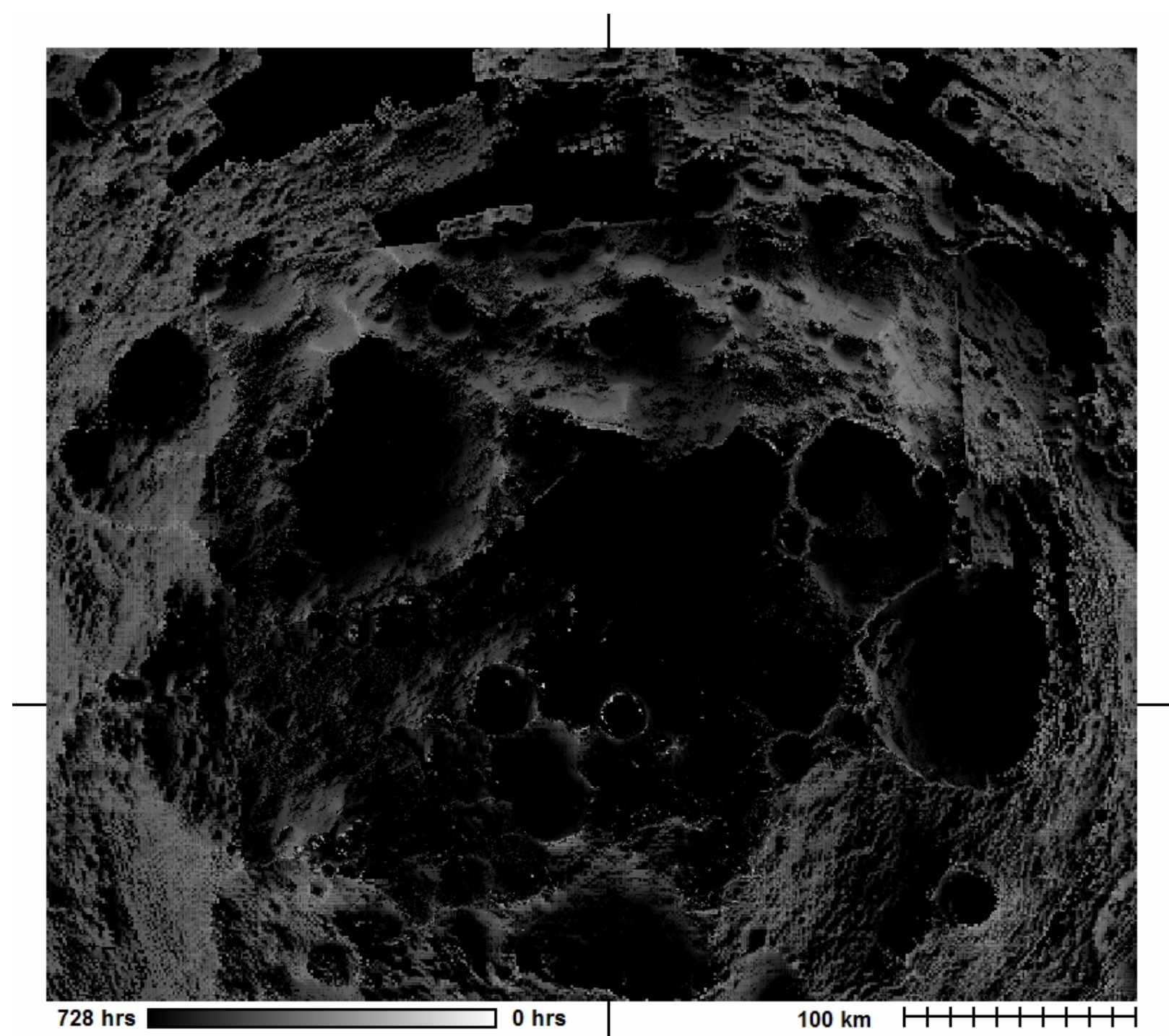

Figure 15.-Lunar south pole slow recharge energy storage duration (worst case lunar day, combined DEM). 


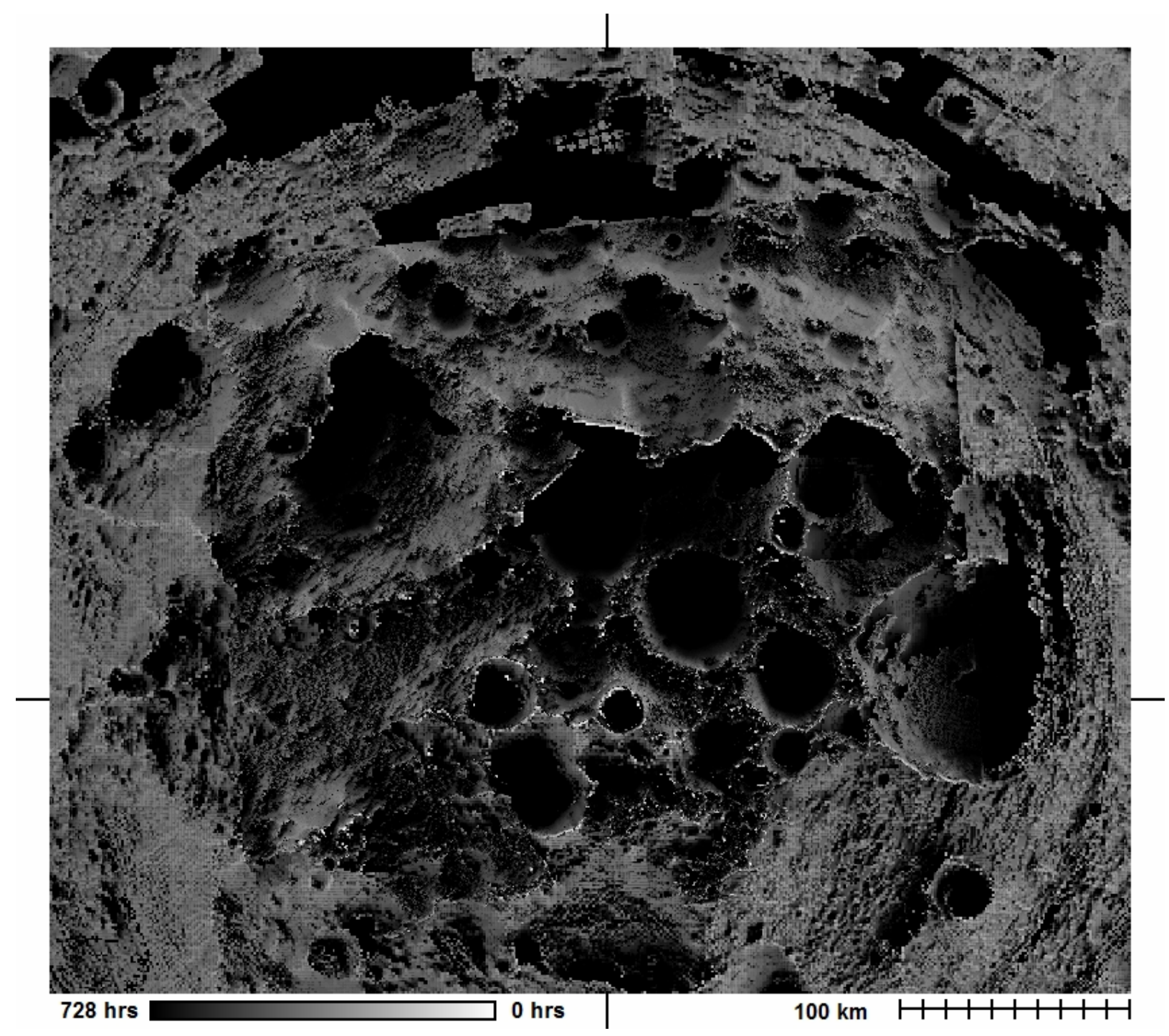

Figure 16.-Lunar south pole slow recharge energy storage duration (best case lunar day, combined DEM). 


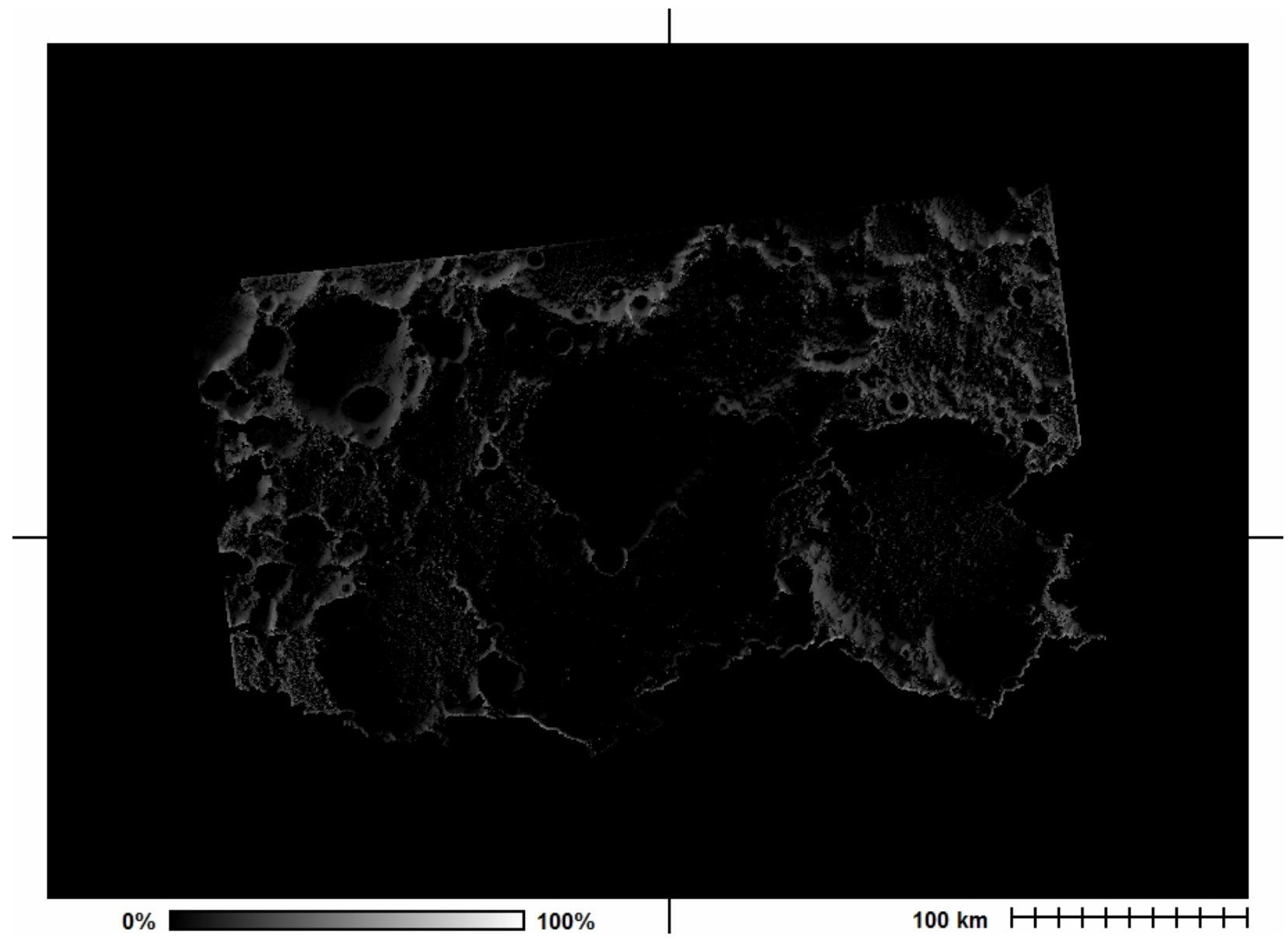

Figure 17.-Lunar north pole average illumination (worst case lunar day, radar DEM). 


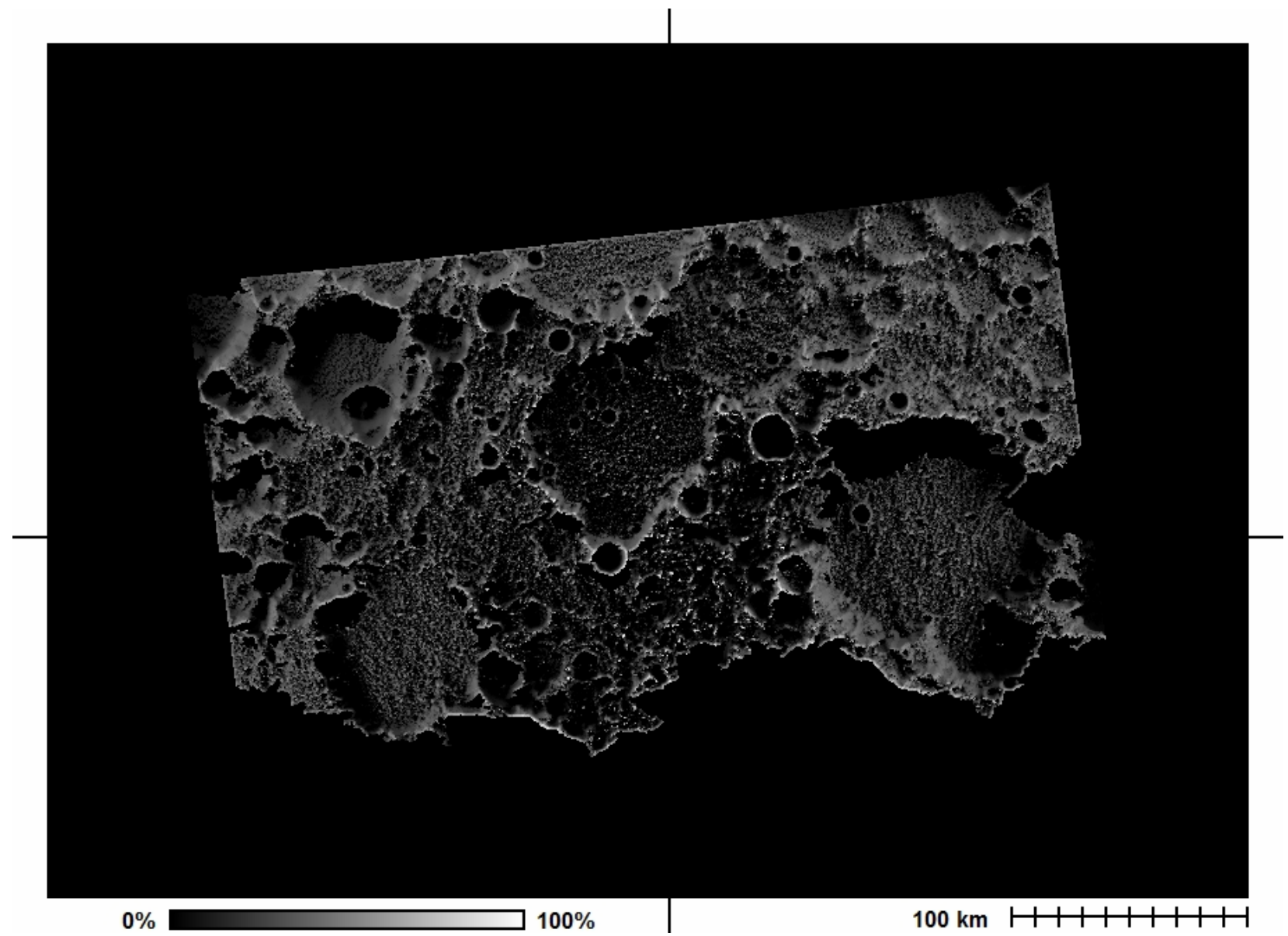

Figure 18.-_Lunar north pole average illumination (best case lunar day, radar DEM). 


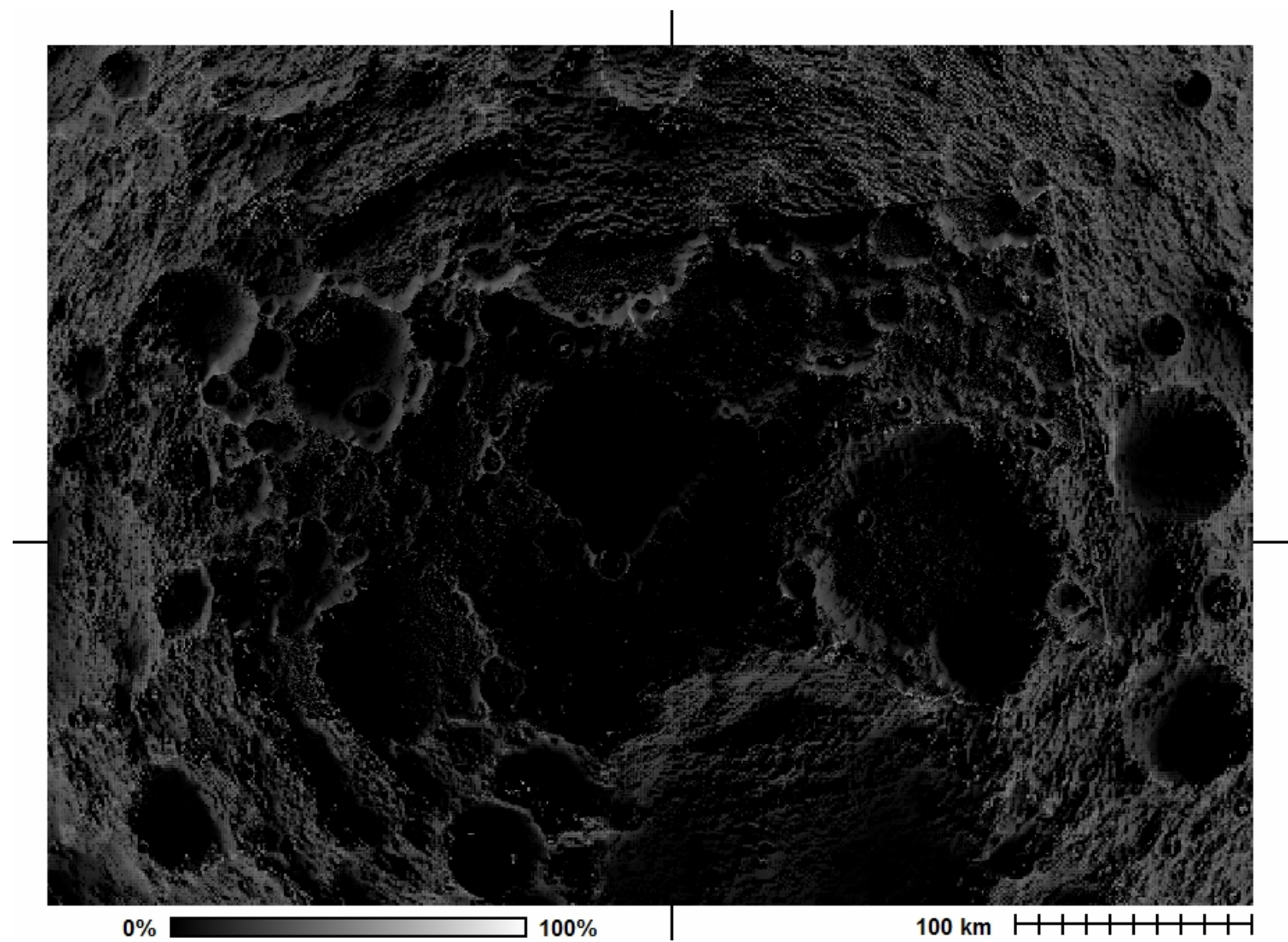

Figure 19.-Lunar north pole average illumination (worst case lunar day, combined DEM). 


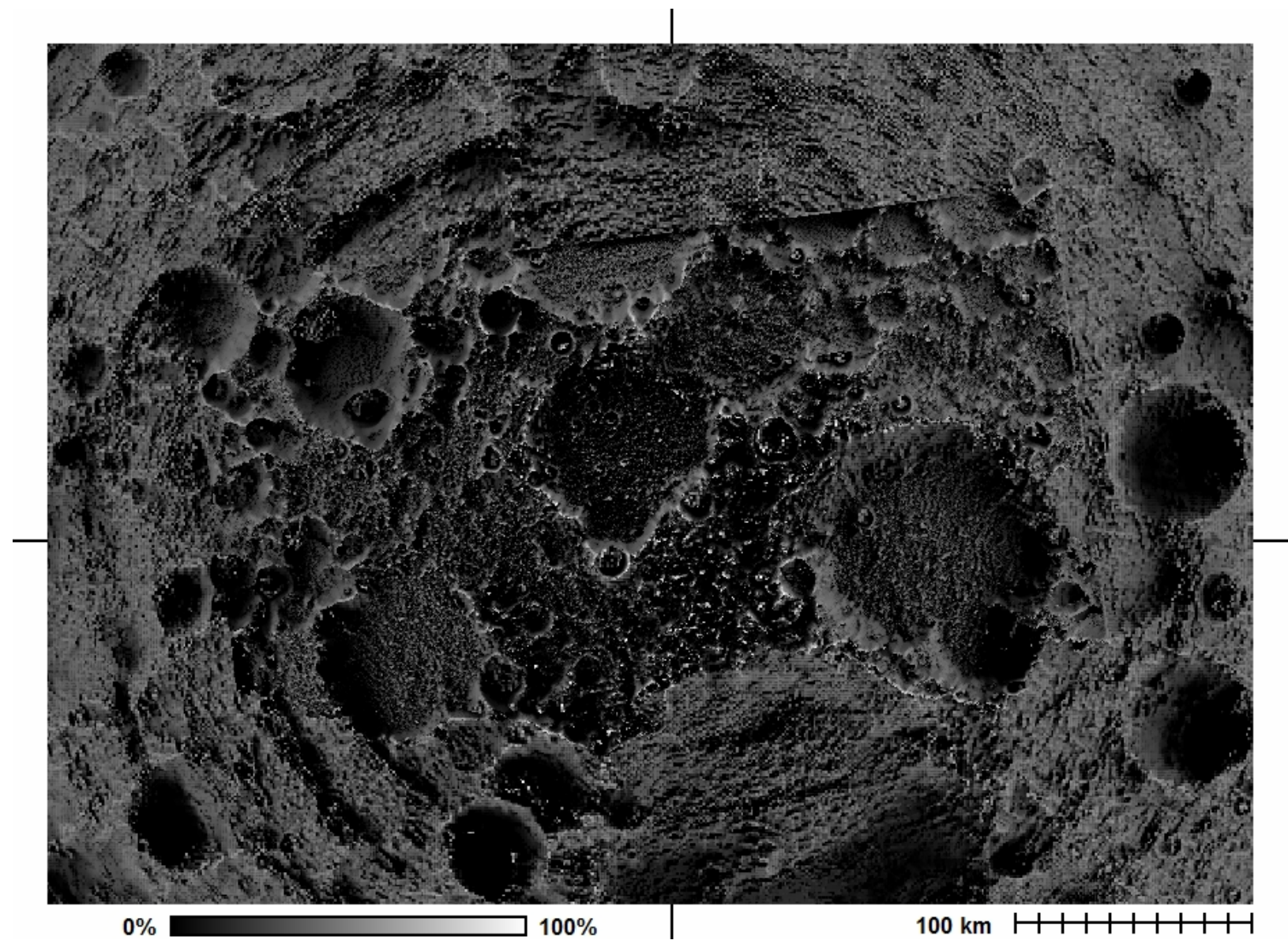

$0 \%$

Figure 20.-Lunar north pole average illumination (best case lunar day, combined DEM) 


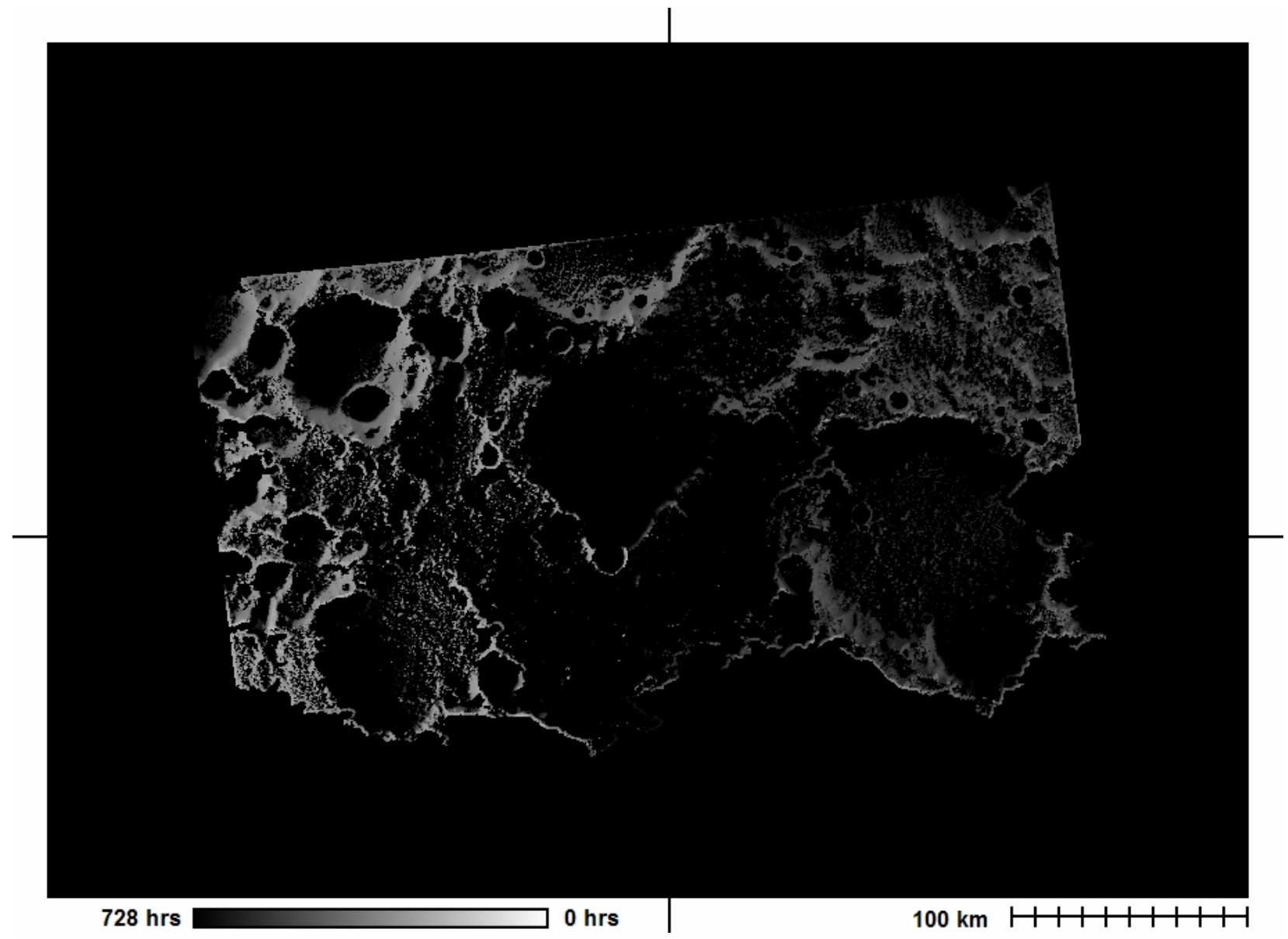

Figure 21. - Lunar north pole fast recharge energy storage duration (worst case lunar day, radar DEM). 


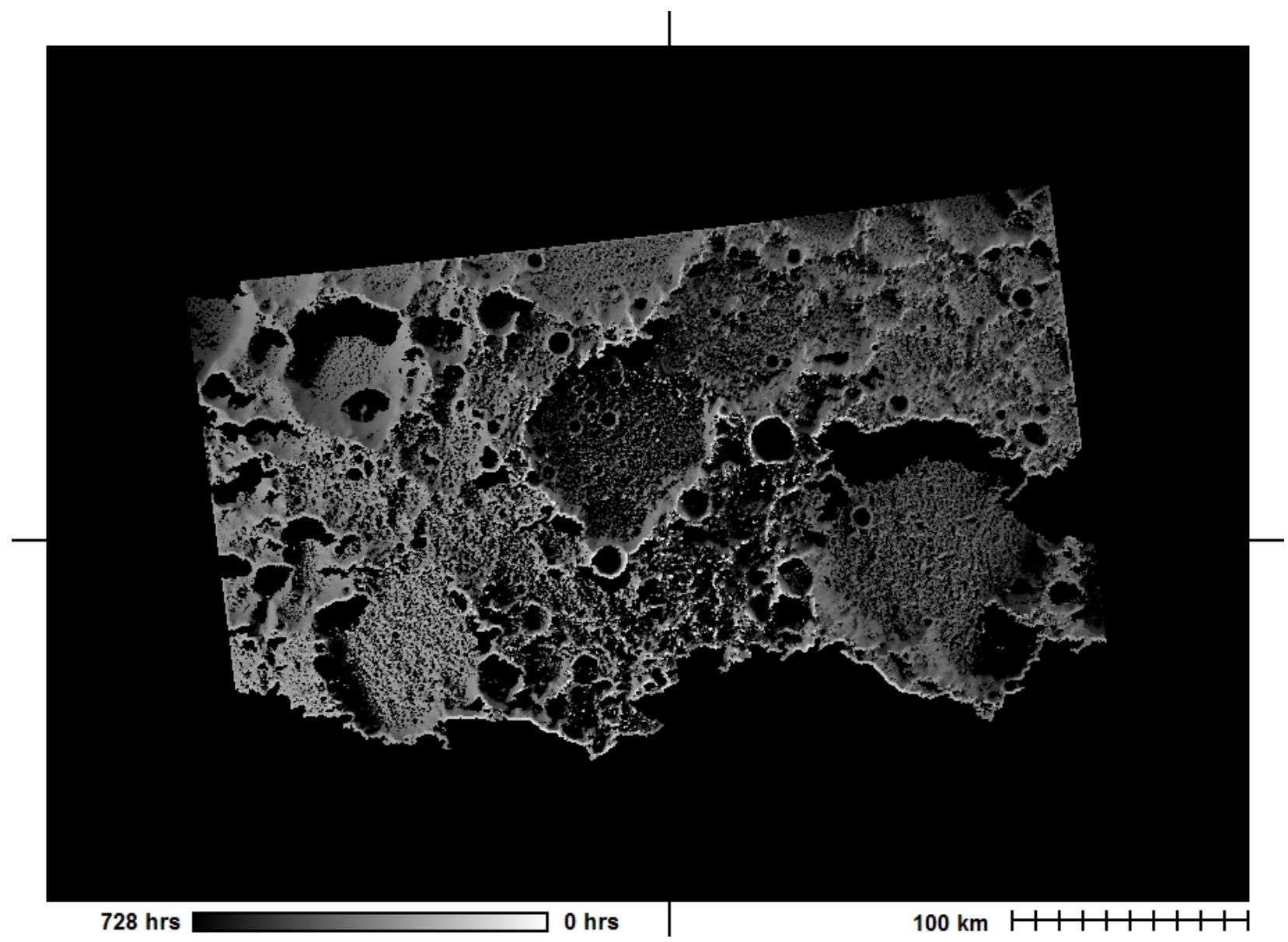

Figure 22.-Lunar north pole fast recharge energy storage duration (best case lunar day, radar DEM). 


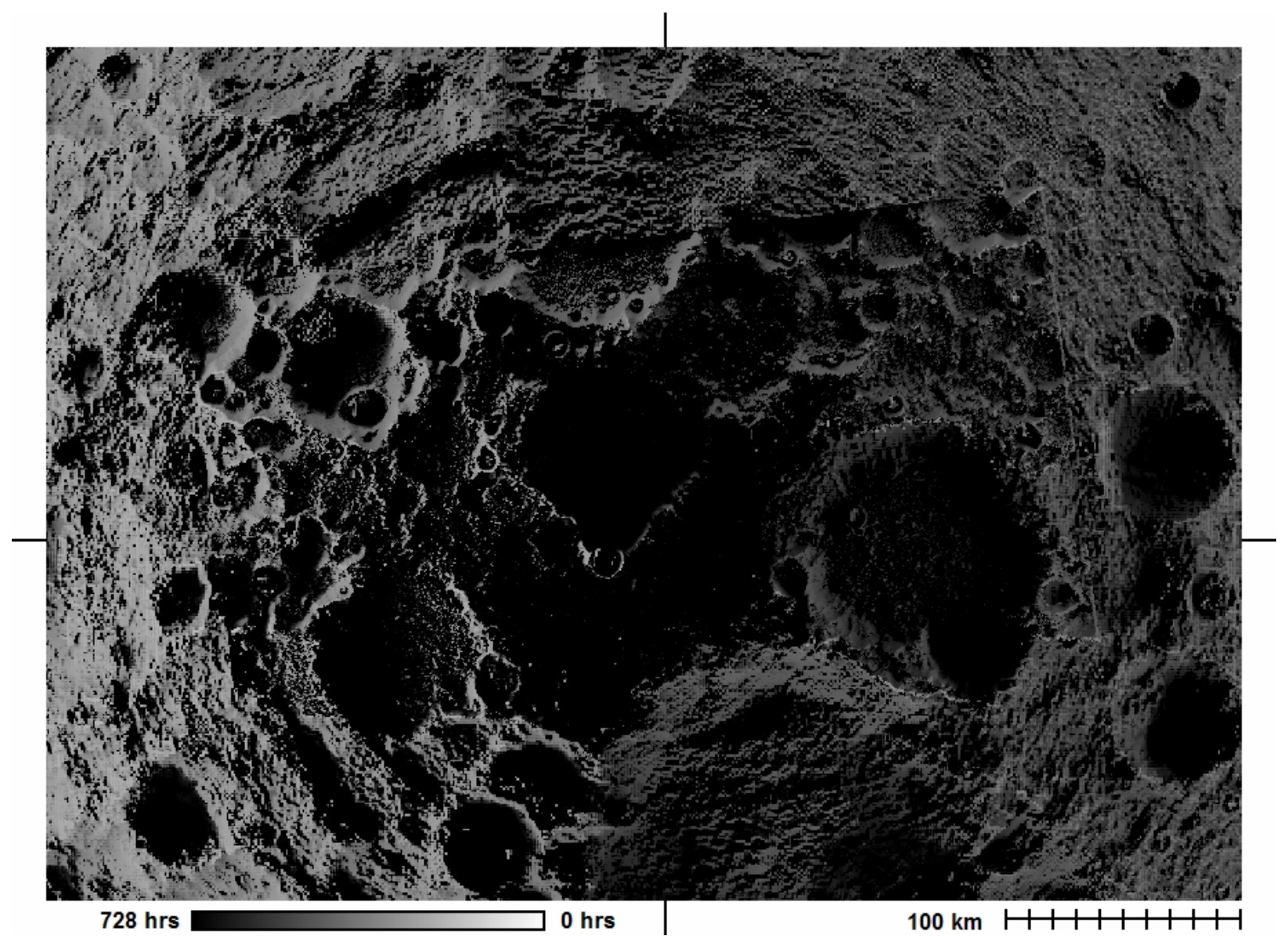

Figure 23.-Lunar north pole fast recharge energy storage duration (worst case lunar day, combined DEM). 


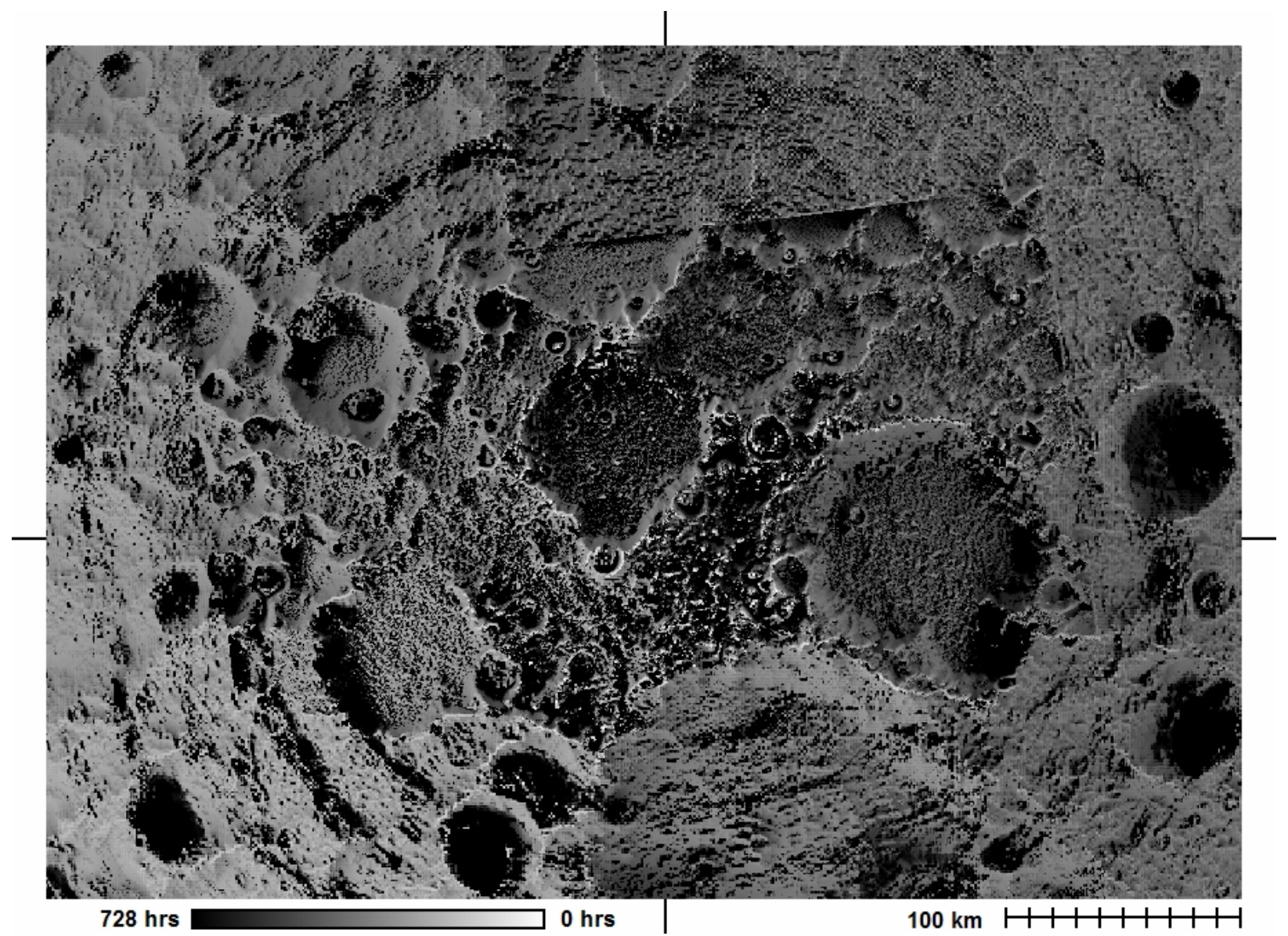

Figure 24.-Lunar north pole fast recharge energy storage duration (best case lunar day, combined DEM). 


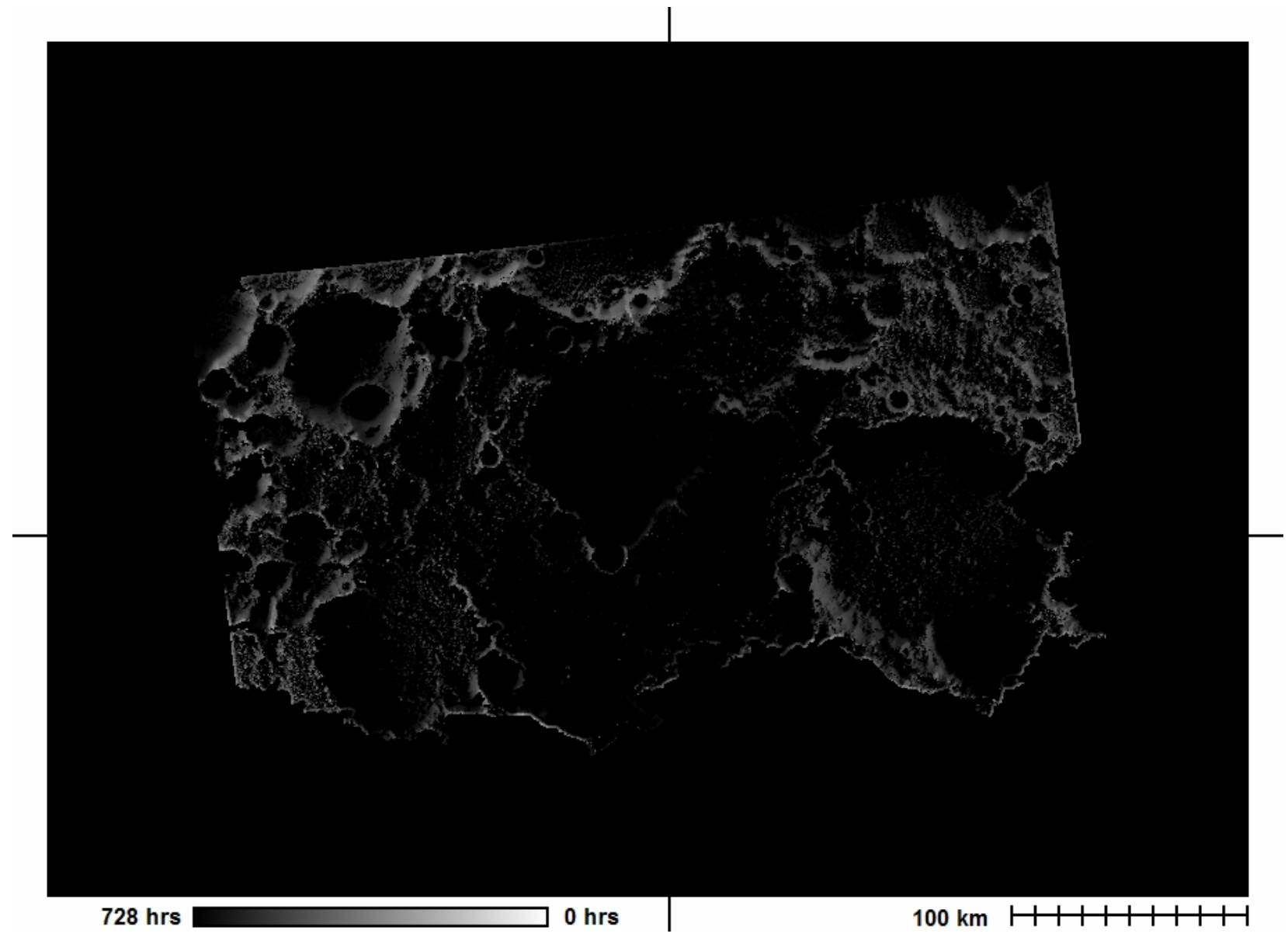

Figure 25.- Lunar north pole slow recharge energy storage duration (worst case lunar day, radar DEM). 


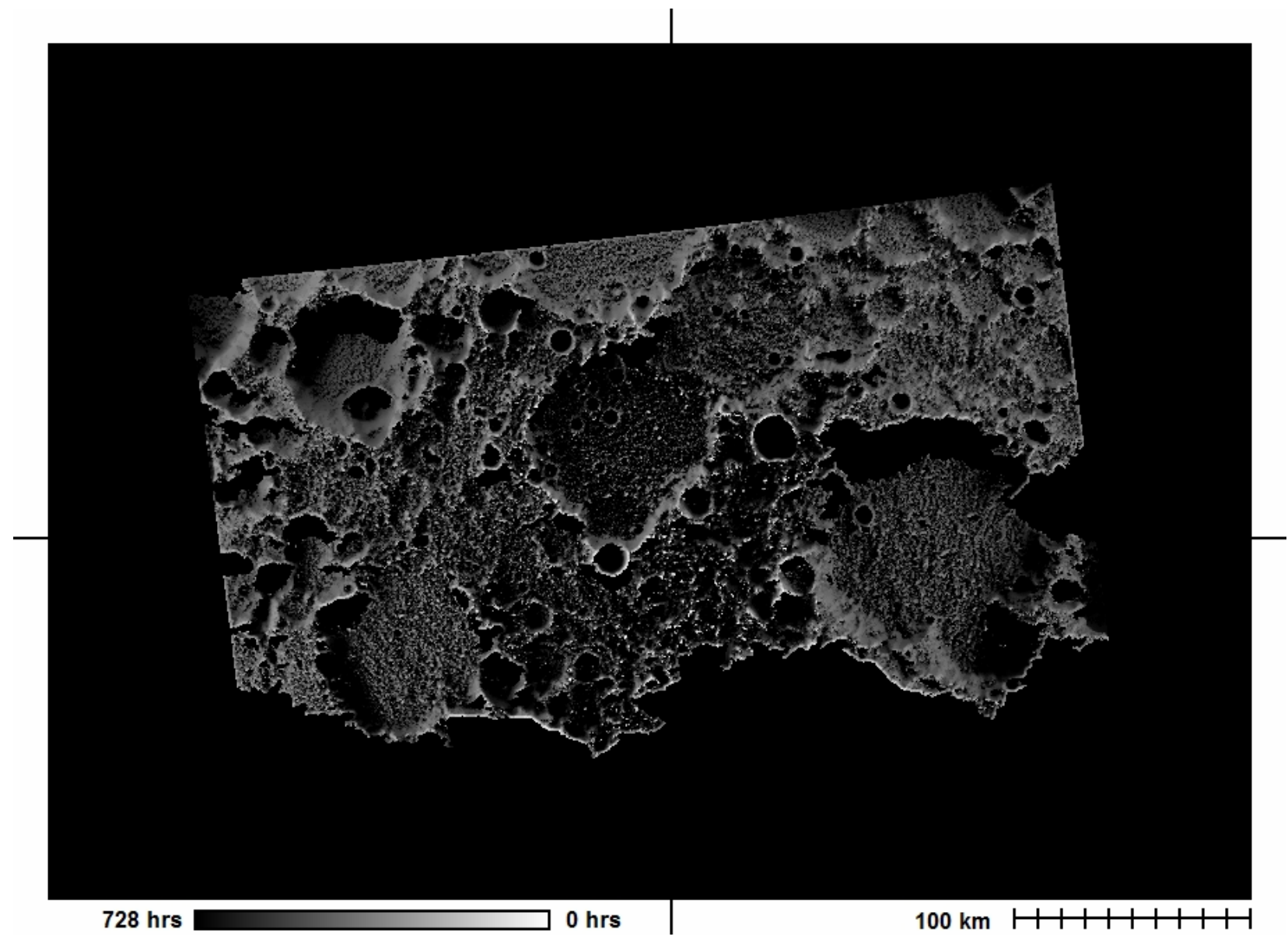

Figure 26.-Lunar north pole slow recharge energy storage duration (best case lunar day, radar DEM). 


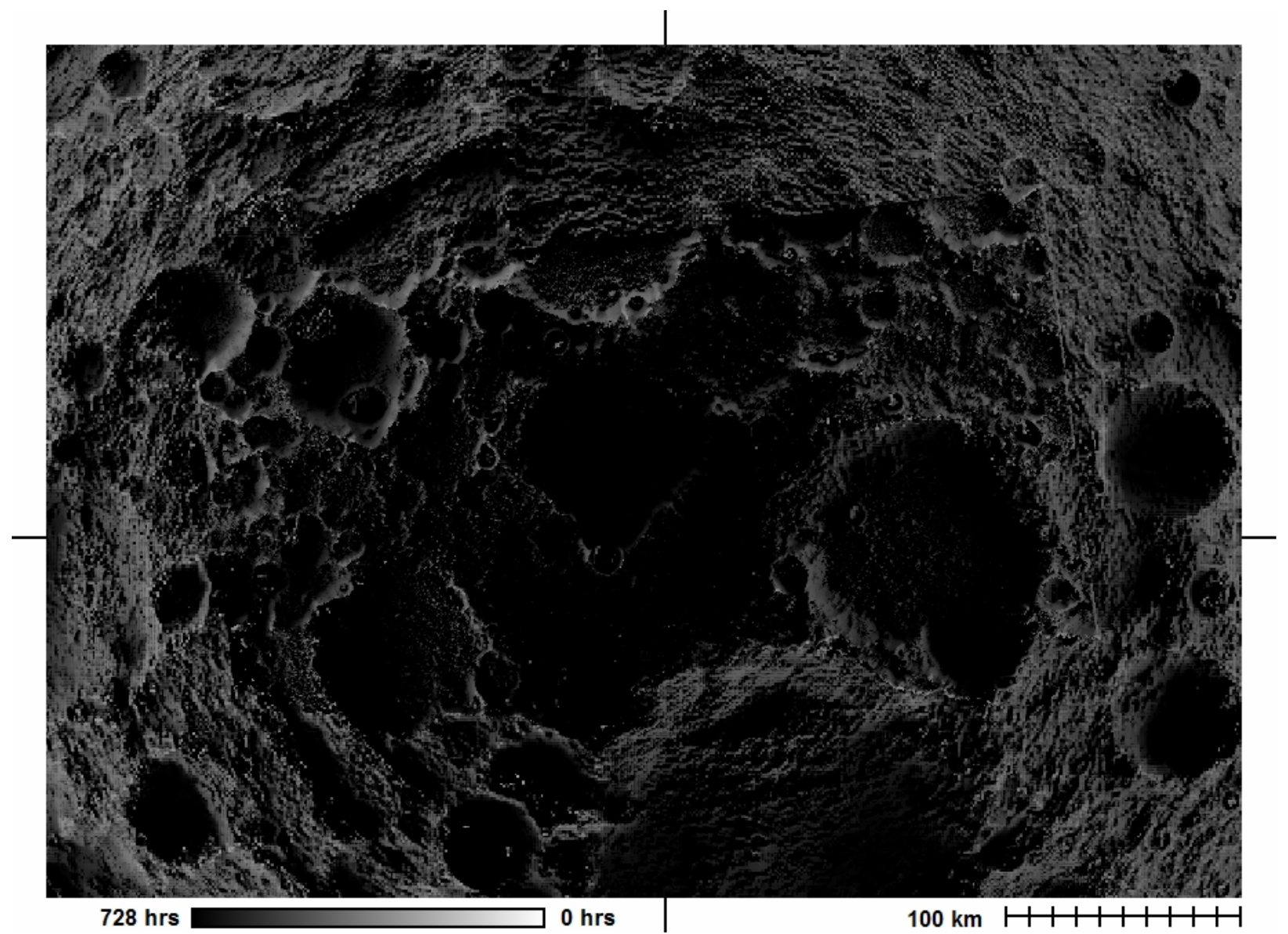

Figure 27. - Lunar north pole slow recharge energy storage duration (worst case lunar day, combined DEM). 


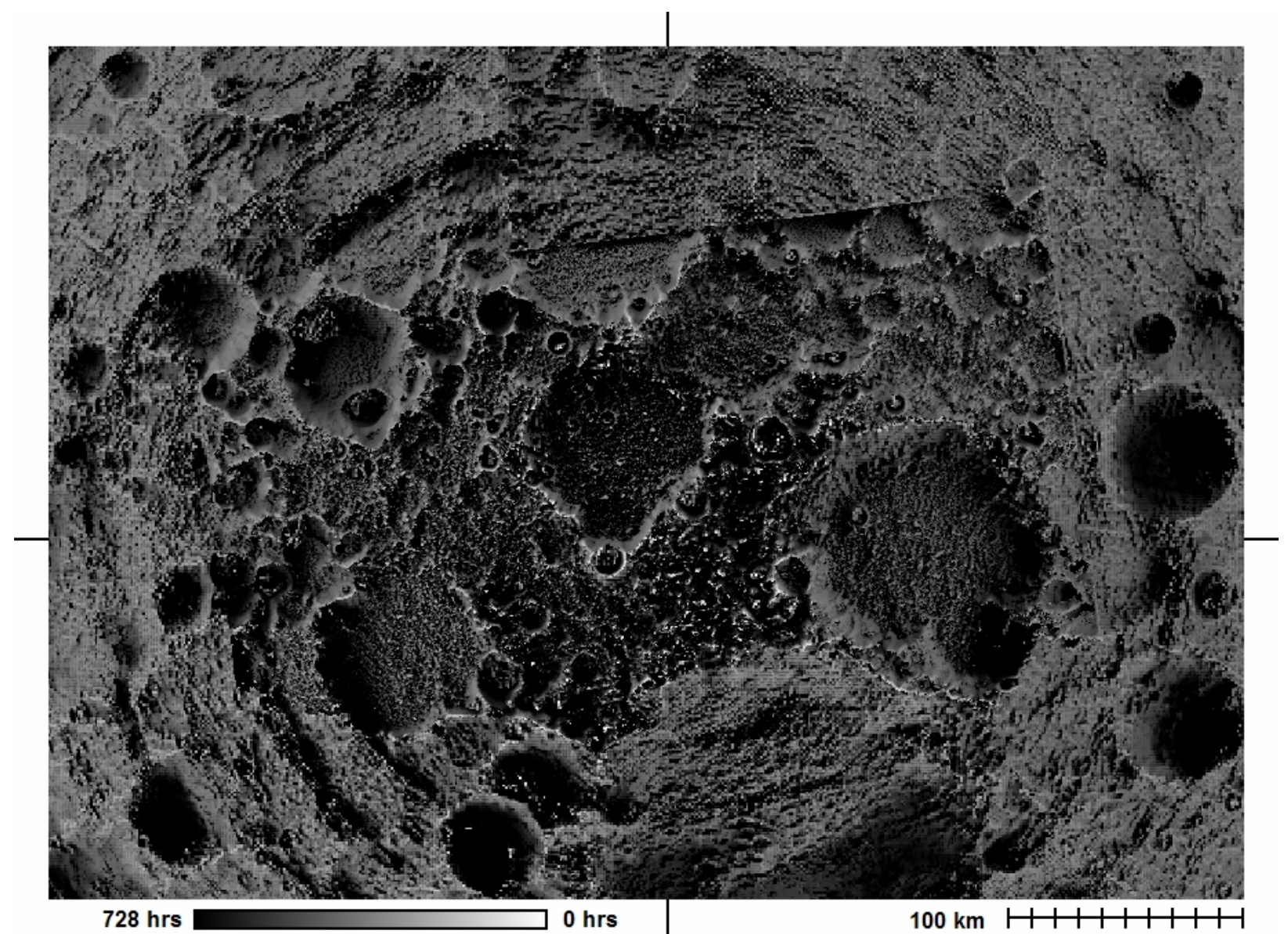

Figure 28. - Lunar north pole slow recharge energy storage duration (best case lunar day, combined DEM). 


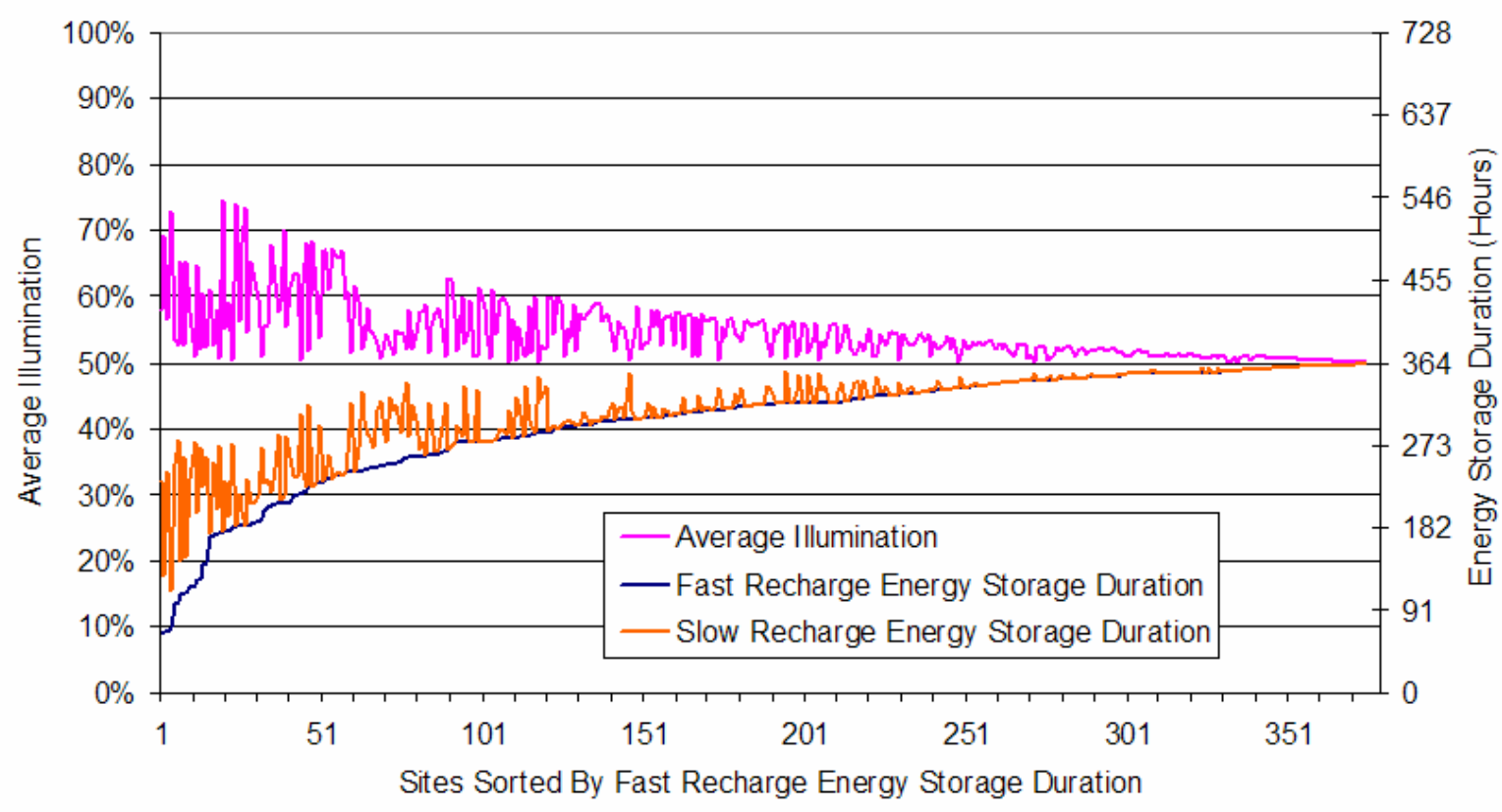

Figure 29.-Comparison of metrics for the south pole radar DEM sites.

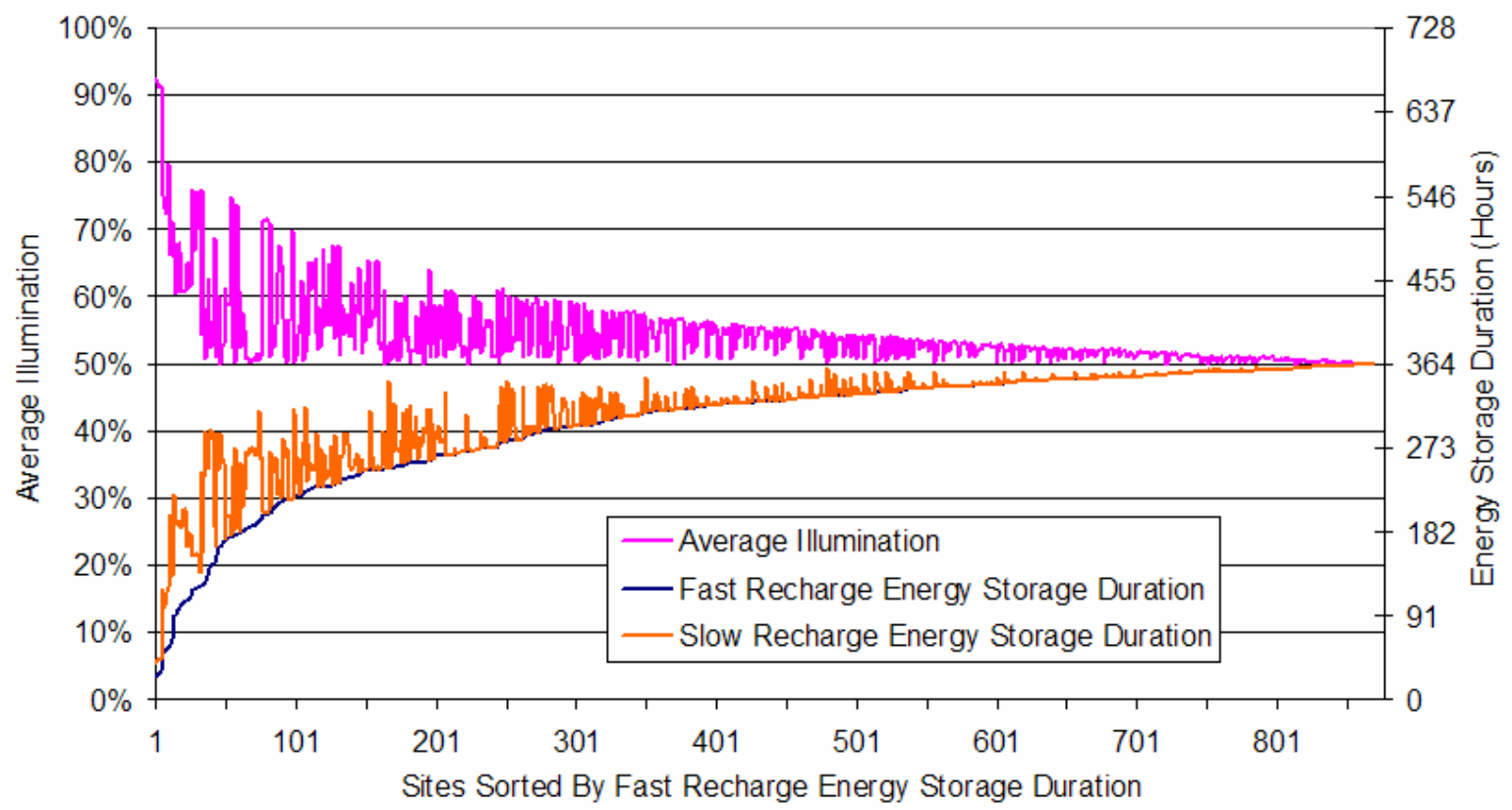

Figure 30.-Comparison of metrics for the south pole combined DEM sites. 
TABLE 1.-SOUTH POLE RADAR DEM SITES WITH FAST RECHARGE ENERGY STORAGE DURATION $<182$ HR SORTED BY WORST CASE LUNAR DAY FAST RECHARGE ENERGY STORAGE DURATION

\begin{tabular}{|c|c|c|c|c|c|c|c|c|c|c|c|c|}
\hline \multirow{4}{*}{$\begin{array}{l}\text { Site } \\
\text { Code } \\
\end{array}$} & \multirow{4}{*}{$\begin{array}{l}\text { Area } \\
\text { Code } \\
\end{array}$} & \multirow{4}{*}{$\begin{array}{l}\text { Latitude } \\
\text { (Degrees) }\end{array}$} & \multirow{4}{*}{$\begin{array}{l}\text { Longitude } \\
\text { (Degrees) }\end{array}$} & \multirow{4}{*}{\begin{tabular}{|l} 
Height \\
$(\mathrm{km})$
\end{tabular}} & \multirow{3}{*}{\multicolumn{2}{|c|}{$\begin{array}{l}\text { Reference Areal } \\
\text { Element Image } \\
\text { Location }\end{array}$}} & \multicolumn{3}{|c|}{ Worst Case Lunar Day } & \multicolumn{3}{|c|}{ Best Case Lunar Day } \\
\hline & & & & & & & \multicolumn{2}{|c|}{ Energy Storage Duration } & \multirow{3}{*}{$\begin{array}{l}\text { Average } \\
\text { Illumination } \\
\%\end{array}$} & \multicolumn{2}{|c|}{ Energy Storage Duration } & \multirow{3}{*}{$\begin{array}{l}\text { Average } \\
\text { Illumination } \\
\%\end{array}$} \\
\hline & & & & & & & \multirow{2}{*}{$\begin{array}{l}\text { Slow } \\
\text { (Hours) }\end{array}$} & \multirow{2}{*}{\begin{tabular}{|l|} 
Fast \\
(Hours)
\end{tabular}} & & \multirow{2}{*}{\begin{tabular}{|l} 
Slow \\
(Hours)
\end{tabular}} & \multirow{2}{*}{$\begin{array}{l}\text { Fast } \\
\text { (Hours) }\end{array}$} & \\
\hline & & & & & $\mathrm{X}$ & $\mathrm{Y}$ & & & & & & \\
\hline 1RS & A-SR & -89.87 & 237.53 & 1.65 & 895 & 904 & 232 & 65 & $58 \%$ & 23 & 23 & $94 \%$ \\
\hline $2 \mathrm{RS}$ & D-SR & -88.93 & 129.07 & 2.11 & 943 & 935 & 129 & 66 & $69 \%$ & 1 & 1 & $100 \%$ \\
\hline $3 R S$ & A-SR & -89.94 & 300.96 & 1.65 & 898 & 899 & 242 & 67 & $57 \%$ & 21 & 13 & $97 \%$ \\
\hline 4RS & A-SR & -89.80 & 212.91 & 1.88 & 895 & 909 & 113 & 71 & $73 \%$ & 1 & 1 & $100 \%$ \\
\hline $5 \mathrm{RS}$ & A-SR & -89.37 & 129.92 & 1.48 & 925 & 921 & 252 & 98 & $54 \%$ & 23 & 23 & $95 \%$ \\
\hline $6 \mathrm{RS}$ & A-SR & -89.80 & 32.91 & 1.54 & 906 & 892 & 279 & 101 & $53 \%$ & 14 & 12 & $97 \%$ \\
\hline 7RS & D-SR & -88.90 & 129.22 & 1.77 & 944 & 936 & 146 & 108 & $65 \%$ & 1 & 1 & $100 \%$ \\
\hline $8 \mathrm{RS}$ & D-SR & -88.91 & 129.87 & 1.77 & 943 & 936 & 149 & 111 & $65 \%$ & 1 & 1 & $100 \%$ \\
\hline 9RS & D-SR & -89.08 & 124.54 & 1.43 & 939 & 927 & 261 & 111 & $53 \%$ & 25 & 25 & $94 \%$ \\
\hline 10RS & A-SR & -89.79 & 210.07 & 1.60 & 895 & 910 & 234 & 116 & $58 \%$ & 20 & 20 & $97 \%$ \\
\hline 11RS & A-SR & -89.36 & 128.80 & 1.37 & 926 & 921 & 277 & 119 & $51 \%$ & 26 & 26 & $95 \%$ \\
\hline 12RS & A-SR & -89.40 & 232.94 & 1.82 & 876 & 919 & 198 & 125 & $65 \%$ & 1 & 1 & $100 \%$ \\
\hline 13RS & A-SR & -89.48 & 231.17 & 1.65 & 880 & 917 & 271 & 126 & $52 \%$ & 45 & 45 & $93 \%$ \\
\hline 14RS & A-SR & -89.39 & 231.48 & 1.77 & 876 & 920 & 226 & 141 & $61 \%$ & 1 & 1 & $100 \%$ \\
\hline 15RS & D-SR & -88.90 & 124.11 & 1.43 & 947 & 932 & 261 & 142 & $52 \%$ & 66 & 66 & $88 \%$ \\
\hline 16RS & E-SR & -86.83 & 138.76 & 1.94 & 1007 & 1022 & 177 & 172 & $61 \%$ & 12 & 10 & $97 \%$ \\
\hline 17RS & E-SR & -86.99 & 129.97 & 1.37 & 1018 & 999 & 255 & 173 & $53 \%$ & 44 & 33 & $91 \%$ \\
\hline 18RS & E-SR & -86.82 & 139.00 & 1.71 & 1007 & 1023 & 203 & 175 & $58 \%$ & 35 & 27 & $95 \%$ \\
\hline 19RS & E-SR & -86.95 & 132.14 & 1.14 & 1016 & 1005 & 272 & 177 & $51 \%$ & 97 & 38 & $82 \%$ \\
\hline 20RS & F-SR & -85.75 & 243.85 & 5.24 & 706 & 996 & 179 & 179 & $75 \%$ & 1 & 1 & $100 \%$ \\
\hline 21RS & E-SR & -86.64 & 147.38 & 1.37 & 993 & 1045 & 194 & 179 & $59 \%$ & 73 & 54 & $87 \%$ \\
\hline 22RS & E-SR & -86.85 & 139.03 & 1.43 & 1006 & 1022 & 232 & 179 & $55 \%$ & 63 & 52 & $87 \%$ \\
\hline 23RS & E-SR & -86.65 & 147.66 & 1.20 & 992 & 1045 & 274 & 182 & $50 \%$ & 125 & 62 & $77 \%$ \\
\hline
\end{tabular}




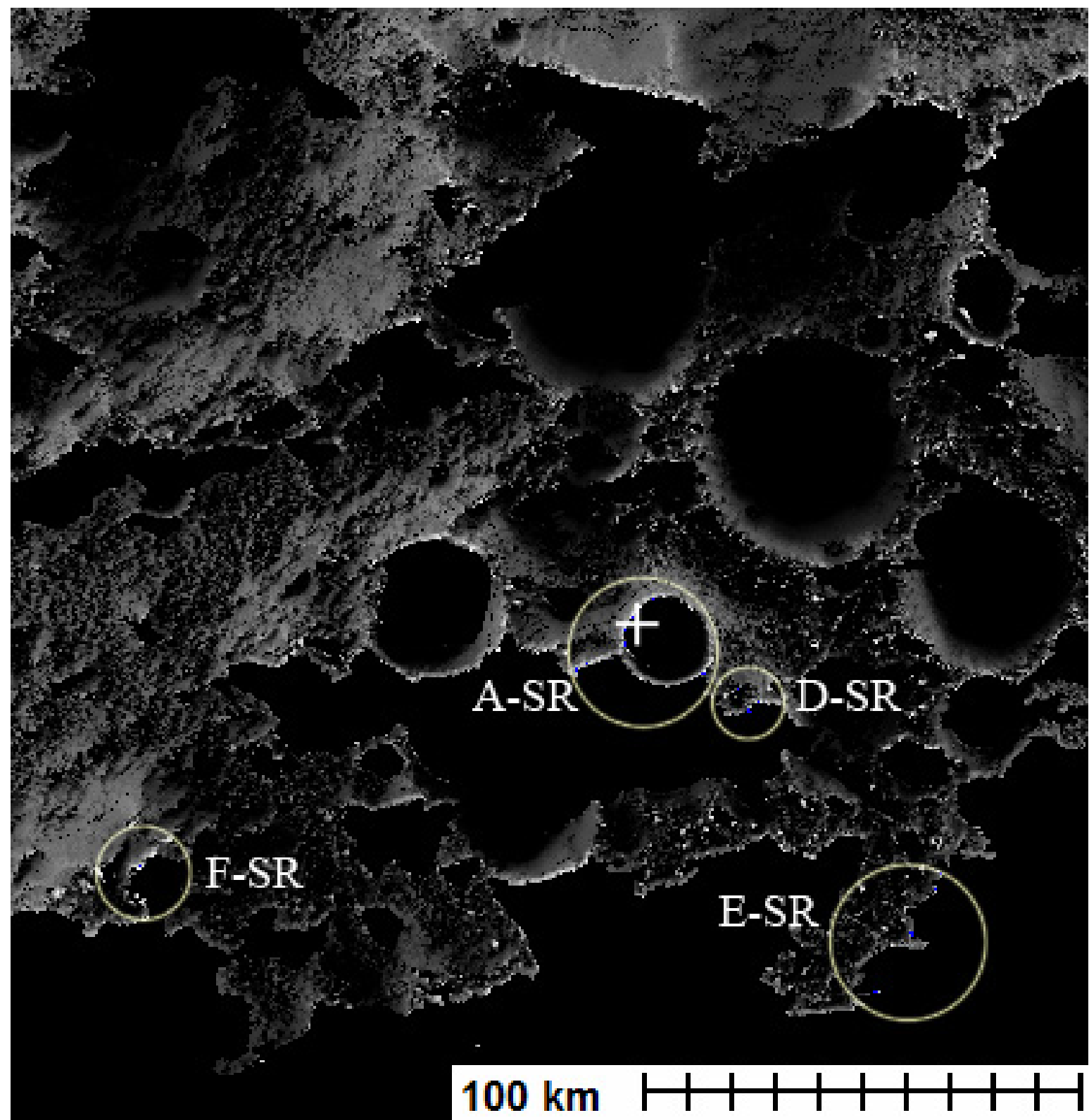

Figure 31.-Sites with under 182 hours energy storage duration (fast recharge) for the south pole radar DEM, worst case lunar day. 
TABLE 2.- SOUTH POLE COMBINED DEM SITES WITH FAST RECHARGE ENERGY STORAGE DURATION $<182$ HR SORTED BY WORST CASE LUNAR DAY FAST RECHARGE ENERGY STORAGE DURATION

\begin{tabular}{|c|c|c|c|c|c|c|c|c|c|c|c|c|}
\hline \multirow{4}{*}{\begin{tabular}{|l}
\multicolumn{1}{l|}{} \\
Site \\
Code \\
\end{tabular}} & \multirow{4}{*}{$\begin{array}{l}\text { Area } \\
\text { Code }\end{array}$} & \multirow{4}{*}{\begin{tabular}{|l|l} 
Latitude \\
(Degrees)
\end{tabular}} & \multirow{4}{*}{\begin{tabular}{|l} 
Longitude \\
(Degrees)
\end{tabular}} & \multirow{4}{*}{$\begin{array}{l}\text { Height } \\
(\mathrm{km})\end{array}$} & \multirow{3}{*}{\multicolumn{2}{|c|}{$\begin{array}{l}\text { Reference Areal } \\
\text { Element Image } \\
\text { Location }\end{array}$}} & \multicolumn{3}{|c|}{ Worst Case Lunar Day } & \multicolumn{3}{|c|}{ Best Case Lunar Day } \\
\hline & & & & & & & \multicolumn{2}{|c|}{ Energy Storage Duration } & \multirow{3}{*}{\begin{tabular}{|l|} 
Average \\
Illumination \\
$\%$
\end{tabular}} & \multicolumn{2}{|c|}{ Energy Storage Duration } & Average \\
\hline & & & & & & & Slow & & & \begin{tabular}{|l|l} 
Slow & \\
\end{tabular} & Fast & Illumination \\
\hline & & & & & $\mathrm{X}$ & $Y$ & (Hours) & (Hours) & & (Hours) & (Hours) & \\
\hline $1 \mathrm{CS}$ & A-SC & -89.81 & 207.90 & 4.02 & 896 & 909 & 39 & 26 & $93 \%$ & 1 & 1 & $100 \%$ \\
\hline $2 \mathrm{CS}$ & A-SC & -89.79 & 205.35 & 4.02 & 896 & 910 & 43 & 28 & $92 \%$ & 1 & 1 & $100 \%$ \\
\hline $3 \mathrm{CS}$ & B-SC & -89.01 & 285.56 & 4.10 & 852 & 887 & 45 & 29 & $91 \%$ & 1 & 1 & $100 \%$ \\
\hline $4 \mathrm{CS}$ & B-SC & -89.03 & 285.87 & 4.10 & 853 & 887 & 43 & 30 & $91 \%$ & 1 & 1 & $100 \%$ \\
\hline $5 \mathrm{CS}$ & A-SC & -89.64 & 178.45 & 2.77 & 901 & 919 & 119 & 49 & $79 \%$ & 32 & 32 & $95 \%$ \\
\hline $6 \mathrm{CS}$ & A-SC & -89.86 & 219.29 & 2.54 & 896 & 906 & 102 & 52 & $73 \%$ & 39 & 29 & $90 \%$ \\
\hline $7 \mathrm{CS}$ & B-SC & -89.04 & 284.74 & 3.63 & 853 & 888 & 99 & 52 & $75 \%$ & 66 & 66 & $91 \%$ \\
\hline $8 \mathrm{CS}$ & A-SC & -89.85 & 225.00 & 2.54 & 895 & 906 & 115 & 55 & $72 \%$ & 47 & 47 & $90 \%$ \\
\hline $9 \mathrm{CS}$ & A-SC & -89.73 & 186.34 & 3.01 & 899 & 914 & 122 & 57 & $80 \%$ & 32 & 32 & $95 \%$ \\
\hline $10 \mathrm{CS}$ & B-SC & -89.03 & 286.98 & 2.93 & 853 & 886 & 200 & 60 & $66 \%$ & 83 & 49 & $86 \%$ \\
\hline $11 \mathrm{CS}$ & A-SC & -89.78 & 203.20 & 2.54 & 896 & 911 & 135 & 64 & $71 \%$ & 54 & 54 & $86 \%$ \\
\hline $12 \mathrm{CS}$ & B-SC & -89.02 & 288.07 & 2.93 & 853 & 885 & 188 & 64 & $68 \%$ & 72 & 39 & $89 \%$ \\
\hline $13 \mathrm{CS}$ & A-SC & -89.55 & 101.31 & 2.15 & 923 & 905 & 189 & 91 & $61 \%$ & 26 & 22 & $93 \%$ \\
\hline $14 \mathrm{CS}$ & B-SC & -89.00 & 287.72 & 2.93 & 852 & 885 & 222 & 91 & $66 \%$ & 91 & 91 & $87 \%$ \\
\hline $15 \mathrm{CS}$ & B-SC & -88.79 & 331.57 & 2.77 & 871 & 846 & 189 & 97 & $68 \%$ & 6 & 6 & $99 \%$ \\
\hline $16 \mathrm{CS}$ & B-SC & -88.79 & 332.39 & 2.77 & 872 & 846 & 188 & 97 & $68 \%$ & 7 & 7 & $99 \%$ \\
\hline $17 \mathrm{CS}$ & B-SC & -88.77 & 332.01 & 2.77 & 871 & 845 & 192 & 98 & $67 \%$ & 6 & 6 & $99 \%$ \\
\hline $18 \mathrm{CS}$ & B-SC & -88.78 & 332.82 & 2.77 & 872 & 845 & 194 & 100 & $67 \%$ & 7 & 7 & $99 \%$ \\
\hline $19 \mathrm{CS}$ & A-SC & -89.53 & 100.84 & 2.15 & 924 & 905 & 186 & 103 & $61 \%$ & 23 & 20 & $93 \%$ \\
\hline $20 \mathrm{CS}$ & A-SC & -89.89 & 15.26 & 2.54 & 902 & 895 & 205 & 105 & $61 \%$ & 113 & 105 & $82 \%$ \\
\hline $21 \mathrm{CS}$ & A-SC & -89.91 & 18.44 & 2.54 & 902 & 896 & 207 & 106 & $61 \%$ & 115 & 106 & $82 \%$ \\
\hline $22 \mathrm{CS}$ & A-SC & -89.88 & 24.44 & 2.54 & 903 & 895 & 165 & 107 & $65 \%$ & 105 & 105 & $84 \%$ \\
\hline $23 \mathrm{CS}$ & A-SC & -89.55 & 98.84 & 2.15 & 923 & 904 & 184 & 108 & $61 \%$ & 26 & 26 & $92 \%$ \\
\hline $24 \mathrm{CS}$ & A-SC & -89.90 & 29.06 & 2.54 & 903 & 896 & 167 & 110 & $65 \%$ & 106 & 106 & $84 \%$ \\
\hline $25 \mathrm{CS}$ & A-SC & -89.53 & 98.47 & 2.15 & 924 & 904 & 179 & 112 & $62 \%$ & 25 & 25 & $92 \%$ \\
\hline $26 \mathrm{CS}$ & C-SC & -85.60 & 32.45 & 7.30 & 1021 & 711 & 156 & 120 & $76 \%$ & 1 & 1 & $100 \%$ \\
\hline $27 \mathrm{CS}$ & A-SC & -89.92 & 35.54 & 2.62 & 903 & 897 & 158 & 120 & $68 \%$ & 14 & 13 & $96 \%$ \\
\hline $28 \mathrm{CS}$ & A-SC & -89.93 & 45.00 & 2.62 & 903 & 898 & 159 & 120 & $67 \%$ & 16 & 14 & $96 \%$ \\
\hline $29 \mathrm{CS}$ & C-SC & -85.60 & 32.80 & 7.30 & 1022 & 712 & 155 & 122 & $76 \%$ & 1 & 1 & $100 \%$ \\
\hline $30 \mathrm{CS}$ & C-SC & -85.59 & 32.67 & 7.30 & 1022 & 711 & 158 & 122 & $75 \%$ & 1 & 1 & $100 \%$ \\
\hline $31 \mathrm{CS}$ & A-SC & -89.93 & 23.20 & 2.62 & 902 & 897 & 137 & 123 & $70 \%$ & 13 & 12 & $96 \%$ \\
\hline $32 \mathrm{CS}$ & A-SC & -89.94 & 30.96 & 2.62 & 902 & 898 & 139 & 123 & $70 \%$ & 16 & 14 & $95 \%$ \\
\hline $33 \mathrm{CS}$ & A-SC & -89.53 & 223.32 & 1.99 & 884 & 918 & 246 & 123 & $55 \%$ & 53 & 53 & $80 \%$ \\
\hline $34 \mathrm{CS}$ & C-SC & -85.61 & 32.59 & 7.30 & 1021 & 712 & 157 & 124 & $76 \%$ & 1 & 1 & $100 \%$ \\
\hline $35 \mathrm{CS}$ & A-SC & -89.52 & 225.00 & 1.99 & 883 & 918 & 241 & 124 & $55 \%$ & 43 & 21 & $91 \%$ \\
\hline $36 \mathrm{CS}$ & B-SC & -88.85 & 294.61 & 2.31 & 847 & 876 & 292 & 128 & $51 \%$ & 51 & 51 & $88 \%$ \\
\hline $37 \mathrm{CS}$ & B-SC & -88.80 & 294.68 & 2.38 & 845 & 875 & 262 & 135 & $58 \%$ & 82 & 60 & $88 \%$ \\
\hline $38 \mathrm{CS}$ & B-SC & -89.01 & 286.65 & 2.93 & 852 & 886 & 250 & 139 & $63 \%$ & 130 & 104 & $82 \%$ \\
\hline $39 \mathrm{CS}$ & B-SC & -88.58 & 341.07 & 2.38 & 877 & 832 & 282 & 143 & $56 \%$ & 18 & 18 & $97 \%$ \\
\hline $40 \mathrm{CS}$ & B-SC & -88.86 & 295.02 & 2.31 & 848 & 876 & 293 & 146 & $52 \%$ & 37 & 37 & $89 \%$ \\
\hline $41 \mathrm{CS}$ & B-SC & -88.57 & 340.32 & 2.38 & 876 & 832 & 288 & 147 & $56 \%$ & 21 & 21 & $97 \%$ \\
\hline $42 \mathrm{CS}$ & C-SC & -85.62 & 34.79 & 7.06 & 1028 & 717 & 187 & 148 & $69 \%$ & 34 & 34 & $95 \%$ \\
\hline $43 \mathrm{CS}$ & D-SC & -88.93 & 129.07 & 2.07 & 943 & 935 & 167 & 154 & $63 \%$ & 14 & 9 & $97 \%$ \\
\hline $44 \mathrm{CS}$ & A-SC & -89.86 & 21.04 & 1.99 & 903 & 894 & 290 & 155 & $51 \%$ & 145 & 145 & $78 \%$ \\
\hline $45 \mathrm{CS}$ & A-SC & -89.50 & 226.59 & 1.99 & 882 & 918 & 247 & 165 & $60 \%$ & 94 & 58 & $85 \%$ \\
\hline $46 \mathrm{CS}$ & A-SC & -89.97 & 18.44 & 2.07 & 901 & 899 & 290 & 167 & $50 \%$ & 134 & 134 & $73 \%$ \\
\hline $47 \mathrm{CS}$ & D-SC & -89.07 & 123.86 & 1.68 & 940 & 927 & 262 & 169 & $53 \%$ & 29 & 14 & $92 \%$ \\
\hline $48 \mathrm{CS}$ & D-SC & -89.05 & 123.20 & 1.68 & 941 & 927 & 257 & 171 & $53 \%$ & 33 & 15 & $91 \%$ \\
\hline $49 \mathrm{CS}$ & E-SC & -86.83 & 138.76 & 1.92 & $\begin{array}{l}1007 \\
\end{array}$ & 1022 & $\begin{array}{l}173 \\
\end{array}$ & 172 & $61 \%$ & 28 & 27 & $95 \%$ \\
\hline $50 \mathrm{CS}$ & E-SC & -86.99 & 129.97 & 1.29 & $\begin{array}{l}1018 \\
\end{array}$ & 999 & 240 & \begin{tabular}{|l|}
173 \\
\end{tabular} & $54 \%$ & 57 & 40 & $88 \%$ \\
\hline $51 \mathrm{CS}$ & E-SC & -86.82 & 139.00 & 1.68 & 1007 & 1023 & \begin{tabular}{|l|}
197 \\
\end{tabular} & 175 & $59 \%$ & 44 & 39 & $93 \%$ \\
\hline $52 \mathrm{CS}$ & F-SC & -85.75 & 243.85 & 5.19 & 706 & 996 & \begin{tabular}{|l|}
178 \\
\end{tabular} & \begin{tabular}{ll|}
176 \\
\end{tabular} & $75 \%$ & 2 & 2 & $100 \%$ \\
\hline $53 \mathrm{CS}$ & D-SC & -88.91 & 129.87 & 1.76 & 943 & 936 & 199 & \begin{tabular}{|l|}
176 \\
\end{tabular} & $59 \%$ & 23 & 10 & $95 \%$ \\
\hline $54 \mathrm{CS}$ & D-SC & -88.90 & 129.22 & 1.76 & 944 & 936 & 200 & 176 & $59 \%$ & 23 & 10 & $95 \%$ \\
\hline $55 \mathrm{CS}$ & E-SC & -86.95 & 132.14 & 1.14 & $\begin{array}{l}1016 \\
\end{array}$ & 1005 & 253 & \begin{tabular}{|l|}
177 \\
\end{tabular} & $53 \%$ & 92 & 50 & $83 \%$ \\
\hline $56 \mathrm{CS}$ & F-SC & -85.74 & 243.61 & 5.04 & 706 & 997 & 183 & \begin{tabular}{|l|}
178 \\
\end{tabular} & $74 \%$ & 2 & 2 & $99 \%$ \\
\hline $57 \mathrm{CS}$ & E-SC & -86.93 & 132.41 & 0.98 & 1016 & 1006 & 273 & \begin{tabular}{|l|}
178 \\
\end{tabular} & $50 \%$ & 143 & 94 & $74 \%$ \\
\hline $58 \mathrm{CS}$ & F-SC & -85.73 & 243.73 & 4.96 & 705 & 997 & 186 & 179 & $74 \%$ & 2 & 2 & $99 \%$ \\
\hline $59 \mathrm{CS}$ & E-SC & -86.85 & 139.03 & 1.37 & 1006 & 1022 & 217 & 179 & $56 \%$ & 67 & 57 & $86 \%$ \\
\hline $60 \mathrm{CS}$ & E-SC & -86.64 & 147.38 & 1.29 & 993 & 1045 & 182 & 180 & $61 \%$ & 82 & 58 & $86 \%$ \\
\hline
\end{tabular}




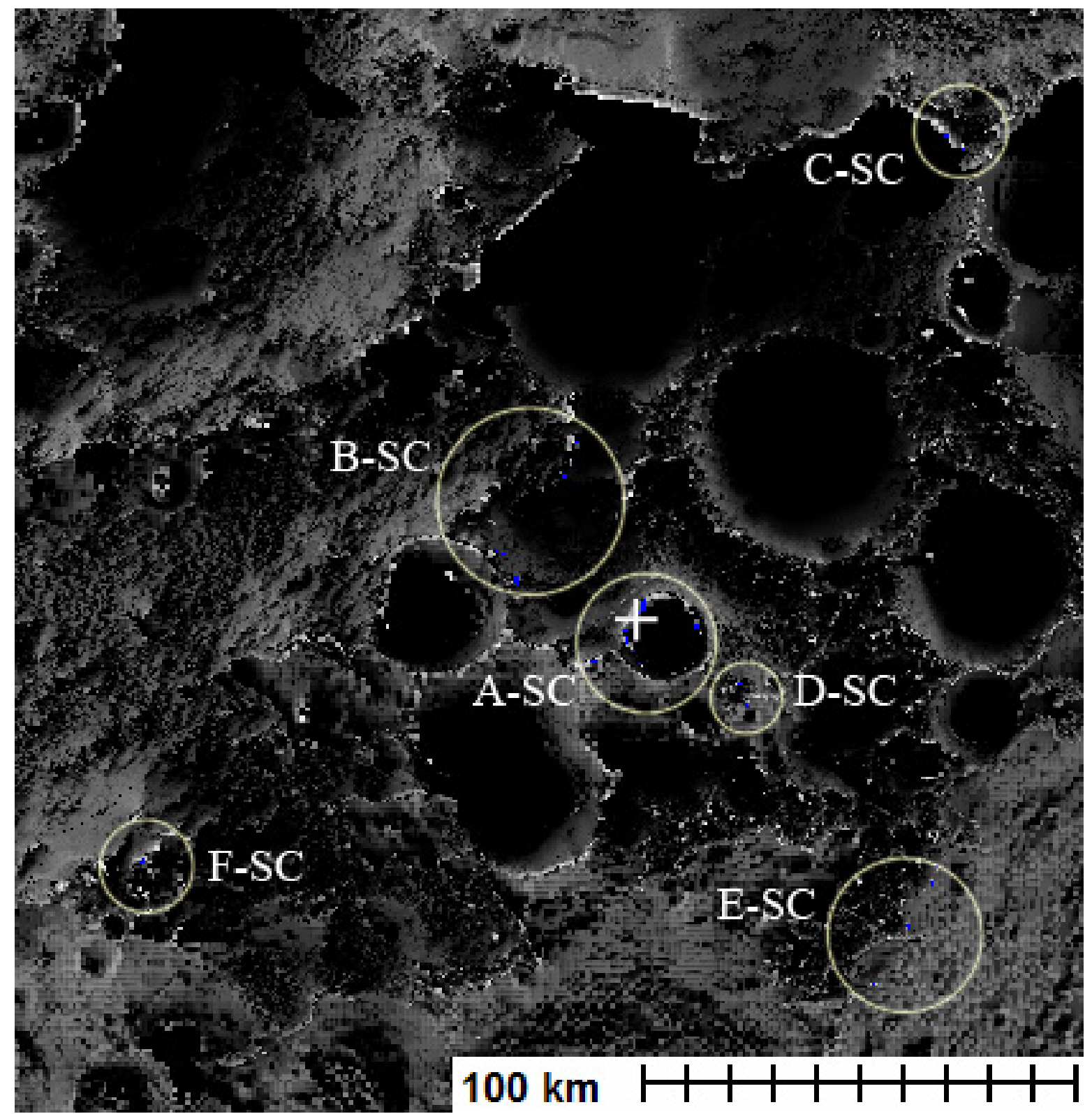

Figure 32.-Sites with under $182 \mathrm{hr}$ energy storage duration (fast recharge) for the south pole combined DEM, worst case lunar day. 


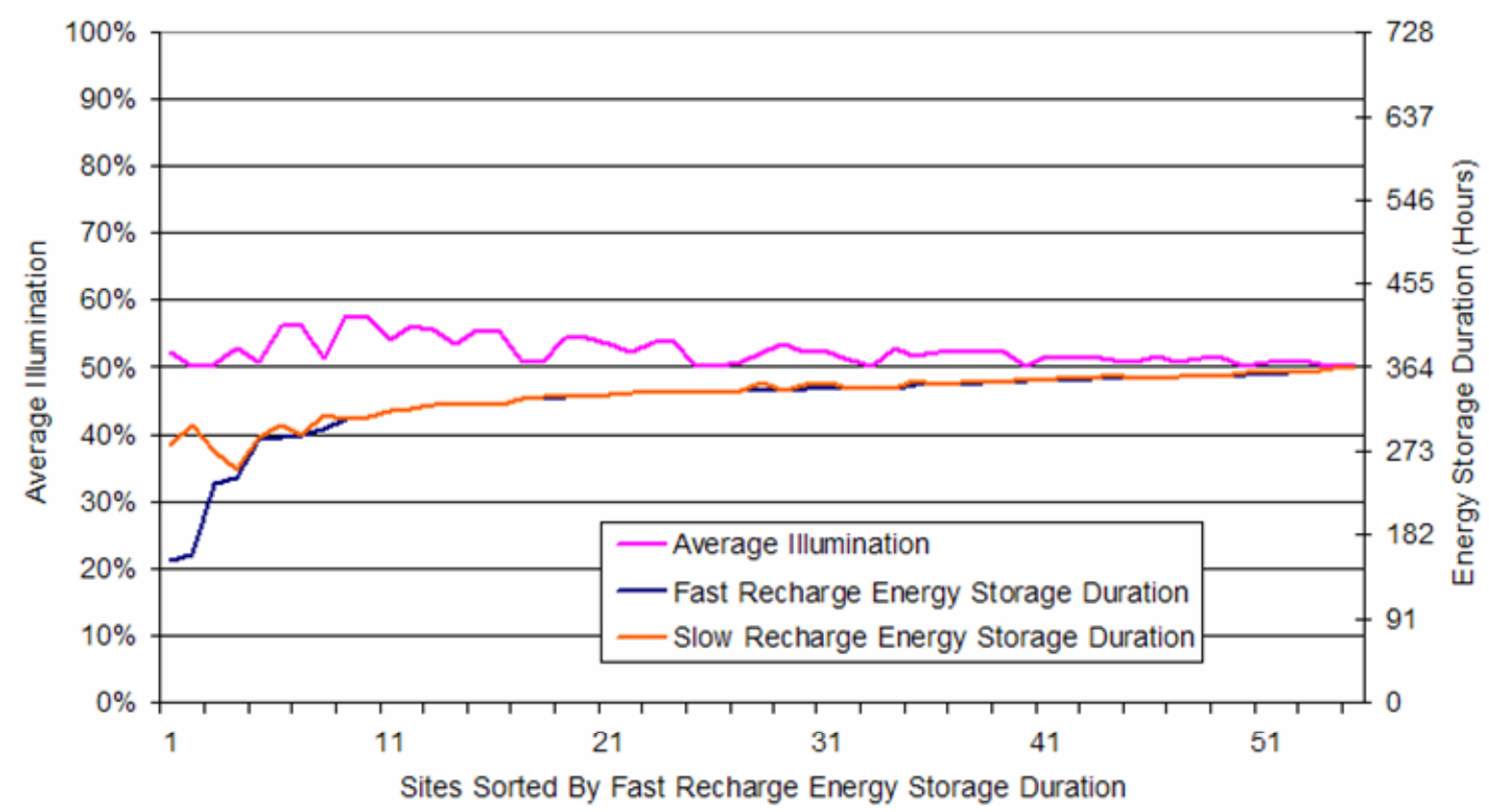

Figure 33.-Comparison of metrics for the north pole radar DEM sites.

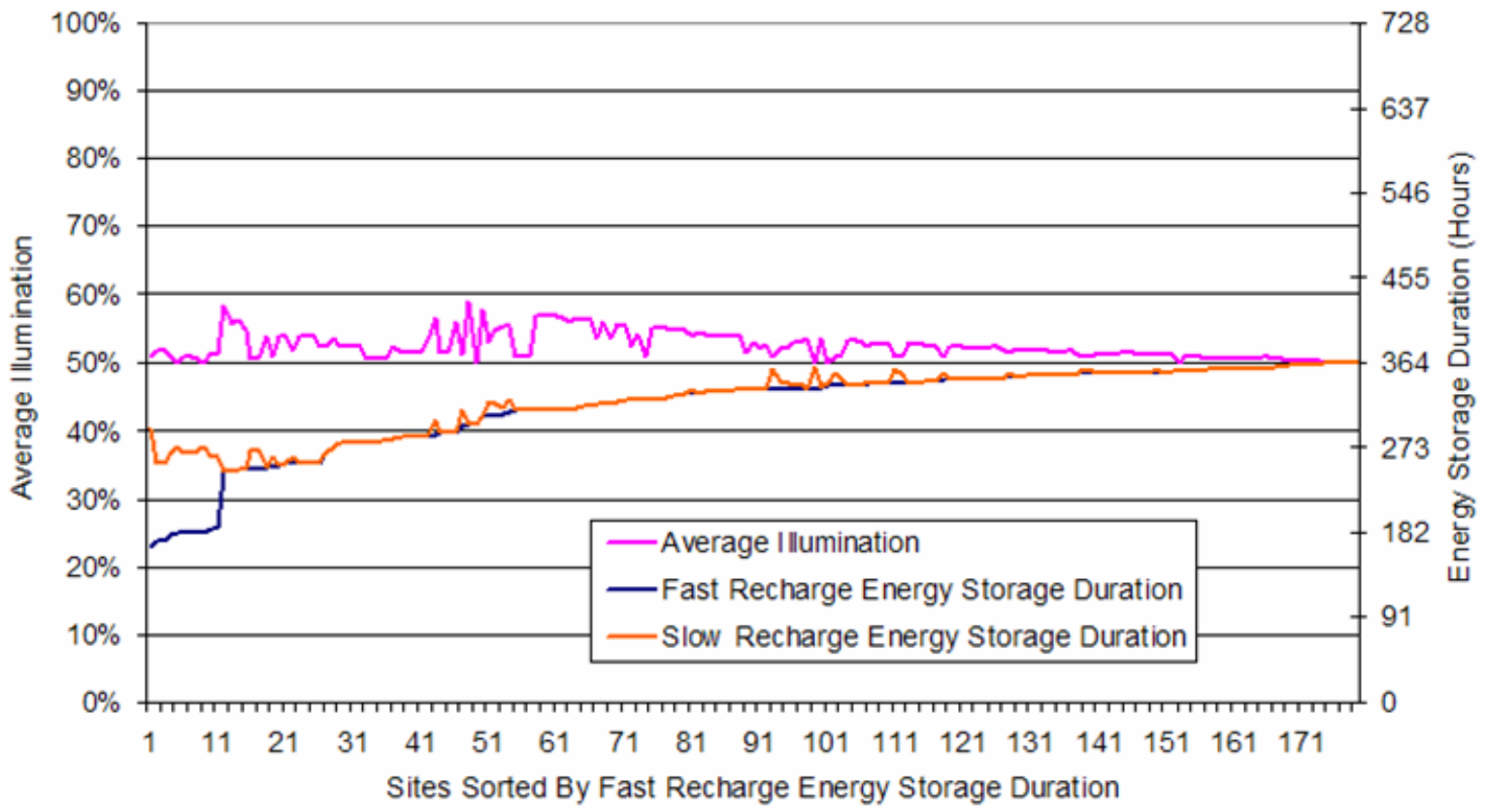

Figure 34.-Comparison of metrics for the north pole combined DEM sites. 
TABLE 3.-NORTH POLE DEM SITES (RADAR: "RN”, COMBINED: “CN”) WITH FAST RECHARGE ENERGY STORAGE DURATION $<182$ HR FOR WORST CASE LUNAR DAY

\begin{tabular}{|c|c|c|c|c|c|c|c|c|c|c|c|c|}
\hline & & & & & Referen & ce Areal & Worst Case LI & -unar Day & & Best Case Lu & unar Day & \\
\hline & & & & & Element & Image & Energy Storag & ge Duration & Average & Energy Stora & age Duration & Average \\
\hline Site & Area & Latitude & Longitude & Height & Location & & \begin{tabular}{|l|} 
Slow \\
\end{tabular} & Fast & Illumination & \begin{tabular}{|l|} 
Slow \\
\end{tabular} & Fast & Illumination \\
\hline Code & Code & (Degrees) & (Degrees) & $(\mathrm{km})$ & $\mathrm{X}$ & Y & (Hours) & (Hours) & $\%$ & (Hours) & (Hours) & \\
\hline $1 \mathrm{RN}$ & A-N & \begin{tabular}{|r|}
89.34 \\
\end{tabular} & 119.22 & 0.10 & 863 & 798 & 278 & \begin{tabular}{|r|}
154 \\
\end{tabular} & $52 \%$ & 1 & 1 & $100 \%$ \\
\hline $2 \mathrm{RN}$ & A-N & 89.25 & 124.32 & 0.10 & 861 & 803 & 301 & 162 & $50 \%$ & 21 & 21 & $97 \%$ \\
\hline $1 \mathrm{CN}$ & A-N & 89.25 & 124.32 & 0.00 & 861 & 803 & 306 & 164 & $50 \%$ & 21 & 21 & $97 \%$ \\
\hline $2 \mathrm{CN}$ & A-N & 89.34 & 119.22 & 0.00 & 863 & 798 & 293 & 167 & $51 \%$ & 1 & 1 & $100 \%$ \\
\hline $3 \mathrm{CN}$ & B-N & 83.10 & 101.88 & 1.35 & 548 & 854 & 258 & 174 & $52 \%$ & 185 & 185 & $66 \%$ \\
\hline $4 \mathrm{CN}$ & B-N & 83.09 & 102.04 & 1.35 & 548 & 855 & 258 & 174 & $52 \%$ & 185 & 185 & $66 \%$ \\
\hline $5 \mathrm{CN}$ & B-N & 82.99 & 102.19 & 1.24 & 543 & 857 & 268 & 180 & $51 \%$ & 184 & 184 & $66 \%$ \\
\hline $6 \mathrm{CN}$ & B-N & 83.29 & 100.69 & 1.04 & 556 & 845 & 273 & 181 & $50 \%$ & 195 & 195 & $62 \%$ \\
\hline $7 \mathrm{CN}$ & B-N & 82.99 & 102.03 & 1.24 & 543 & 856 & 268 & 181 & $51 \%$ & 185 & 185 & $66 \%$ \\
\hline $8 \mathrm{CN}$ & B-N & 83.07 & 102.33 & 1.09 & 547 & 857 & 342 & 181 & $43 \%$ & 188 & 188 & $62 \%$ \\
\hline
\end{tabular}

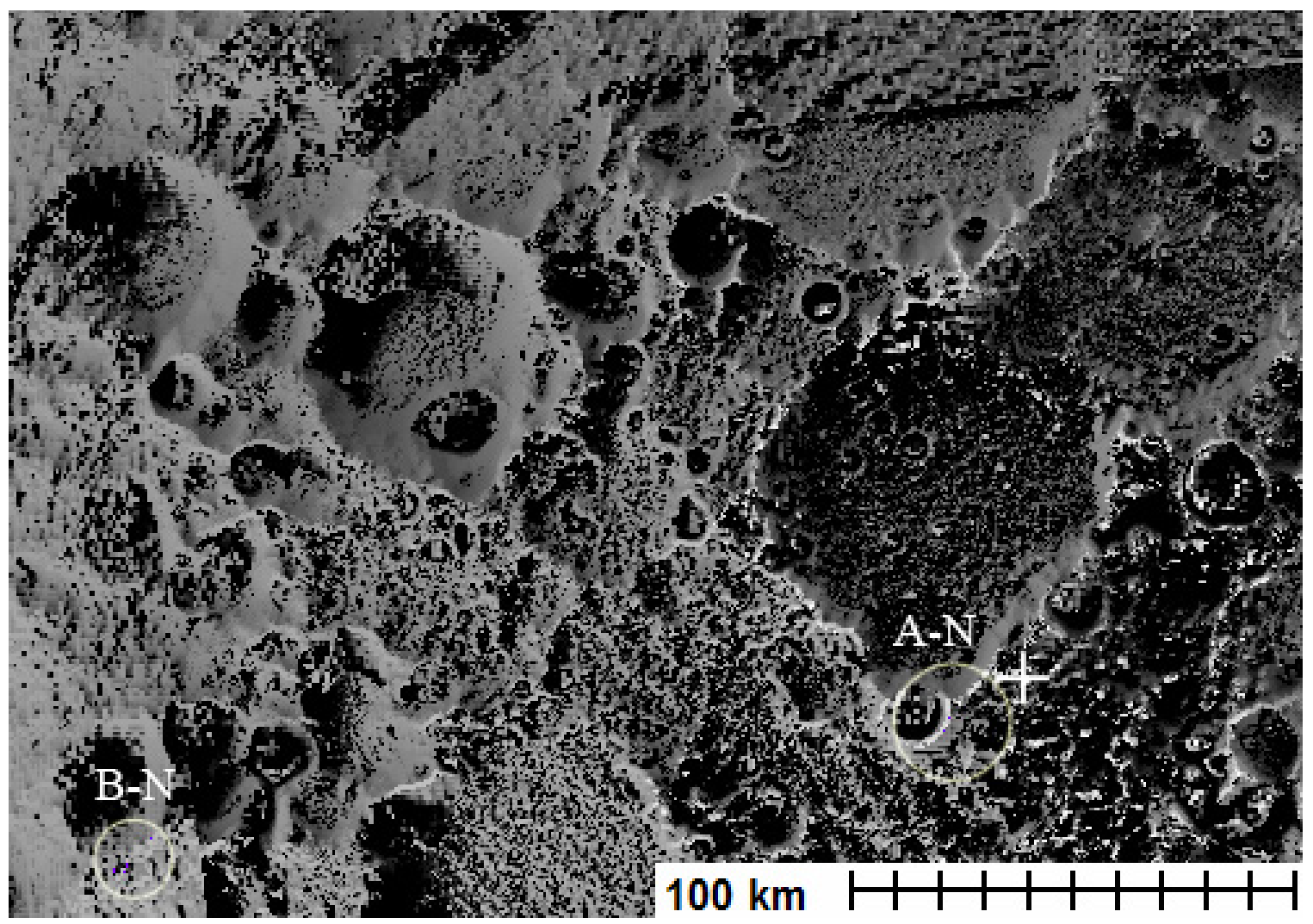

Figure 35.- Sites with under $182 \mathrm{hr}$ energy storage duration (fast recharge) for both the radar and combined north pole DEMs, worst case lunar day. 


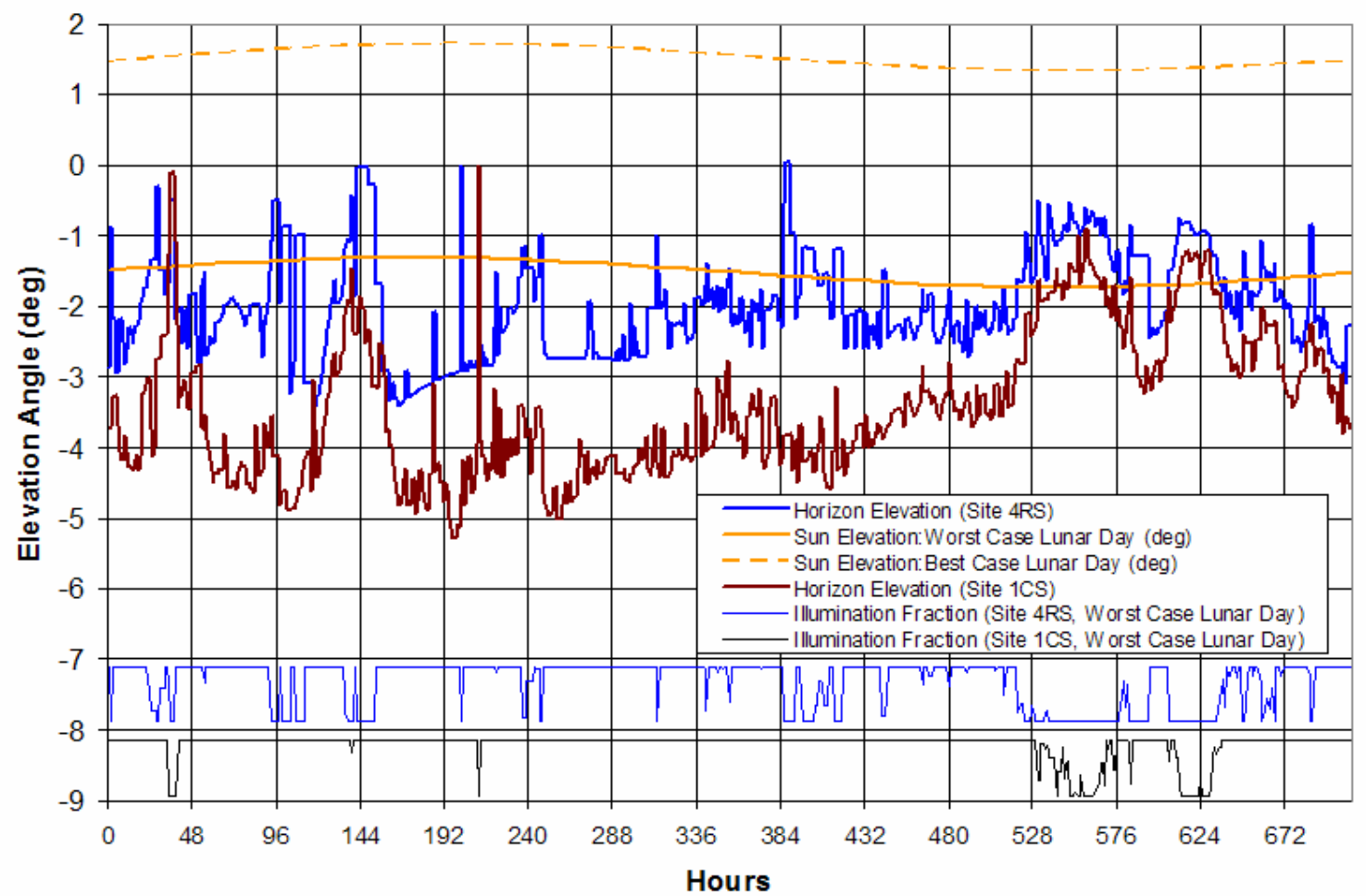

Figure 36.-Elevation and illumination profiles for south pole Sites 4RS and 1CS.

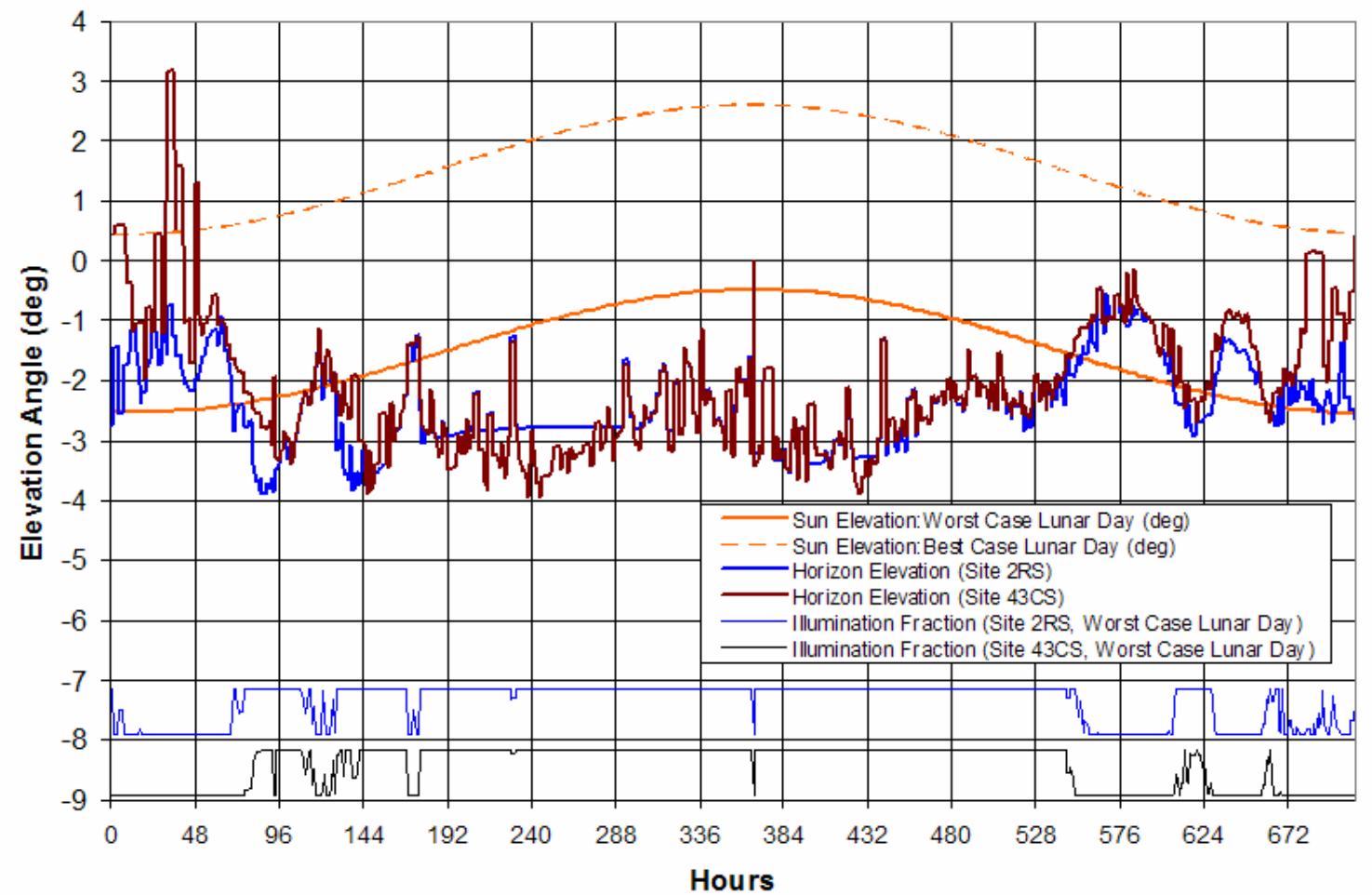

Figure 37.-Elevation and illumination profiles for south pole Sites $2 \mathrm{RS}$ and $43 \mathrm{CS}$. 


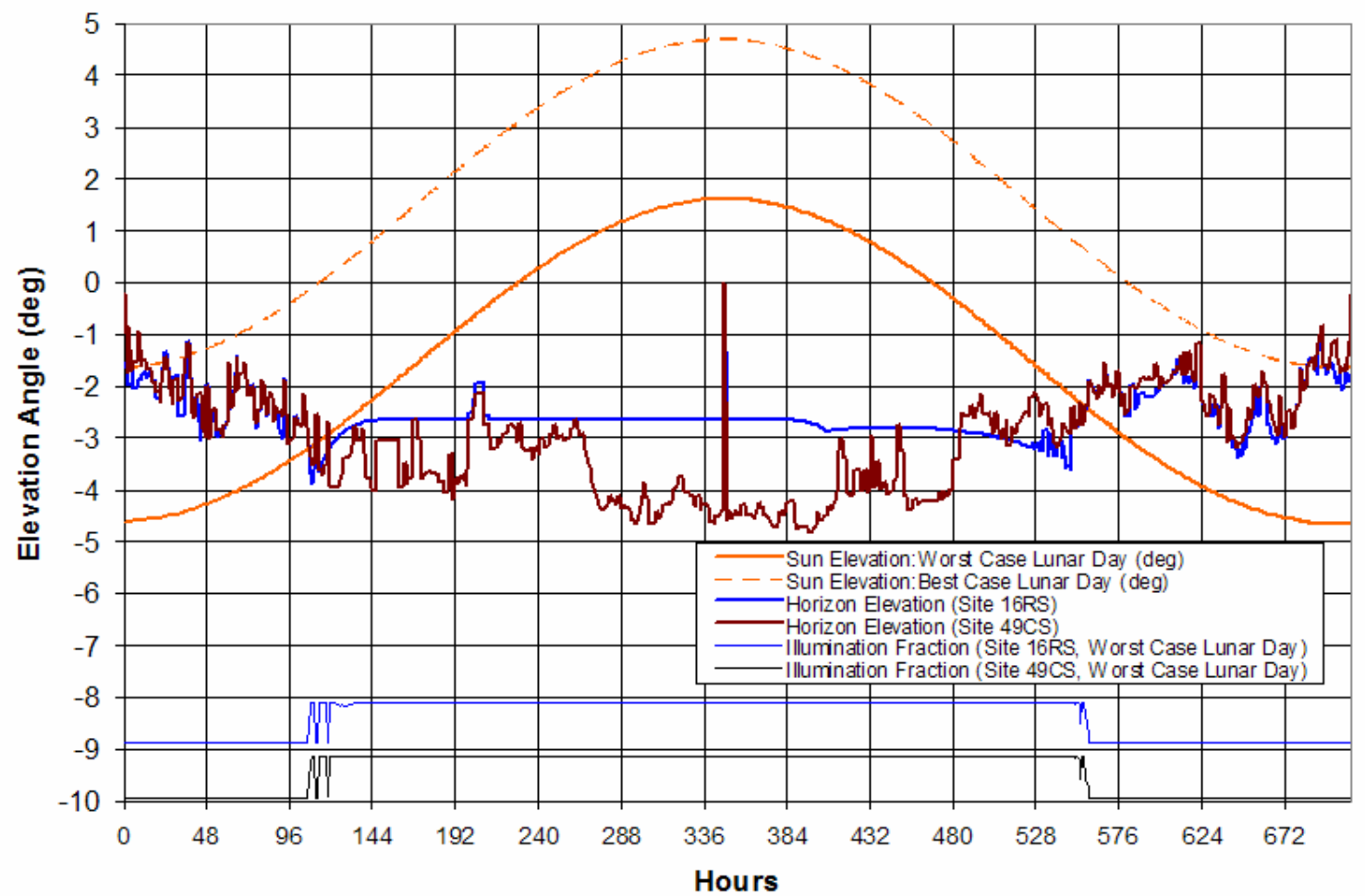

Figure 38.-Elevation and illumination profiles for south pole Sites 16RS and 49CS.

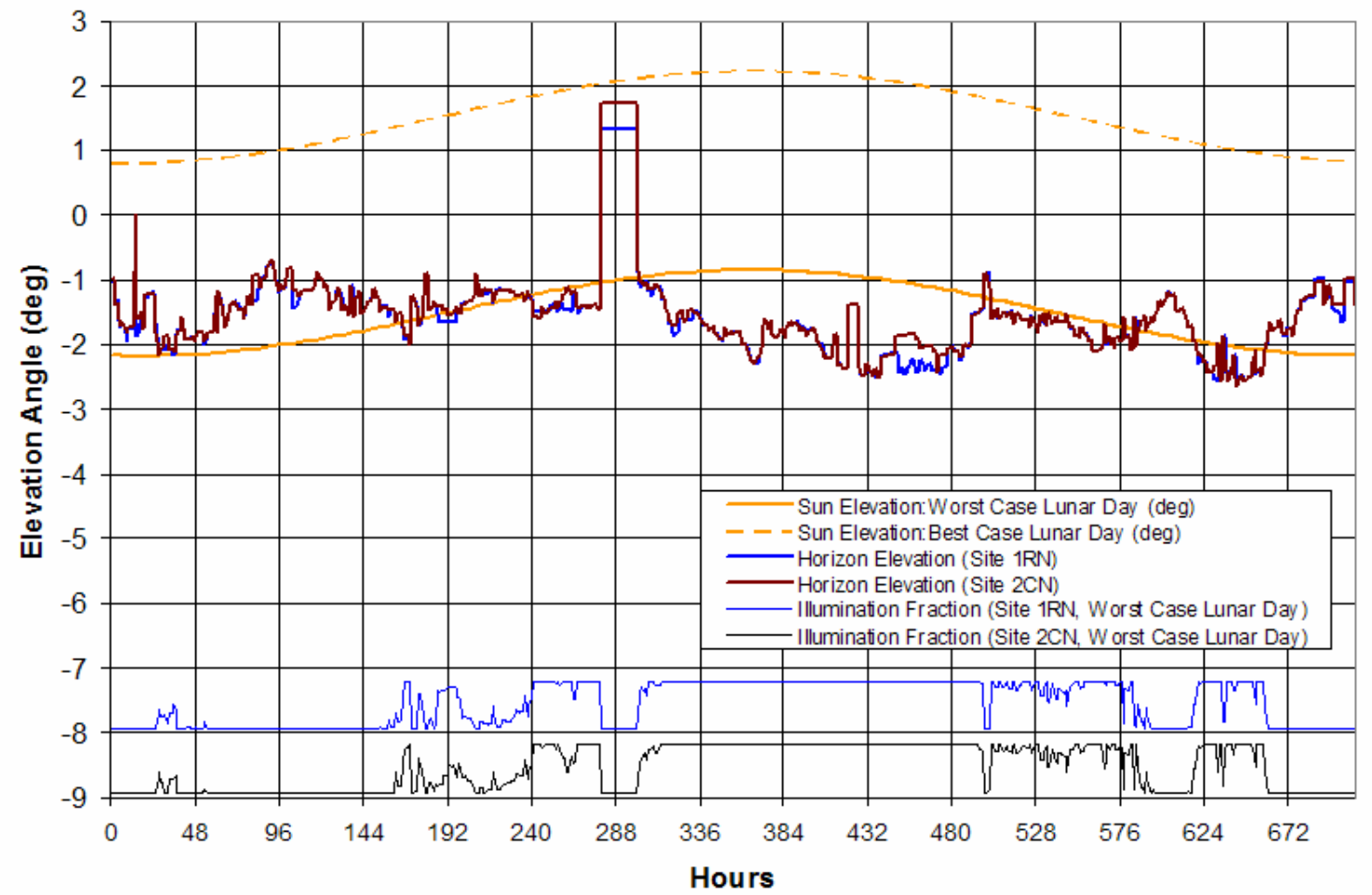

Figure 39.-Elevation and illumination profiles for north pole Sites $1 \mathrm{RN}$ and $2 \mathrm{CN}$. 


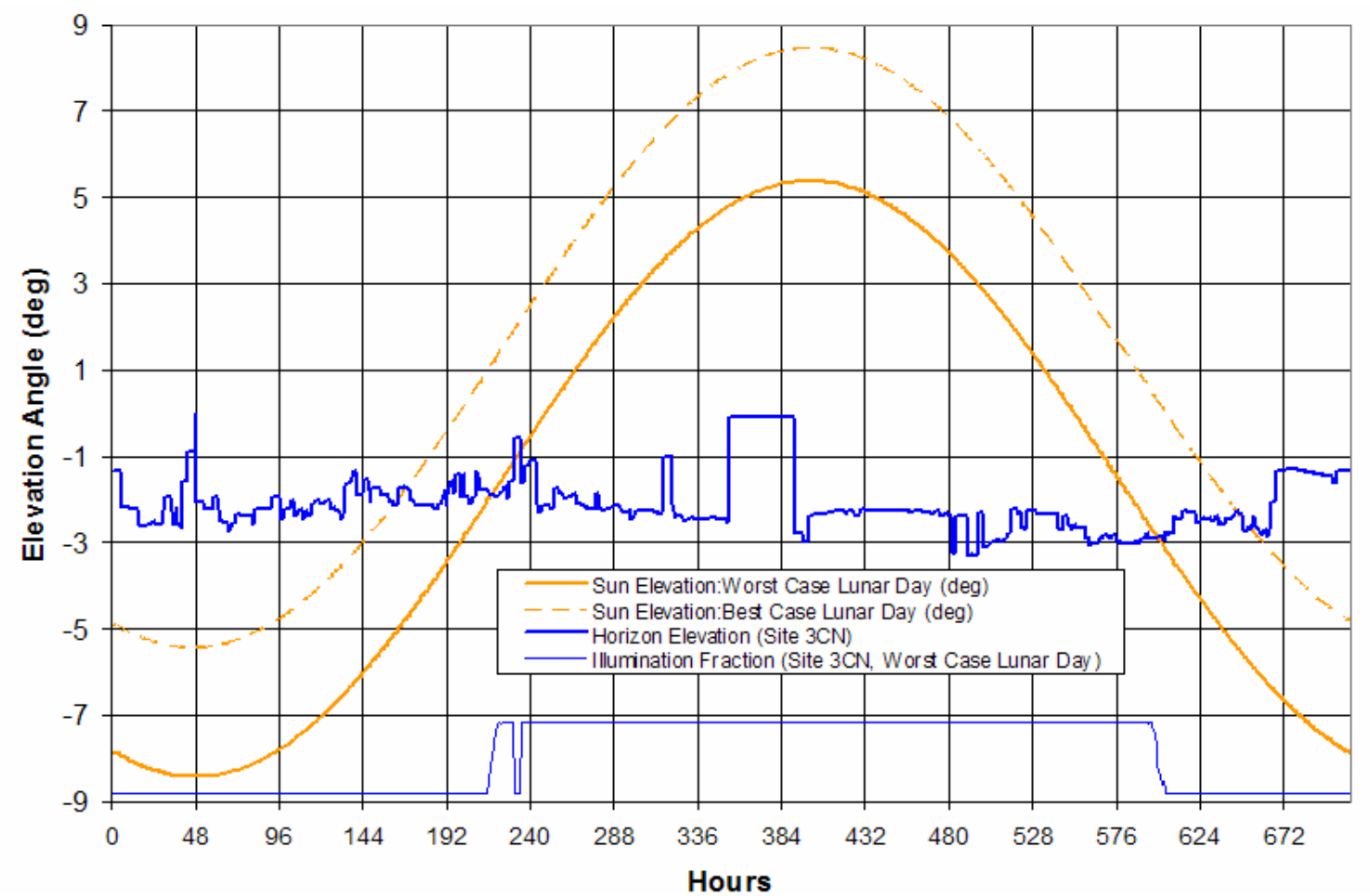

Figure 40.-Elevation and illumination profiles for north pole Site $3 \mathrm{CN}$.

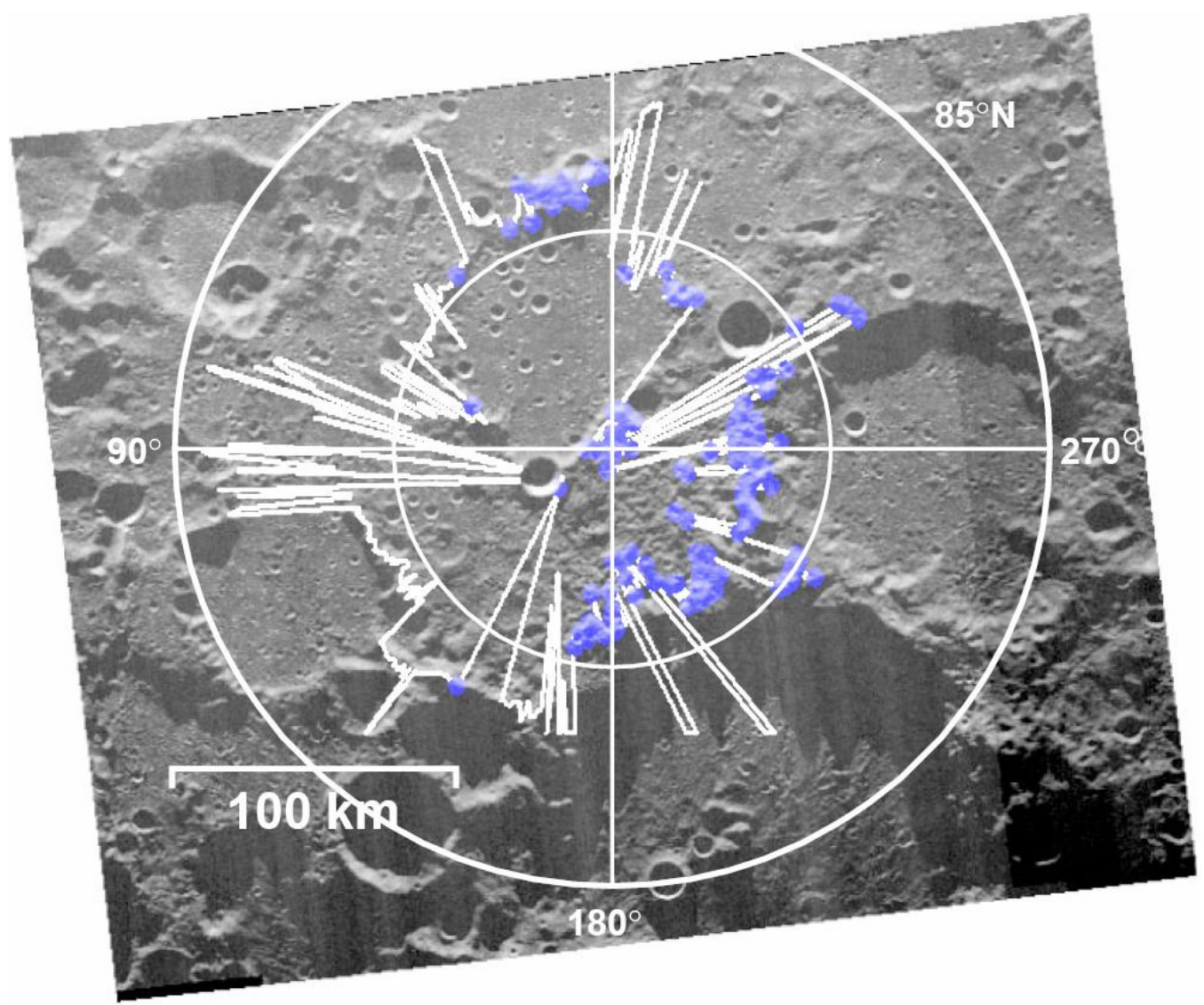

Figure 41.-Shadowing terrain for worst case lunar day for north pole Site 1RN. 


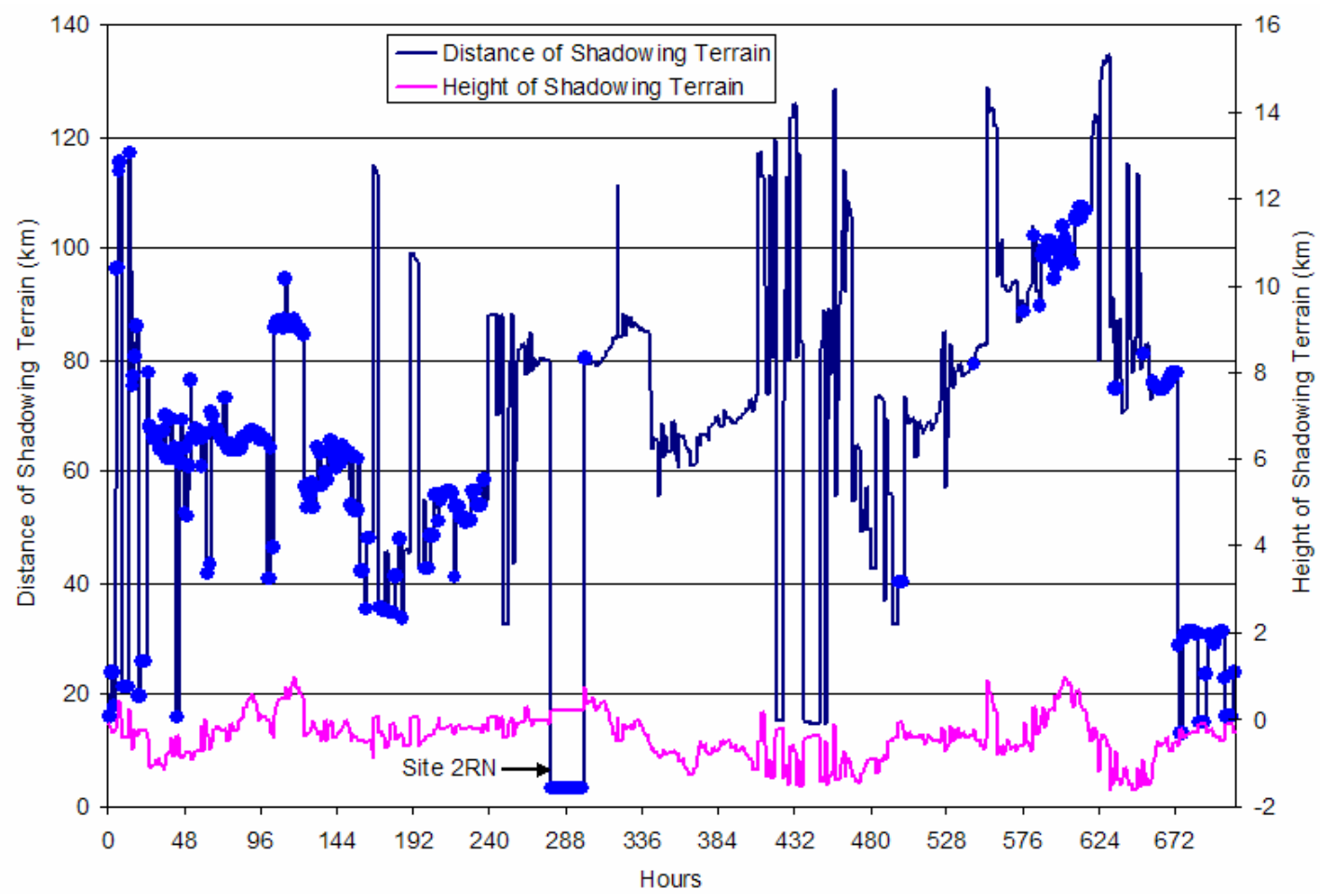

Figure 42.-Shadowing terrain heights for north pole Site 1RN.

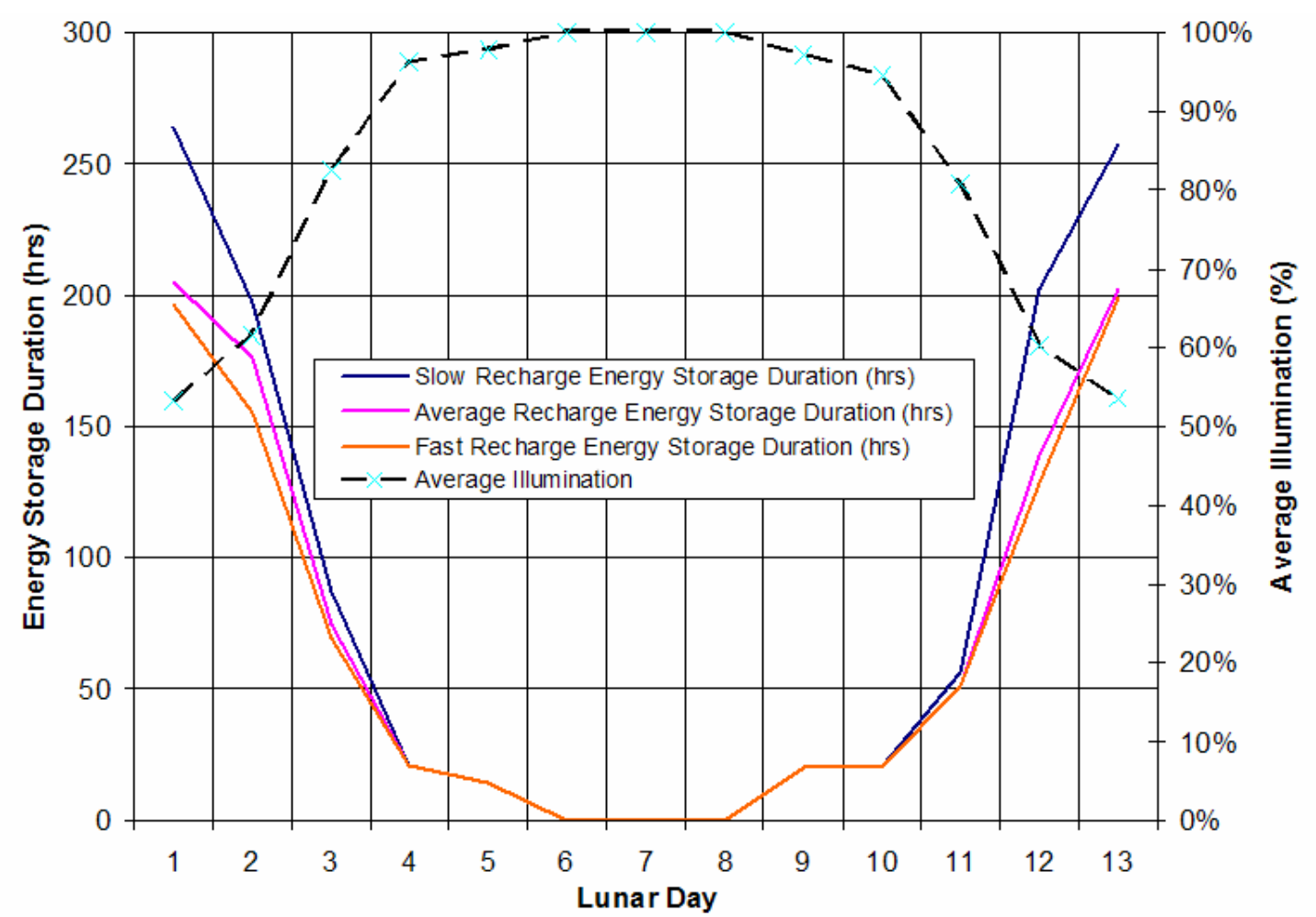

Figure 43.-Yearly variation of average illumination and energy storage duration for north pole Site 1RN. 


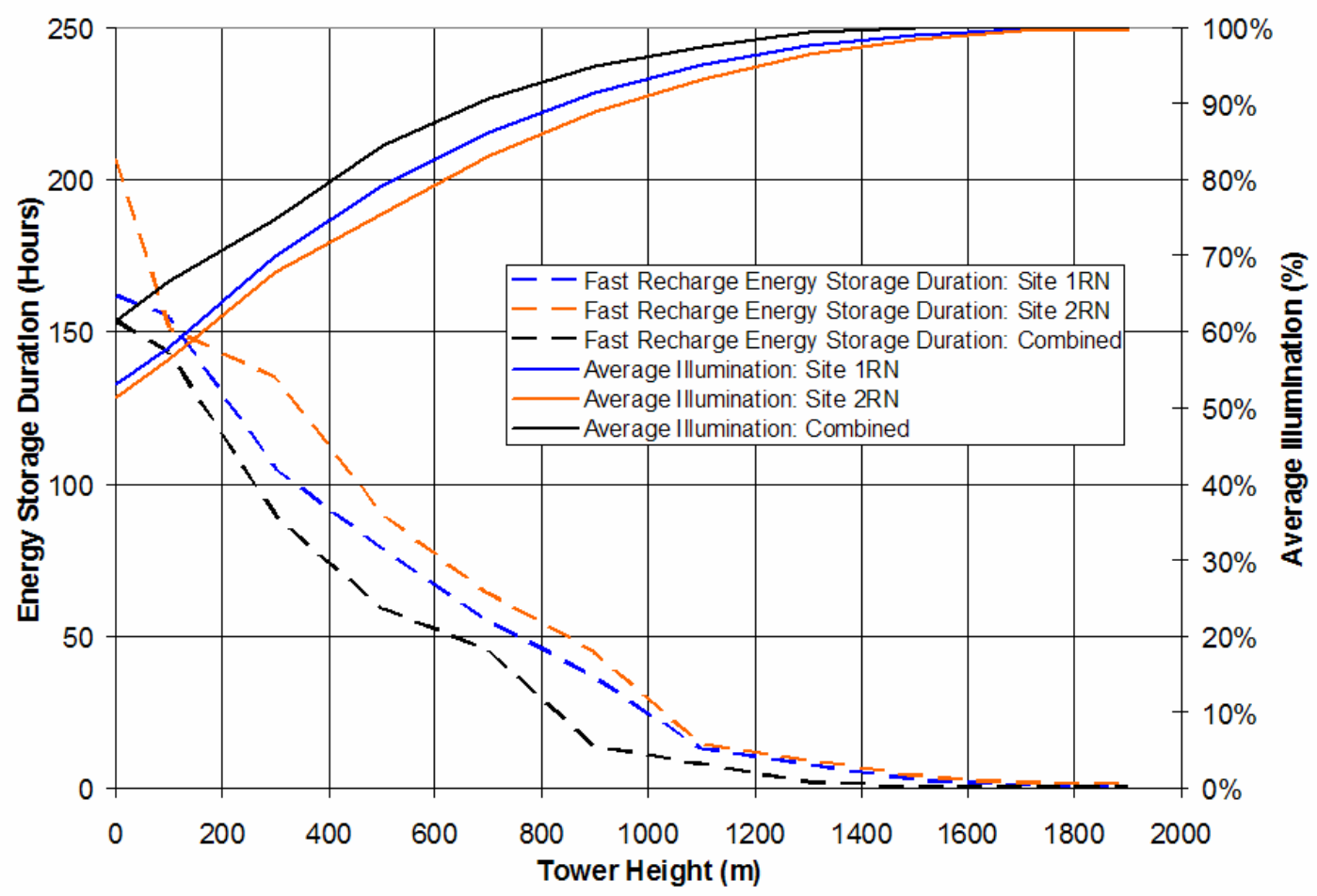

Figure 44.-Effect of power tower mast height on average illumination and energy storage duration for worst case lunar day for north pole Sites 1RN, 2RN, and their combination. 


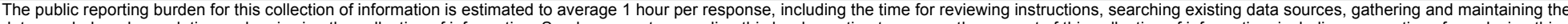

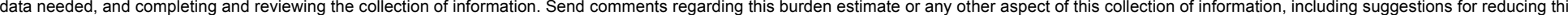

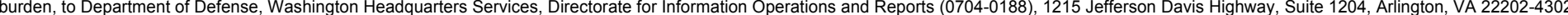

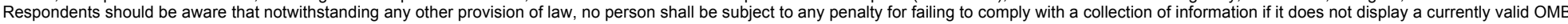
control number.

PLEASE DO NOT RETURN YOUR FORM TO THE ABOVE ADDRESS.

\section{REPORT DATE (DD-MM-YYYY) \\ 2. REPORT TYPE \\ 3. DATES COVERED (From - To)}

01-05-2008

\section{TITLE AND SUBTITLE}

Technical Memorandum

Characterization of Lunar Polar Illumination From a Power System Perspective

5b. GRANT NUMBER

5c. PROGRAM ELEMENT NUMBER

\section{AUTHOR(S)}

Fincannon, James

\section{5d. PROJECT NUMBER}

5e. TASK NUMBER

5f. WORK UNIT NUMBER

WBS 986249.01.13.03.20

\section{PERFORMING ORGANIZATION \\ REPORT NUMBER}

E-16431

National Aeronautics and Space Administration

John H. Glenn Research Center at Lewis Field

Cleveland, Ohio 44135-3191

\section{SPONSORING/MONITORING AGENCY NAME(S) AND ADDRESS(ES)}

National Aeronautics and Space Administration

Washington, DC 20546-0001

\section{DISTRIBUTION/AVAILABILITY STATEMENT}

Unclassified-Unlimited

Subject Categories: 91 and 20

Available electronically at http://gltrs.grc.nasa.gov

This publication is available from the NASA Center for AeroSpace Information, 301-621-0390

\section{SUPPLEMENTARY NOTES}

\section{ABSTRACT}

This paper presents the results of illumination analyses for the lunar south and north pole regions obtained using an independently developed analytical tool and two types of digital elevation models (DEM). One DEM was based on radar height data from Earth observations of the lunar surface and the other was a combination of the radar data with a separate dataset generated using Clementine spacecraft stereo imagery. The analysis tool enables the assessment of illumination at most locations in the lunar polar regions for any time and any year. Maps are presented for both lunar poles for the worst case winter period (the critical power system design and planning bottleneck) and for the more favorable best case summer period. Average illumination maps are presented to help understand general topographic trends over the regions. Energy storage duration maps are presented to assist in power system design. Average illumination fraction, energy storage duration, solar/horizon terrain elevation profiles and illumination fraction profiles are presented for favorable lunar north and south pole sites which have the potential for manned or unmanned spacecraft operations. The format of the data is oriented for use by power system designers to develop mass optimized solar and energy storage systems.

\section{SUBJECT TERMS}

Lunar terrain; Energy storage; Solar energy; Radar digital elevation model; Lunar illumination; Lunar shadowing; Clementine imagery; Solar array towers; Lunar south pole; Illumination simulation; Computer program; Algorithms; Landing sites

\begin{tabular}{|c|c|c|c|c|c|}
\hline \multicolumn{3}{|c|}{ 16. SECURITY CLASSIFICATION OF: } & \multirow{2}{*}{$\begin{array}{l}\text { 17. LIMITATION OF } \\
\text { ABSTRACT } \\
\text { UU }\end{array}$} & \multirow{2}{*}{$\begin{array}{l}\text { 18. NUMBER } \\
\text { OF } \\
\text { PAGES } \\
58\end{array}$} & \multirow{2}{*}{$\begin{array}{l}\text { 19a. NAME OF RESPONSIBLE PERSON } \\
\text { STI Help Desk (email:help@ sti.nasa.gov) } \\
\text { 19b. TELEPHONE NUMBER (include area code) } \\
\text { 301-621-0390 }\end{array}$} \\
\hline $\begin{array}{l}\text { a. REPORT } \\
\text { U }\end{array}$ & $\begin{array}{l}\text { b. ABSTRACT } \\
\text { U }\end{array}$ & $\begin{array}{l}\text { c. THIS } \\
\text { PAGE } \\
\text { U }\end{array}$ & & & \\
\hline
\end{tabular}



